USGS-

\author{
UNITED STATES \\ DEPARTMENT OF THE INTERIOR \\ GEOLOGICAL SURVEY
}

Denver, Colorado

\title{
ANALYSIS OF EARTHQUAKE DATA RECORDED BY DIGITAL FIELD SEISMIC SYSTEMS, JACKASS FLATS, NEVADA
}

by

Arthur C. Tarr and A. M. Rogers

\section{DISCLAIMER}

This report was prepared as an account of work sponsored by an agency of the United States Government. Neither the United States Government nor any agency thereof, nor any of their employees, makes any warranty, express or implied, or assumes any legal liability or responsibility for the accuracy, completeness, or usefulness of any information, apparatus, product, or process disclosed, or represents that its use would not infringe privately owned rights. Reference herein to any specific commercial product, process, or service by trade name, trademark, manufacturer, or otherwise does not necessarily constitute or imply its endorsement, recommendation, or favoring by the United States Government or any agency thereof. The views and opinions of authors expressed herein do not necessarily state or reflect those of the United States Government or any agency thereof. 


\section{DISCLAIMER}

\section{Portions of this document may be illegible in electronic image products. Images are produced from the best available original document.}


Abstract ....................... 1

1.0 Introduction . . . . . . . . . . . . . 1

2.0 Data acquisition . . . . . . . . . . . . . . 3

2.1 Instrumentation . . . . . . . . . . . . 3

2.2 Instrument deployment . . . . . . . . . . . 3

3.0 Data analysis . . . . . . . . . . . . . . 7

3.1 Playback . . . . . . . . . . . . . . 7

3.2 Seismic Data Analysis Package . . . . . . . . . . 7

4.0 Results . . . . . . . . . . . . . . . . 8

4.1 Software system development . . . . . . . . . . . . 8

4.2 Arrival times and first-motions . . . . . . . . . . . . . 8

4.3 Spectra . . . . . . . . . . . . . . 10

4.31 General procedures . . . . . . . . . . 10

4.32 Windowing . . . . . . . . . . . . 11

4.33 Seismic moment . . . . . . . . . . 11

4.34 Corner frequency . . . . . . . . . . . . . . 14

4.35 Radius and stress drop . . . . . . . . . . . 14

4.36 Apparent stress . . . . . . . . . . . . . 17

4.4 Magnitude . . . . . . . . . . . . . . . 18

4.41 Moment magnitude . . . . . . . . . . . 18

4.42 Local magnitude . . . . . . . . . . . . 20

4.5 Peak ground motion parameters . . . . . . . . . 20

5.0 Discussion . . . . . . . . . . . . . . . 25

References cited . . . . . . . . . . 26

Appendix A. Displays of time series by event . . . . . . . . . 28

Appendix B. Displays of time series and spectra by station . . . . . . 40

\section{ILLUSTRATIONS}

Page

Figure 1. Graphs showing nominal portable seismic system response . . . 4

2. Maps of NTS showing seismic stations and earthquakes . . . 6

3. Graphs showing variation of corner frequency and depth with seismic moment . . . . . . . . . . 15 


\section{ILLUSTRATIONS-Continued}

Figure 4. Graphs showing variation of seismic moment and depth with stress drop ................. 16

5. Graph showing seismic moment as a function of coda-length magnitude . . . . . . . . . . . . 18

6. Graph showing comparison of moment magnitude with coda-length magnitude determined in two ways . . . . . . . . . 19

7. Graph showing comparison of moment magnitude and WoodAnderson magnitude with coda duration magnitude . . . . . 22

8. Graph showing comparison of moment magnitude with WoodAnderson magnitude . . . . . . . . . . . 23

9. Graph showing variation of peak ground motion parameter $R \mathbf{v}$ with seismic moment . . . . . . . . . . . . 24

\section{TABLES}

Table 1. Jackass Flats seismic stations, April 26, 1981 through June 28, $1981 \quad 5$

2. Earthquakes recorded by Jackass Flats digital field systems . . 9

3. Spectral data from earthquake \#3 . . . . . . . . . . 13 


\title{
UNITED STATES \\ DEPARTMENT OF THE INTERIOR GEOLOGICAL SURVEY
}

\section{ANALYSIS OF EARTHQUAKE DATA RECORDED BY DIGITAL FIELD SEISMIC SYSTEMS, JACKASS FLATS, NEVÁDA}

by

\author{
Arthur C. Tarr and A. M. Rogers
}

\begin{abstract}
Analysis of 59 time series from ten small magnitude earthquakes recorded in 1981 by portable digital seismic systems at the southern Nevada Test Site (NTS) yielded several significant results. We find that moment magnitude $\left\langle M_{L}\right\rangle$ (local magnitude determined from seismic moment) correlates closely with coda duration magnitudes $M_{d}$ determined by the Southern Great Basin Seismic Network (SGBSN). Further, local magnitude $M_{W A}$ computed from displacement seismograms simulating Wood-Anderson response are, on average, 0.38 magnitude units larger than $M_{d}$ and 0.44 magnitude units larger than $\left\langle M_{L}\right\rangle$. Another result is that stress drops for the ten earthquakes are significantly smaller than typical stress drops for earthquakes of similar seismic moment in California. Similarly, determinations of the peak ground motion parameter $R \mathrm{v}$ are up to 10 to 20 times smaller than a previously determined empirical formula relating $R \mathrm{v}$ to seismic moment. We conclude that seismic waves from southern Nevada Test Site earthquakes suffer from significant anelastic attenuation, possibly in the near-surface crust under the recording sites, yielding reduced amplitude and frequency of the peak ground motion and shifting the apparent corner frequency of the source spectrum to lower values, thereby producing unexpectedly low stress drops.
\end{abstract}

\subsection{INTRODUCTION}

Between April and July of 1981, the U.S. Geological Survey (USGS) deployed digital field seismic systems at Jackass Flats on the southern NTS to record small earthquakes occurring east of Yucca Mountain, the proposed site of a high-level nuclear waste repository. The first objective of the experiment was to perform spectral analyses on the recorded waveforms so that comparisons of source parameters (energy, seismic moment, source radius, stress drop) could be made between the normally quiescent seismic regime near Yucca Mountain and the more active regime at Pahute Mesa on the northern NTS where considerable tectonic stress has been released. A second objective was to provide additional data on low-level seismic activity occurring below the detection threshold of the SGBSN to improve control of focal depth and focal mechanism determinations. A third objective was to compare moment magnitudes (calculated from the spectra of selected NTS earthquakes) and local magnitude $M_{W A}$ (calculated from equivalent Wood-Anderson displacement seismograms) with magnitudes $M_{d}$ computed from a new coda duration magnitude scale used 
by the SGBSN. The new scale replaced an earlier SGBSN coda duration magnitude scale (using constants appropriate for California) that consistently overestimated the equivalent $M_{L}$ magnitude for NTS earthquakes.

The field team, composed of USGS personnel from the Golden, Colorado, and Menlo Park, California, offices, used digital recorders provided by the USGS in Menlo Park. In 1981, the digital records were scanned using a visual stripchart recorder, in 1982 selected records were transferred from cassette tapes to the Menlo Park DEC PDP11/70 RSX computer while existing analysis software was refined in Menlo Park, and finally, in late 1983, transferral and conversion of software and data sets to the VAX 11/750 VMS computer was completed in Golden. Further software revisions, debugging, and processing of the digital data extended throughout much of 1984.

This report discusses (1) results of spectral analyses of ten earthquakes occurring in or near the NTS and recorded by stations of the field network and the SGBSN and (2) evidence supporting the validity of the new SGBSN coda duration magnitude scale. Spectral analyses of SGBSN digital seismic recordings of earthquakes in or near the NTS and of Jackass Flats recordings of microearthquakes not recorded by the SGBSN will be the subject of another report.

A number of persons were crucial to the completion of this study. The assistance and suggestions of the following individuals is gratefully acknowledged: John Boatwright, David Carver, Stephen Harmsen, Robert Herrmann, Mark Meremonte, and Gene Sembera. Much of the data analysis software was either written or revised by Edward Cranswick; his generosity and cooperation are greatly appreciated. The study was conducted as part of the Nevada Nuclear Waste Storage Investigations project and was supported in part by Department of Energy Interagency Agreement DE-AT08-78ET44802. 


\subsection{DATA ACQUISITION}

\subsection{Instrumentation}

The field instrumentation consisted of Sprengnether DR-100 three-component digital recorders employing Mark Products L4C and Sprengnether S6000 three-component seismometers. The natural frequencies of the $\mathrm{L} 4 \mathrm{C}$ and $\mathrm{S} 6000$ seismometers were $1.0 \mathrm{~Hz}$ and $2.0 \mathrm{~Hz}$, respectively; a damping factor of 0.8 was selected for both models of transducers. Velocity and displacement sensitivities of the systems are shown in figure 1. The signals were conditioned with an anti-aliasing $50 \mathrm{~Hz}$, five-pole Butterworth low-pass filter prior to input to the digital recorder.

The DR-100 samples, multiplexes, digitizes, and records the input signals on cassette tape. The sample rate was selected to be 200.32 samples per second; the Nyquist frequency, therefore, is about $100 \mathrm{~Hz}$. The continuously-sampled digitized time series are shifted through a buffer until a detection algorithm, based on the ratio of short-term average (STA) to long-term average (LTA) signal, triggers the recorder. The buffer, including up to $2.7 \mathrm{sec}$ of pre-event signal, is recorded on cassette tape until the STA/LTA ratio declines to below the trigger threshold. Each cassette holds approximately ten minutes of threecomponent digital data.

Each block of time series (data) records, representing one event recorded at one station, is preceded by a header record and succeeded by a trailer record on the cassette tape. The header contains a number of previously-set constants and the trigger time of the internal clock. The DR-100 is a 12-bit (11-bit plus sign) system, permitting sample values of the time series to range from -2048 to 2047 counts, each count representing a voltage increment of $4.88 \mathrm{mV}$.

\subsection{Instrument deployment}

Locations, periods of operation, and instrumental constants of Jackass Flats seismic stations are tabulated in table 1. Instruments were deployed between April 26, 1981 and May 1, 1981, after which time the network of field systems continued in operation until June 21. By June 28 all systems were removed. The locations of the stations (fig. 2) were in Rock Valley, on the eastern side of Jackass Flats, and on the flanks of Skull Mountain and Lookout Peak. Two permanent stations of the SGBSN (LOP and LSM) were enclosed by the network of digital systems.

After installation and after operating gains were established, the stations were visited regularly to change tapes (if necessary) and to record the clock correction in field notes. The clock corrections and gain changes were reduced later to entries in special data files that were used in the data analysis to correct for clock drift and to scale the spectrum to ground response. 

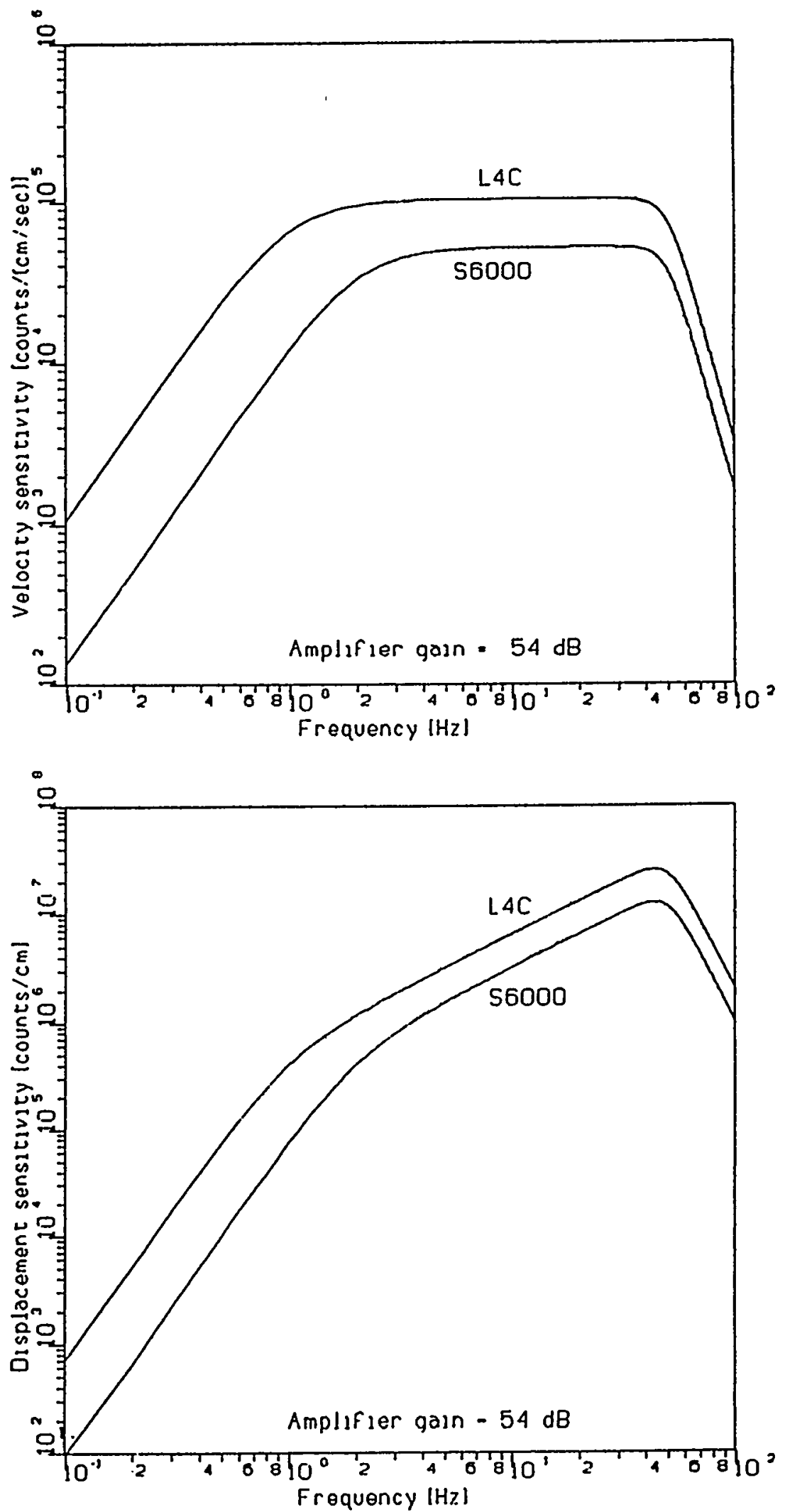

Figure 1. Graphs showing nominal portable seismic system response. Response is shown as velocity sensitivity (top) and displacement sensitivity (bottom) at an amplifier gain of $54 \mathrm{~dB}$ for L4C and $\mathrm{S} 6000$ seismometers. 
TABLE 1.-Jackass Flats seismic stations, April 26, 1981 through June 28, 1981

[Seismometer parameters: $f_{0}$, resonant frequency, in $\mathrm{Hz} ; G_{L E}$, loaded motor constant, in $\mathrm{V} /(\mathrm{m} / \mathrm{sec}) ; \lambda$, damping factor $]$

\begin{tabular}{|c|c|c|c|c|c|c|c|c|}
\hline \multirow{2}{*}{$\begin{array}{l}\text { Abbrev- } \\
\text { ation }\end{array}$} & \multirow{2}{*}{$\begin{array}{l}\text { Lati- } \\
\text { tude } \\
{ }^{\circ} \mathrm{N} .\end{array}$} & \multirow{2}{*}{$\begin{array}{c}\text { Longi- } \\
\text { tude } \\
{ }^{\circ} \mathrm{W} .\end{array}$} & \multirow{2}{*}{$\begin{array}{r}\text { Eleva- } \\
\text { tion } \\
(\mathrm{m})\end{array}$} & \multirow{2}{*}{$\begin{array}{r}\text { Operation dates } \\
\text { (Date on-date off) }\end{array}$} & \multicolumn{4}{|c|}{ Seismometer } \\
\hline & & & & & Model & $f_{0}$ & $G_{L E}$ & $\lambda$ \\
\hline JFA & 36.723 & 116.129 & 1158 & $04 / 27 / 81-06 / 28 / 81$ & $\mathrm{~S} 6000$ & 2.0 & 50 & 0.8 \\
\hline JFB & 36.693 & 116.175 & 1040 & $04 / 26 / 81-04 / 29 / 81$ & $\mathrm{~L} 4 \mathrm{C}$ & 1.0 & 100 & 0.8 \\
\hline JFC & 36.678 & 116.293 & 960 & $04 / 27 / 81-06 / 21 / 81$ & L4C & 1.0 & 100 & 0.8 \\
\hline JFD & 36.823 & 116.166 & 1380 & $04 / 30 / 81-06 / 26 / 81$ & S6000 & 2.0 & 50 & 0.8 \\
\hline JFF & 36.726 & 116.345 & 930 & $04 / 28 / 81-06 / 29 / 81$ & $\mathrm{~L} 4 \mathrm{C}$ & 1.0 & 100 & 0.8 \\
\hline JFG & 36.788 & 116.328 & 1092 & $04 / 27 / 81-06 / 28 / 81$ & S6000 & 2.0 & 50 & 0.8 \\
\hline $\mathrm{JFH}$ & 36.866 & 116.158 & 1463 & $04 / 27 / 81-04 / 30 / 81$ & $\mathrm{~L} 4 \mathrm{C}$ & 1.0 & 100 & 0.8 \\
\hline JFI & 36.850 & 116.289 & 1236 & $04 / 27 / 81-06 / 28 / 81$ & 56000 & 2.0 & 50 & 0.8 \\
\hline $\mathrm{JFJ}$ & 36.898 & 116.212 & 1536 & $04 / 27 / 81-06 / 28 / 81$ & $\mathrm{~S} 6000$ & 2.0 & 50 & 0.8 \\
\hline JFK & 36.719 & 116.238 & 1098 & $04 / 30 / 81-06 / 28 / 81$ & $\mathrm{~L} 4 \mathrm{C}$ & 1.0 & 100 & 0.8 \\
\hline JFL & 36.873 & 116.161 & 1410 & $05 / 01 / 81-06 / 28 / 81$ & $\mathrm{~L} 4 \mathrm{C}$ & 1.0 & 100 & 0.8 \\
\hline
\end{tabular}




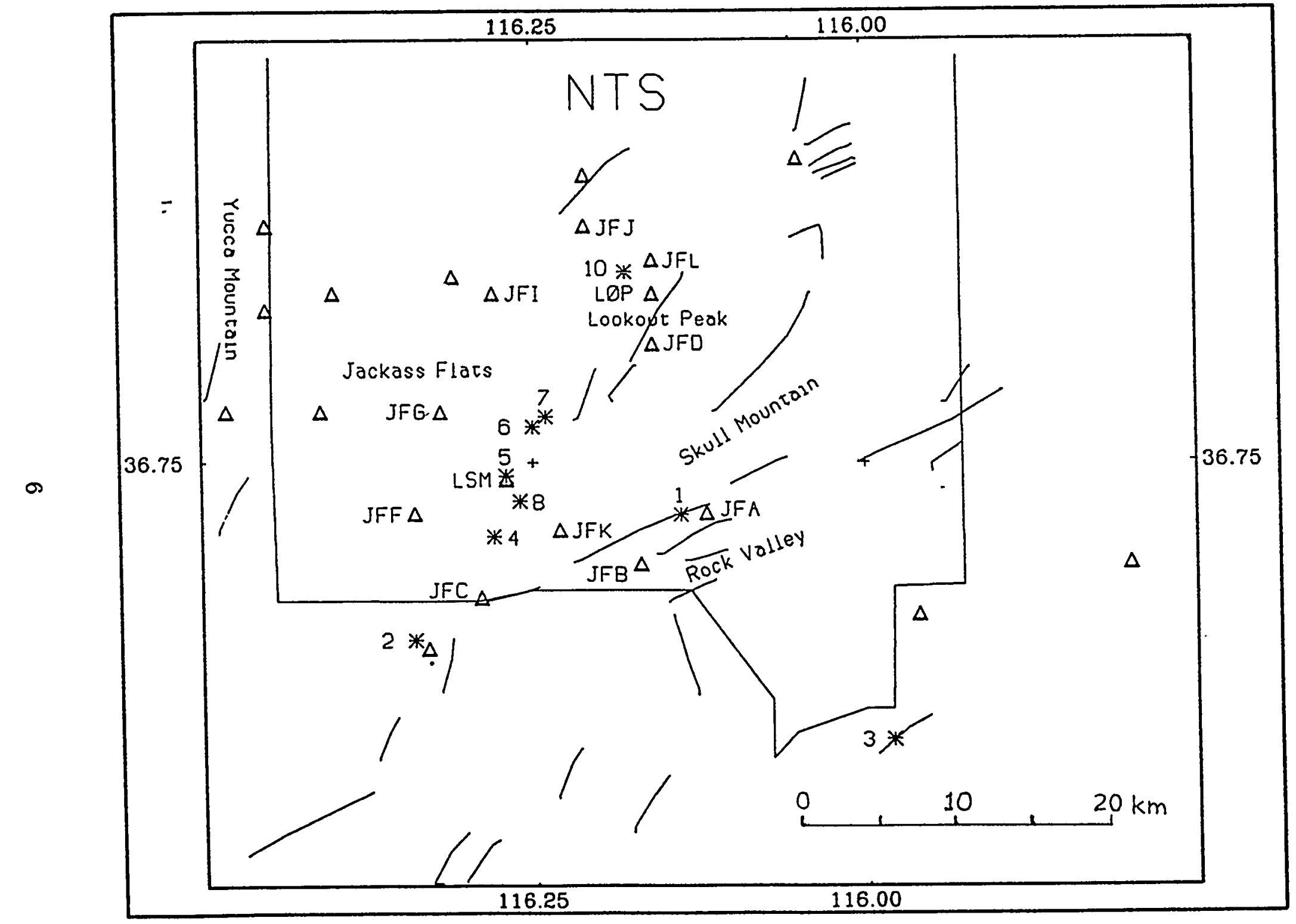

Figure 2. Map of southern NTS showing locations of seismic stations and earthquakes. Faults are shown as line segments. The period of operation of digital seismic stations (filled triangles) was April 26, 1981 through June 28, 1981; earthquakes recorded by the digital stations and SGBSN stations (open triangles) during the time period are designated by asterixes. A numeral beside the earthquake symbol refers to the event number in Table 2. 


\subsection{DATA ANALYSIS}

\subsection{Playback}

Ordinarily, after the cassette tapes have been returned from the field, they are played back immediately on a DP-100 playback recorder connected to the computer upon which the data analyses are to be performed. In the case of the Jackass Flats data, the cassettes were played out as hard-copy traces and scanned for potentially useful records. Later, selected event records were demultiplexed and converted to standard format files on a DEC PDP11/70 RSX computer in Menlo Park, California.

Each component of each cassette event record becomes, on playback, a separate file in the analysis package described in section 3.2. The conversion program generates two header records (from the cassette headers) for each time series file; extra information may be inserted into the headers at this time. The data records are 256 samples long and a time series may contain any number of data records; partial data records are padded with zeroes.

\subsection{Seismic data analysis package}

Analysis of the digital records is performed with the Seismic Data Analysis Package (SDAP), a set of programs and subprograms originally designed for GEOS and DR-100 field seismic systems but now expanded to include other digital field systems used by the USGS (A. C. Tarr and E. A. Cranswick, unpub. data, 1986). SDAP contains two principal analysis programs, RECSEC and SPCJMP. RECSEC is used to display correlated time series traces and to make picks of $P$ - and $S$-wave arrivals. SPCJMP is used to display the three components of individual time series records, to window a particular trace, and to perform a Fast Fourier Transform (FFT) to produce a spectrum. The displacement amplitude spectrum $\Omega(\omega)$ is corrected for instrument response; later, the spectrum may also be corrected for attenuation and radiation pattern. A corner frequency $f_{c}$ corresponding to a simple Brune $(1970 ; 1971)$ source model can be picked from the resultant displacement spectrum and the asymptotic low-frequency level $\Omega(0)\left(\equiv \Omega_{0}\right)$ is measured to determine the seismic moment of the earthquake.

Another program, INTDR100, integrates the time series traces to produce displacement seismograms which, when scaled by a factor of 2800 , simulate Wood-Anderson seismograms, especially for frequencies well above the natural frequency $(1.25 \mathrm{~Hz})$ of the Wood-Anderson torsion seismometer. The peak motion is measured on the horizontal component seismograms and a mean local magnitude $M_{W A}$ is computed. 


\subsection{RESULTS}

As a consequence of this study, significant results may be cited in three topics: (1) software development, (2) arrival times and first-motions, and (3) spectra, magnitudes, and peak ground motion parameters. Each of these topics is discussed below. Because software documentation is not yet published, the sub-sections to follow are detailed to assist those who will use the digital seismic systems and the SDAP software in the future.

\subsection{Software system development}

One of our first results was a set of revisions and extensions to software (E. A. Cranswick, unpub. data, 1986) originally designed to analyze DR-100 and GEOS digital seismic records. This work required the transport of both data sets and software to analyze the data from the DEC PDP11/70 RSX computer system in Menlo Park to the VAX 11/750 VMS computer in Golden. After conversion to the VAX 11/750 computer in Golden, several of the programs were modified by the first author to permit greater flexibility in their operation, to permit analysis of digital data from other systems (Bison, Geotech MCR-600, and Sprengnether DR-200), and to permit analysis of SGBSN digital data. Further, new programs were written to permit editing of digital data file headers and to simplify the bookkeeping procedures necessary to rapidly analyze a large number of files. Other programs were written to integrate the digital time series to produce displacement seismograms and to automate the computation of source parameters.

A user's guide and programmer's manual was prepared (A. C. Tarr and E. A. Cranswick, unpub. data, 1986) to assist users of the SDAP software. Although the programmer's manual portion is incomplete, the draft of the user's guide has been in use in Golden since early 1984 .

\subsection{Arrival times and first-motions}

Using the new software, a list of $P$ - and $S$-wave arrival times was prepared from displays of the digital data (appendix A). The list supplemented the phase arrival lists of the SGBSN, thereby providing additional control on previously determined hypocenters. Useful digital records were obtained for ten local (that is, on or near NTS) earthquakes occurring between April 30,1981 and June 27, 1981 (fig. 2; table 2). All ten earthquakes were recorded by the SGBSN; event parameters were published in the SGBSN catalog (Rogers and others, 1983). The clear graphics display and ability to rotate components permitted accurate phase identifications and precise measurement of arrival times. Onset times of $S$-phases, in particular, could be easily picked on the three-component display.

The hypocenter parameters in table 2 differ slightly from the SGBSN catalog values because nine of the ten events were relocated using the digital arrival time data. (Additional phase data were considered unnecessary for relocation of one of the earthquakes because the field stations were located at distances and azimuths that could not provide supplemental control on either epicenter or depth of focus.) In addition, magnitudes in table 2 are revised values computed by using a new coda duration magnitude scale $M_{d}=1.67 \cdot \log (\tau)+.00227 R-1.28$ where $\tau$ is the coda duration in seconds and $R$ is the hypocentral distance in kilometers. The revised magnitudes are, on the average, about one 


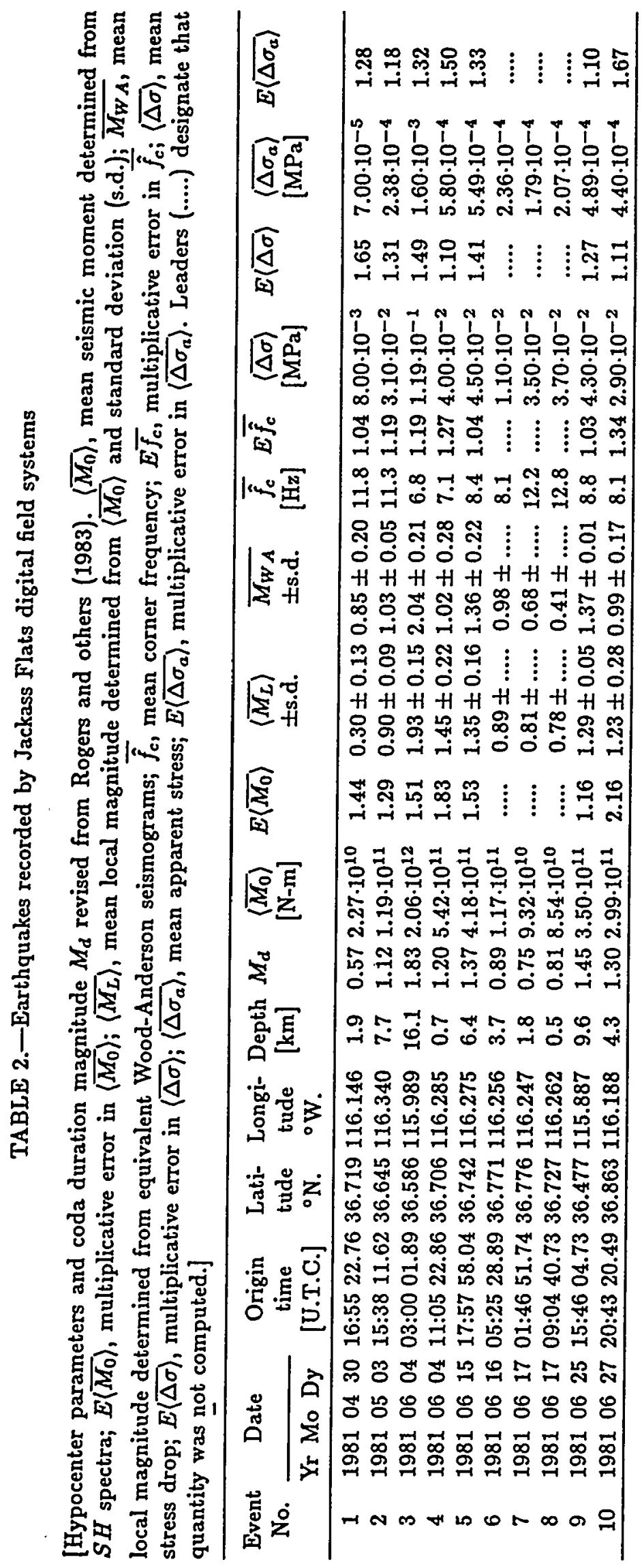


magnitude unit smaller than the previously published values of $M_{d}$ that were computed using California constants in the coda length formula.

The digital records also provided additional first-motion data for the NTS earthquakes, most of which were not adequately covered in earlier attempts at SGBSN focal mechanism determinations. Even though no new focal mechanisms resulted exclusively from the analysis of the digital records, the supplemental digital first-motion data supported SGBSN first-motion data determined previously. Independent checks using nuclear events were used to verify correct polarity at eight stations (JFA, JFC, JFD, JFG, JFH, JFI, JFJ, and JFK).

\subsection{Spectra}

The spectra obtained from 59 digital seismic recordings of NTS earthquakes provided the most important results of this study. Despite the variability of the individual time series records, the spectra provided consistent estimates of the seismic moment. Nevertheless, some problems presented themselves during the analysis; a description of the problems and their solutions are described in the following sub-sections.

In the following discussion, special notation is employed to distinguish between measured quantities and computed values of source parameters. The circumflex mark ( $\left.{ }^{\wedge}\right)$ designates a quantity, such as corner frequency $\hat{f}_{c}$ and low-frequency spectral level $\hat{\Omega}_{0}$, measured from a displacement spectrum; the Brune $(1970 ; 1971)$ source model is assumed in these discussions. Angle brackets $(\langle\rangle)$ designate quantities computed from spectral parameters; examples are seismic moment $\left\langle M_{0}\right\rangle$, radius $\left\langle r_{0}\right\rangle$, and stress drop $\langle\Delta \sigma\rangle$. In addition, special notation is required to distinguish the various magnitudes, all of which are calibrated to local magnitude $M_{L}$. Magnitude determined from seismic moment $\left\langle M_{0}\right\rangle$ through a moment-magnitude relationship (such as given by Thatcher and Hanks (1973)), we call moment magnitude and designate $\left\langle M_{L}\right\rangle$. Magnitude determined from maximum trace amplitude on equivalent Wood-Anderson seismograms we designate $M_{W A}$. Magnitudes determined from coda duration are designated $M_{d}$.

\subsection{General procedures}

Following playback of potentially useful recordings from the cassette tapes, the records were displayed on a graphics terminal with program RECSEC to determine which were actually recordings of time series of earthquakes located by the SGBSN; these displays are found in appendix $A$. In addition, the quality of each recording was assessed; for example, very noisy and clipped traces unsuitable for spectra were eliminated. Table 2 lists the ten local events located by the SGBSN for which digital time series existed that passed the quality assessment. Ideally, three components should have been recorded at each of the stations listed in table 2; however, because of isolated cases of equipment malfunction and late triggering, traces of some components were missing or of low quality. Nevertheless, since seismic moment can be determined from the recording of just one identifiable bodywave phase (usually the $S$-wave) some recordings that were unsuitable for earthquake location purposes could be used for determining moment.

Some individual events, representing very small earthquakes, larger regional earthquakes, and unidentified triggers, were not processed for this study. We concentrated on 
earthquakes that were large enough to have been recorded and located by the SGBSN so that well-determined event parameters such as epicentral distance, depth of focus, and magnitude would be available.

The waveforms recorded at each station were displayed on a graphics display terminal using program SPCJMP; these displays are found in appendix B. The $P$-wave and $S$-wave packets were windowed using the crosshairs to center the windows. The same window duration and center were used for all the three components of the particular phase; the window width for $S$-waves generally was twice the $P$-wave window duration. The choice and placement of the window was critical to accurately measuring spectral parameters from $P$-waves recorded at close distances and $S$-waves at far distances because of interference from reflected phases and surface waves.

\subsection{Windowing}

Windowing prior to performing an FFT on a waveform is accomplished in SPCJMP by a cosine-bell whose length in samples is some power of two. The cosine-bell is centered by means of crosshairs on the screen display of the graphics terminal and the window width is interactively chosen. Ordinarily, the peak amplitude of the cosine-bell is centered on the peak amplitude of the waveform in the section to be analyzed. However, the flanks of the cosine-bell pick up the energy carried on either side of the peak amplitude of motion, and that energy may not originate entirely in the phase desired. This problem has been discussed elsewhere (for example, Thatcher and Hanks, 1973) and seems unavoidable.

The spectra of $P$-waves and $S$-waves were analyzed for one well-recorded event (\#3); only $S$-waves were analyzed for the rest of the events. It was discovered early on that $P$-wave spectra from the closest stations displayed a peaked appearance at low frequencies where the Brune spectrum is ideally flat. Holes were commonly superimposed on the spectrum. Such effects are due to multiple phase interference from converted waves, reflected phases, and localized site resonance. Site effects should have been minimized as a consequence of the careful selection of stations on rock or thin-soil sites.

\subsection{Seismic moment}

After an FFT was performed on each windowed time series, the spectra were corrected for instrument response and displayed (appendix B). A line coincident with the asymptotic value $\hat{\Omega}_{0}$ of the low-frequency part of the displacement spectrum and a line (whose slope was -2 on a $\log$-log plot) to match the high-frequency part of the spectrum were visually determined; the intersection of the two lines provided an estimate of the corner frequency, $\hat{f}_{c} .\left\langle M_{0}\right\rangle$ was computed for each component by employing the $\hat{\Omega}_{0}-M_{0}$ relation (after Aki and Richards, 1980, p. 116; Boatwright, 1985):

$$
\begin{aligned}
& \left\langle M_{0}\right\rangle=\frac{4 \pi \alpha_{s}^{\frac{5}{2}} \alpha_{r}^{\frac{1}{2}} \rho_{s}^{\frac{1}{2}} \rho_{r}^{\frac{1}{2}} \hat{\Omega}_{0}(P)}{C(P)} \\
& \left\langle M_{0}\right\rangle=\frac{4 \pi \beta_{s}^{\frac{5}{2}} \beta_{r}^{\frac{1}{2}} \rho_{s}^{\frac{1}{2}} \rho_{r}^{\frac{1}{2}} \hat{\Omega}_{0}(S)}{C(S)}
\end{aligned}
$$


for $P$-waves and $S$-waves, respectively. Subscripts $s$ and $r$ refer to source and receiver, respectively. The denominator $C$ corrects for geometrical spreading, attenuation, and radiation pattern:

$$
\begin{aligned}
& C(P)=\frac{2 \Phi_{P}(\theta, \phi) G(R)}{\sqrt{2}} \\
& C(S)=\frac{2 \Phi_{S}(\theta, \phi) G(R)}{\sqrt{2}}
\end{aligned}
$$

$G(R)$ in these formulas is the combined geometrical spreading factor and whole-path attenuation factor, which we assume to be of the form $G(R)=R^{-n} e^{-\gamma R}$ where $R$ is the hypocentral distance, $n$ is a constant, and $\gamma$ is the frequency dependent anelastic attenuation coefficient:

$$
\begin{aligned}
& \gamma_{P}=\frac{\pi f}{Q_{P} \bar{\alpha}} \\
& \gamma_{S}=\frac{\pi f}{Q_{S} \bar{\beta}} .
\end{aligned}
$$

$Q_{P}$ and $Q_{S}$ are the quality factors for $P-$ and $S$-waves, respectively, and $\bar{\alpha}$ and $\bar{\beta}$ are $P$ - and $S$-wave velocities averaged along the propagation path. In southern Nevada, A. M. Rogers (unpub. data, 1986) finds that $n=0.833$ and $\gamma=0.0022 f$ at epicentral distances greater than $50 \mathrm{~km}$. At shorter distances $n=1.0$ is appropriate. The factor $\sqrt{2}$ in the denominator of $C$ corrects for the fact that we observe the average projection of the wave on each of the three components. Other numerical constants in $C$ correct for the free-surface effect $(=2)$ and average radiation pattern $\Phi(\theta, \phi)$. Rogers and others (1986) find that the predominant focal mechanism in the southern NTS is vertical, strike-slip so the average radiation pattern corrections (Boore and Boatwright, 1984) are:

$$
\begin{gathered}
\Phi(\theta, \phi)_{P}=0.50 \\
\Phi(\theta, \phi)_{S V}=0.16 \\
\Phi(\theta, \phi)_{S H}=0.50
\end{gathered}
$$

The values of velocities and densities

$$
\begin{array}{cccc}
\alpha=3.8 \mathrm{~km} / \mathrm{sec} & \beta=2.2 \mathrm{~km} / \mathrm{sec} & \rho=2.5 \mathrm{gm} / \mathrm{cm}^{3} & 0 \mathrm{~km}<z<1 \mathrm{~km} \\
\alpha=5.9 \mathrm{~km} / \mathrm{sec} & \beta=3.45 \mathrm{~km} / \mathrm{sec} & \rho=2.7 \mathrm{gm} / \mathrm{cm}^{3} & 1 \mathrm{~km}<z<3 \mathrm{~km} \\
\alpha=6.15 \mathrm{~km} / \mathrm{sec} & \beta=3.6 \mathrm{~km} / \mathrm{sec} & \rho=2.8 \mathrm{gm} / \mathrm{cm}^{3} & z>3 \mathrm{~km}
\end{array}
$$

are from the crustal model of Rogers and others (1983). A tabulation of the values of level and corner frequency for all stations recording earthquake \#3 is found in table 3 to demonstrate that spectral parameters may be obtained from both vertical and horizontal components of $P$ and $S$. However, only source parameters determined from $S H$ components are tabulated in table 2.

In some cases, it was extremely difficult or impossible to determine the low-frequency level for the spectrum; either because of deep holes in the spectrum or because there was no obvious flat section of the spectrum. Even for the best spectra the level can vary by a factor of two over the low-frequency part of the spectrum. 
TABLE 3.-Spectral data from NTS earthquake \#3

[Components 1, 2, and 3 are vertical, $N-\mathrm{S}$, and E-W respectively; $\Delta$, epicentral distance; $\mathrm{R}$, hypocentral distance; $\hat{f}_{c}$, corner frequency; $\hat{\Omega}_{0}$, asymptotic zero-frequency spectral level; $\left\langle M_{0}\right\rangle$; seismic moment computed from $\hat{\Omega}_{0} ;\left\langle M_{L}\right\rangle$, local magnitude computed from $\left\langle M_{0}\right\rangle$.]

\begin{tabular}{|c|c|c|c|c|c|c|c|c|c|c|c|}
\hline \multirow{2}{*}{$\begin{array}{c}\text { Station } \\
\text { abbre- } \\
\text { via- } \\
\text { tion }\end{array}$} & \multirow{2}{*}{$\begin{array}{c}\text { Com- } \\
\text { po- } \\
\text { nent }\end{array}$} & \multirow{2}{*}{$\underset{[\mathrm{km}]}{\Delta}$} & \multirow{2}{*}{$\begin{array}{c}\mathrm{R} \\
{[\mathrm{km}}\end{array}$} & \multicolumn{4}{|c|}{$P$-wave } & \multicolumn{4}{|c|}{$S$-wave } \\
\hline & & & & $\begin{array}{c}\hat{f}_{c} \\
{[\mathrm{~Hz}]}\end{array}$ & $\begin{array}{c}\hat{\Omega}_{0} \\
{[\mathrm{~cm}-\mathrm{sec}]}\end{array}$ & $\begin{array}{l}\left\langle M_{0}\right\rangle \\
{[N-\mathrm{m}]}\end{array}$ & $\left\langle M_{L}\right\rangle$ & $\begin{array}{c}\hat{f}_{c} \\
{[\mathrm{~Hz}]}\end{array}$ & $\begin{array}{c}\hat{\Omega}_{0} \\
{[\mathrm{~cm}-\mathrm{sec}]}\end{array}$ & $\begin{array}{l}\left\langle M_{0}\right\rangle \\
{[\mathrm{N}-\mathrm{m}]}\end{array}$ & $\left\langle M_{L}\right\rangle$ \\
\hline \multirow[t]{3}{*}{ JFA } & 1 & 19.6 & 25.3 & 12.5 & $2.08 \cdot 10^{-6}$ & $4.54 \cdot 10^{12}$ & & 10.5 & $2.66 \cdot 10^{-6}$ & $33 \cdot 10^{12}$ & \\
\hline & 2 & & & 18.5 & 7.56 & & & 5.5 & & & \\
\hline & 3 & & & 18.5 & $1.15 \cdot 10^{-6}$ & 2.51 . & & 8.4 & $5.02 \cdot 10^{-6}$ & & \\
\hline \multirow[t]{3}{*}{ JFC } & 1 & 29.0 & 33.2 & 6.6 & $1.75 \cdot 10^{-6}$ & 4.99 . & 2. & 6.1 & $2.04 \cdot 10^{-6}$ & & 2.34 \\
\hline & 2 & & & 7.4 & $1.39 \cdot 10^{-6}$ & 3.96 . & 2.17 & 5.5 & $3.60 \cdot 10^{-6}$ & & 1.93 \\
\hline & 3 & & & 10.2 & $2.12 \cdot 10^{-6}$ & 6.05 & 2.32 & 7.0 & $2.13 \cdot 10^{-6}$ & & 1.74 \\
\hline \multirow[t]{2}{*}{ JFF } & 1 & 35.4 & 38.9 & 8.2 & $7.03 \cdot 10^{-7}$ & $2.35 \cdot 10^{12}$ & 1.98 & 8.7 & $1.83 \cdot 10^{-6}$ & 6.6 & 2.35 \\
\hline & 2 & & & 8.2 & $2.82 \cdot 10^{-7}$ & 9.43 & 1.65 & 8.7 & $2.01 \cdot 10^{-6}$ & & 1.77 \\
\hline \multirow[t]{3}{*}{ JFL } & 1 & 35.3 & 38.8 & 9.1 & $2.30 \cdot 10^{-6}$ & $7.67 \cdot 1$ & 2.40 & 6.9 & $2.68 \cdot 10^{-6}$ & & 2.49 \\
\hline & 2 & & & 10.0 & $1.03 \cdot 1$ & & 2 . & 5.0 & $6.97 \cdot 10^{-6}$ & & 2.22 \\
\hline & 3 & & & 10.0 & $5.62 \cdot 10^{-7}$ & $1.87 \cdot 10^{12}$ & 1.89 & 7.0 & $3.10 \cdot 10^{-6}$ & $2.06 \cdot 10^{12}$ & 1.93 \\
\hline
\end{tabular}


Geometric mean values of seismic moment $\left\langle\overline{M_{0}}\right\rangle$ determined from $S H$ levels and associated multiplicative error $E\left\langle\overline{M_{0}}\right\rangle$ are tabulated in table 2. Figure 3 shows that corner frequency decreases with increasing moment and that deeper shocks generally had larger moments.

Variations by a factor of two in $\left\langle M_{0}\right\rangle$ (as in the best spectra) result in variations in $\left\langle M_{L}\right\rangle$ of 0.2 to 0.3 magnitude units. Apart from errors of measurement of $\hat{\Omega}_{0}$, misestimation of moment might be caused by any of the following possible sources of error:

1. Lateral variation of $\alpha, \beta$, and $\rho$.

2. The radiation pattern effect may differ significantly from the average value at any given station (Bakun and McEvilly (1981)).

3. Contamination of the spectrum with energy from unwanted phases (Thatcher and Hanks, 1973).

\subsection{Corner frequency}

The accuracy of corner frequency determination depends on the accuracy of lowfrequency spectral level and of visual estimates of the high-frequency spectral roll-off. Although corner frequency is ordinarily the least well-determined of the spectral parameters, $\hat{f}_{c}$ estimates in this study show low dispersion (table 2).

The corner frequency data tabulated in table 3 show that $\hat{f}_{c}$ from a $P$-wave spectrum is usually higher than the $\hat{f}_{c}$ determined from the corresponding $S$-wave spectrum. Similar results were reported by Molnar, Tucker, and Brune (1973) and Brune, Archuleta, and Hartzell (1979).

\subsection{Radius and stress drop}

The effective source radius $\left\langle r_{0}\right\rangle$ and stress drop $\langle\Delta \sigma\rangle$ are computed from the corner frequency $\hat{f}_{c}$ by means of the relationships:

$$
\begin{aligned}
\left\langle r_{0}\right\rangle & =\frac{2.34 \beta_{s}}{2 \pi f_{c}} \\
\langle\Delta \sigma\rangle & =\frac{7\left\langle M_{0}\right\rangle}{16\left\langle r_{0}\right\rangle^{3}}
\end{aligned}
$$

Despite the sensitivity of $\langle\Delta \sigma\rangle$ to uncertainties, in estimates in $\hat{f}_{c}$, our data show a clear increase of stress drop with increasing moment and suggest an increase of stress drop with increasing hypocentral depth (fig. 4). Fletcher (1980) and Fletcher and others (1984) have reported a similar effect for Oroville, California, earthquakes although at considerably higher levels of maximum stress drop. The stress drops themselves are relatively small, ranging between 0.008 and $0.119 \mathrm{MPa}$. Small stress drops for low magnitude, shallow earthquakes have been reported elsewhere (Thatcher and Hanks, 1973; Fletcher, 1980; Bakun and Lindh, 1977; Scherbaum and Kisslinger, 1984) but it is notable that even the largest earthquake in this study $\left(M_{d}=1.8\right.$ ) had a stress drop of only about $0.1 \mathrm{MPa}$ (table 2). 


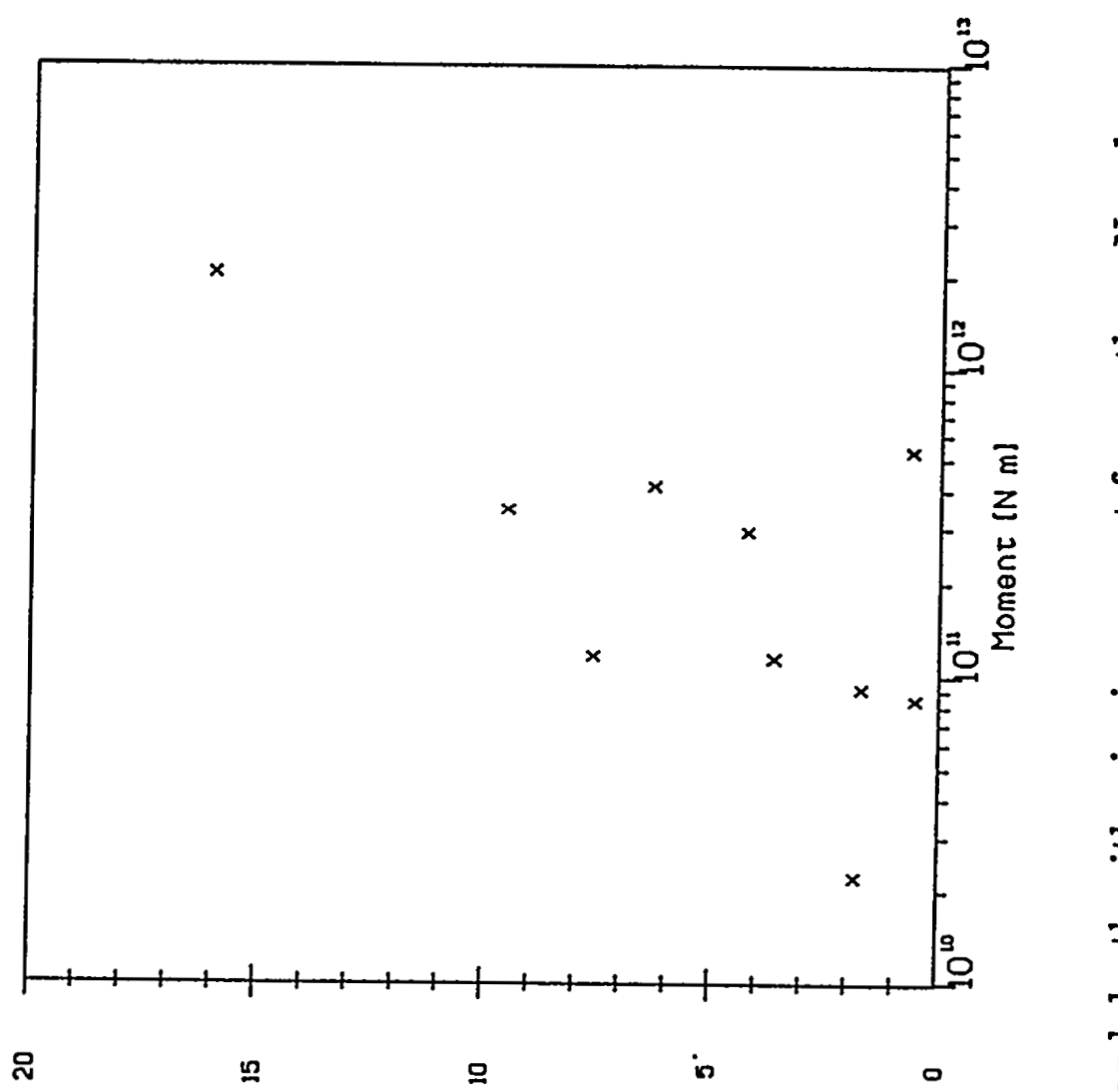

[ux] 47dor

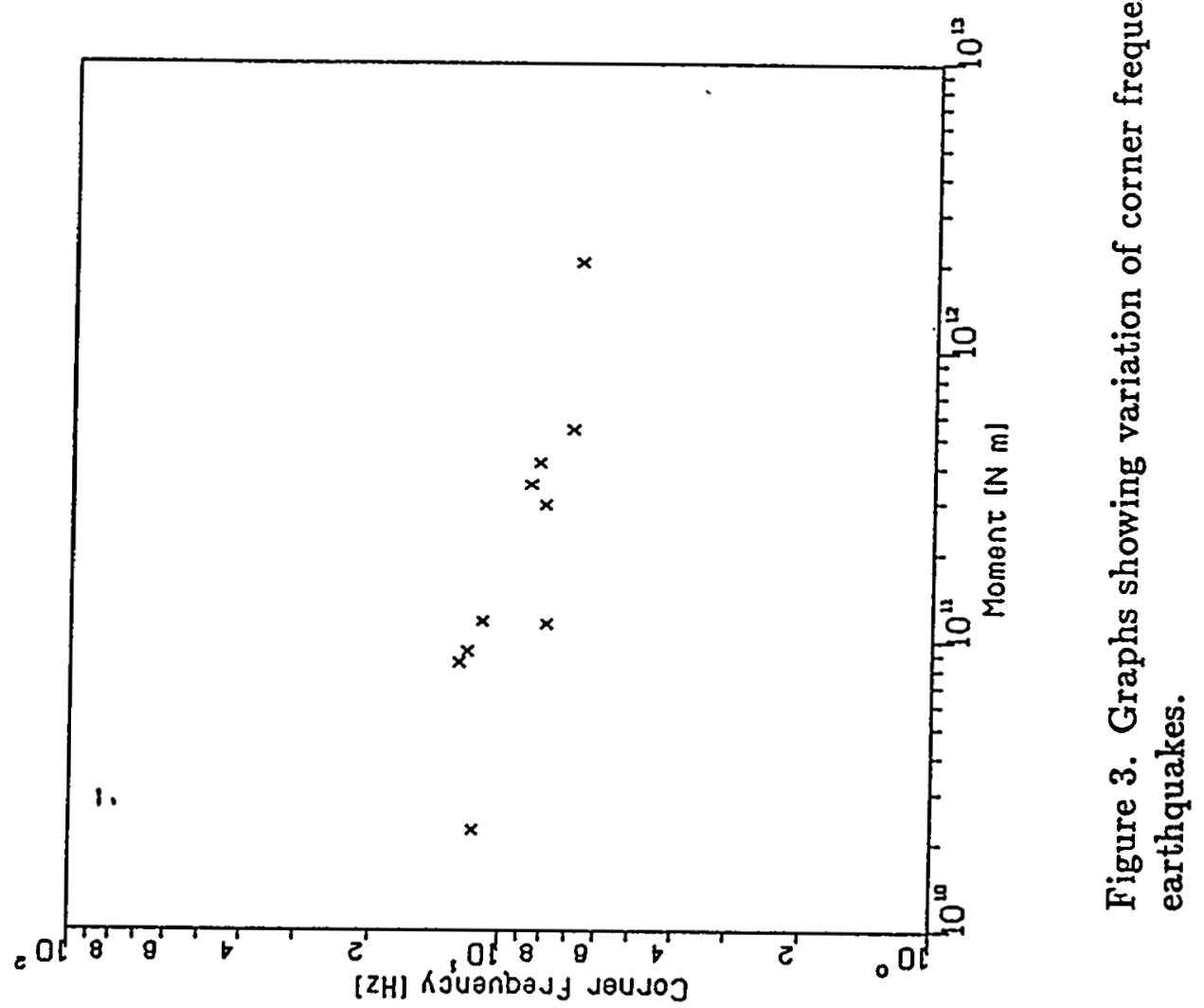



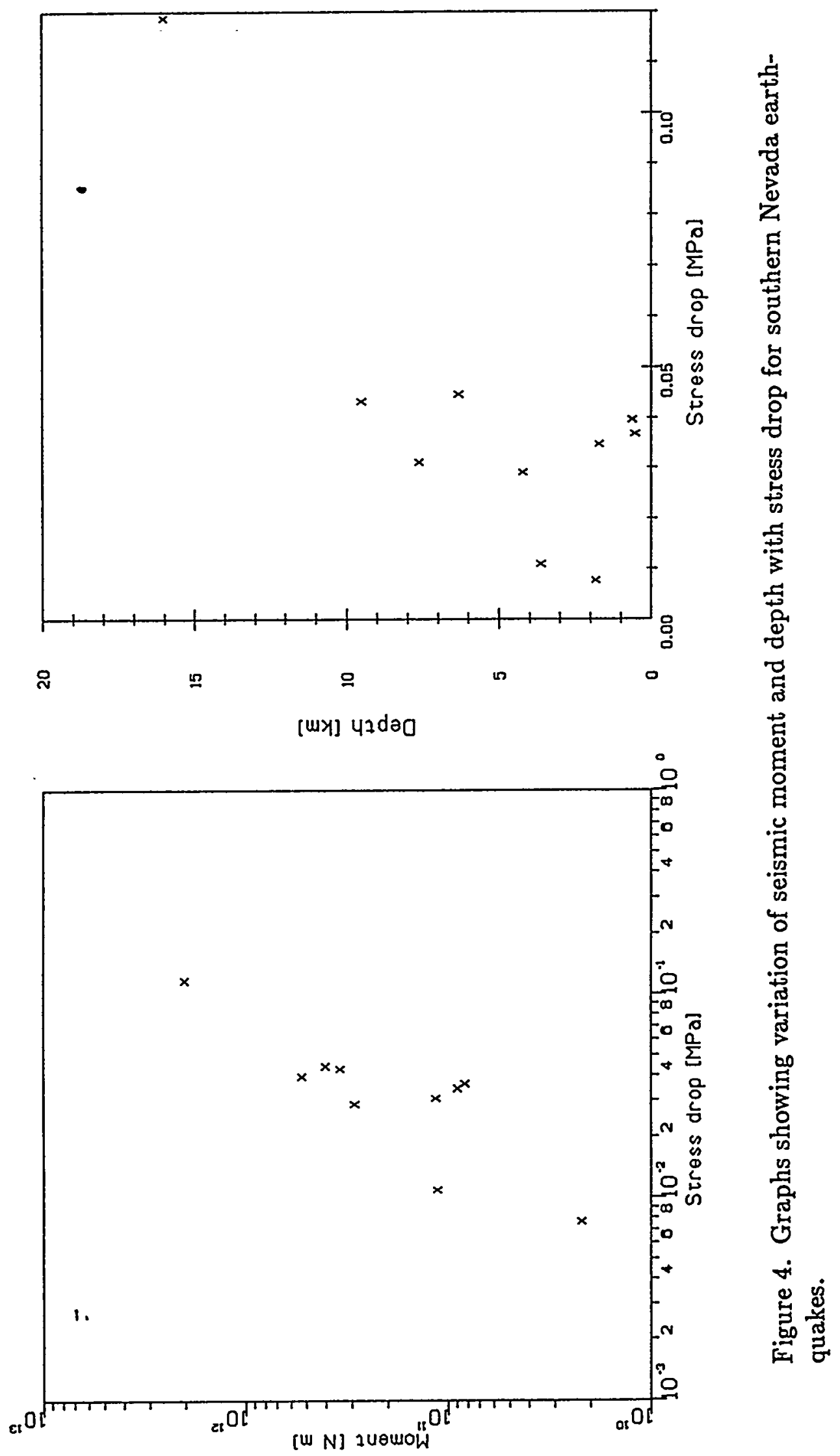


\subsection{Apparent stress}

Apparent stress $\left\langle\sigma_{a}\right\rangle$ (Aki, 1966; Brune, 1968; Hanks and Thatcher, 1972; Thatcher and Hanks, 1973) is the product of the seismic efficiency $\eta$ and the average of the initial and final stresses $\bar{\sigma}$ acting in the source region:

$$
\left\langle\sigma_{a}\right\rangle=\eta \bar{\sigma}
$$

The apparent stress is computed from the shear modulus $\mu$, the radiated seismic energy $E_{s}$, and the seismic moment $\left\langle M_{0}\right\rangle$ :

$$
\left\langle\sigma_{a}\right\rangle=\frac{\mu E_{s}}{\left\langle M_{0}\right\rangle}
$$

We use the relationship between radiated seismic energy $E_{s}$ and $M_{L}$ magnitude given by Thatcher and Hanks (1973)

$$
\log E_{s}=2.0 M_{L}+8.1
$$

for southern California earthquake data. Computed values of apparent stress are tabulated in table 2. The values are relatively small, generally in the kilopascal range. Although small values of apparent stress have been reported elsewhere, our values are abnormally low.

\subsection{Magnitude}

Although seismic moment is a more fundamental earthquake parameter than magnitude, magnitude is a convenient quantity for comparing earthquakes, particularly those shocks for which seismic moment is not available. In this section, we describe the computation of equivalent local magnitude using two different techniques.

\subsection{Moment magnitude}

Moment magnitudes $\left\langle M_{L}\right\rangle$ were determined by means of moment-magnitude relationships adapted from Bakun (1984)

$$
\begin{gathered}
\left\langle M_{L}\right\rangle=\left[\log \left(\left\langle M_{0}\right\rangle\right)-9.0\right] / 1.5 \quad M_{L}>3.3 \\
\left\langle M_{L}\right\rangle=\left[\log \left(\left\langle M_{0}\right\rangle\right)-10.0\right] / 1.2 \quad M_{L}<3.3
\end{gathered}
$$

where $\left\langle M_{0}\right\rangle$ has units of $\mathrm{N} \mathrm{m}$. The first relationship is the same as that of Thatcher and Hanks (1973) which, if extrapolated to smaller magnitudes, consistently overestimates moment magnitude (Bakun, 1984; Hanks and Boore, 1984). The moment-magnitude relationship for $M_{L}<3.3$ seems to work well for the present set of ten events (fig. 5).

Figure 6 is a comparison of moment magnitude, using the above relationships, with the old coda duration magnitude (using California constants), and with the new coda duration magnitude. The moment magnitude values are much more compatible with new coda duration magnitudes than with the old. Nevertheless, the scatter of $\left\langle M_{L}\right\rangle$ suggests the need to investigate possible sources of error in determining moment magnitude. (This report does not consider possible sources of error in the coda duration magnitude scale.) Arithmetic mean equivalent local magnitudes $\left\langle\overline{M_{L}}\right\rangle$ and associated standard deviations 


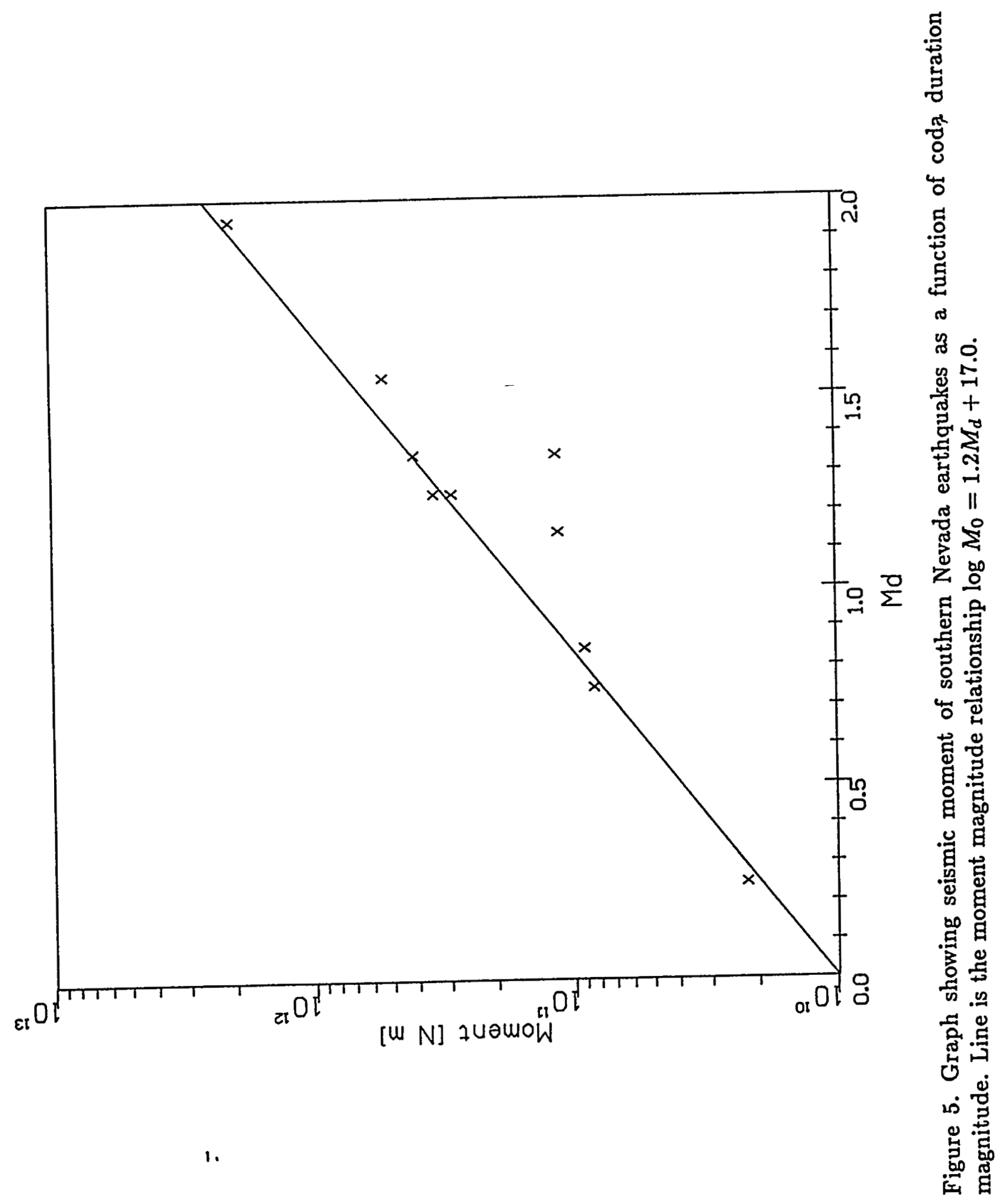




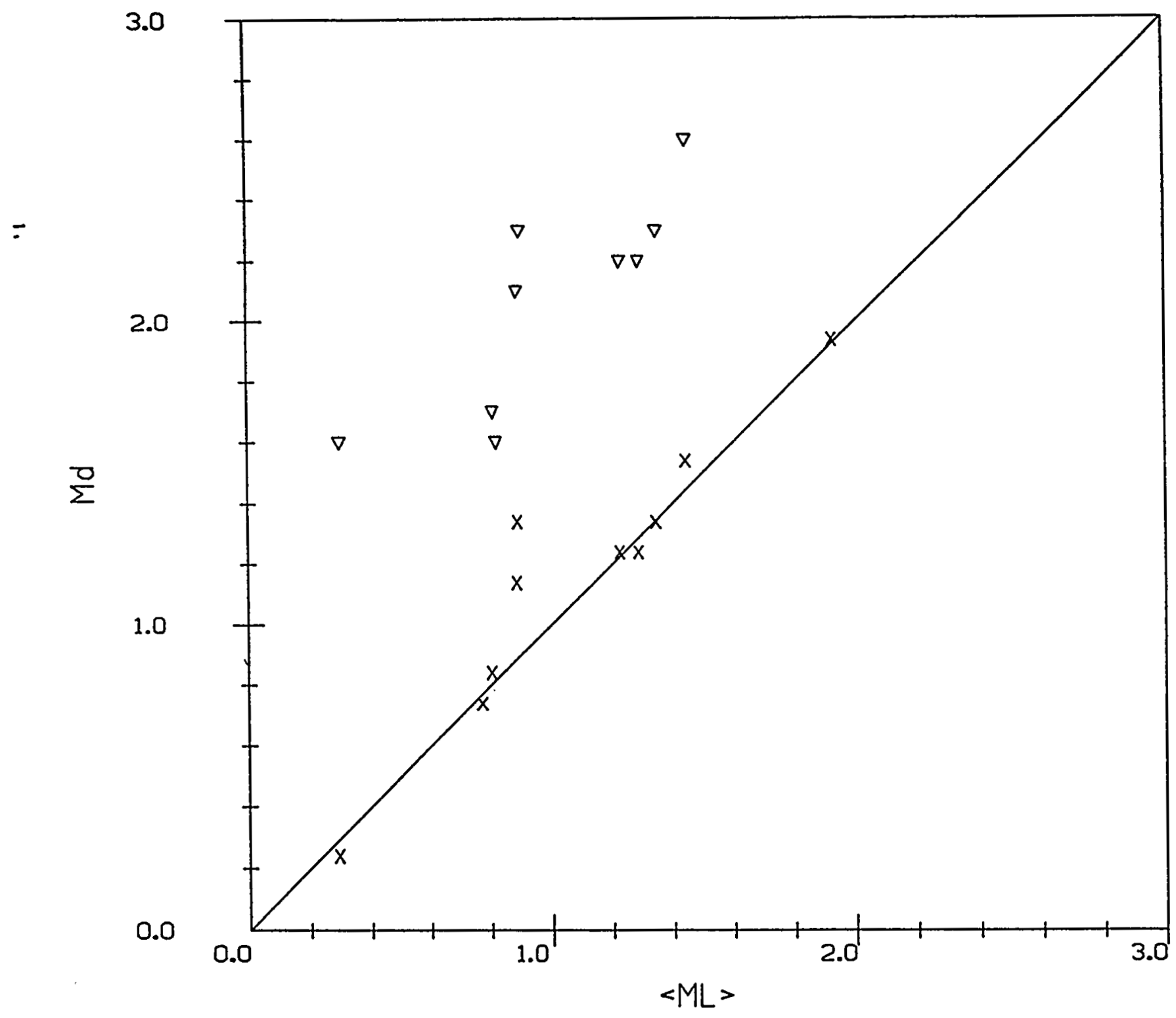

Figure 6. Graph showing coda duration magnitude $M_{d}$ versus moment magnitude $\left\langle\overline{M_{0}}\right\rangle$ determined from $S H$ spectra. Symbols designate coda duration magnitude $M_{d}$ determine using California constants in formula (triangles) and new coda duration magnitude $M_{d}$ (crosses). The diagonal line represents $M_{d}=\left\langle\overline{M_{L}}\right\rangle$. 
are tabulated in table 2. Examination of the table shows that $\left\langle M_{L}\right\rangle$ estimates are close to corresponding $M_{d}$ estimates; the mean deviation of $\left\langle M_{L}\right\rangle$ from $M_{d}$ is -0.06 magnitude units.

\subsection{Local magnitude}

One of the most direct methods of estimating magnitude is to simulate the local magnitude determination process, that is, transform the digital velocity time series into a displacement time series for a standard Wood-Anderson seismograph and scale the maximum displacement amplitude. We determined the pseudo-Wood-Anderson amplitude by removing the seismic system response from the displacement spectrum and applying the Wood-Anderson magnification (2800) to the peak displacement amplitude. The standard $M_{L}$ formula $M_{L}=\log (A)-\log \left(A_{0}\right)$ in southern Nevada (Rogers and others, 1986, table 4) is cast as:

$$
M_{W A}=\log (A)+n \cdot \log (R)+\gamma_{1} R+\gamma_{2}
$$

where $A$ is the Wood-Anderson trace amplitude in millimeters, $R$ is the hypocentral distance in kilometers, $n$ is the geometrical spreading exponent, and $\gamma_{1}$ and $\gamma_{2}$ are empirical constants. In order to compare the $M_{W A}$ with the $M_{d}$ determined from distant stations, it was considered appropriate to use the formula

$$
M_{W A}=\log (A)+0.833 \cdot \log (R)+0.00164 R+0.88
$$

If the $M_{d}$ had been determined from the observations of near stations, the appropriate formula would have been

$$
M_{W A}=\log (A)+1.0 \cdot \log (R)+0.000734 R+0.7
$$

because hypocentral distances were always less than $43 \mathrm{~km}$; at such small distances, it is reasonable to assume a geometrical spreading exponent of 1.0. Using either formula produces identical values of $M_{W A}$ at about $10 \mathrm{~km}$; differences between the formulas are about 0.2 magnitude units at $1 \mathrm{~km}$ and 0.06 units at $50 \mathrm{~km}$.

The method is appropriate when several conditions are met. The frequency of the peak motion must fall in the flat part of the Wood-Anderson response curve (well above $1.25 \mathrm{~Hz}$ ) and in the flat part of the Brune model spectrum (below the corner frequency $\hat{f}_{c}$ ). These conditions are satisfied for all records.

The average $\overline{M_{W A}}$ and average moment magnitude $\left\langle\overline{M_{L}}\right\rangle$ are plotted against coda duration magnitude $M_{d}$ in figure 7 ; figure 8 shows the comparison of $\left\langle\overline{M_{L}}\right\rangle$ and $\overline{M_{W A}}$. The $M_{d}$ are on average about 0.38 magnitude units smaller than $\overline{M_{W A}}$. Part of the offset is explained by results of stochastic modelling experiments by Rogers and others (1986, table 5) wherein it was found that $M_{d}$ underestimates true $M_{L}$ by 0.1 to 0.2 magnitude units. Since $\left\langle M_{L}\right\rangle$ and $M_{d}$ correlate closely, $\left\langle M_{L}\right\rangle$ must also underestimate true $M_{L}$, a conclusion that suggests the need to refine the moment-magnitude relationships discussed in section 4.41 .

\subsection{Peak ground motion parameters}

McGarr(1984) has shown that peak ground motion parameters $R v$ and $\rho R$ a (combining hypocentral distance $R$, density $\rho$, peak velocity $\mathrm{v}$, and peak acceleration a) are functions of focal depth $z$ and stress regime. If the focal depth and faulting type (thrust, 
normal, and strike-slip) are properly accounted for, the peak velocity can be directly related to seismic moment $M_{0}$ :

$$
\log R v=c_{1}+c_{2} \log M_{0}
$$

In McGarr's (1984) data set, the constants $c_{1}=-4.78$ and $c_{2}=0.44$ fit seismic moments ranging over ten orders of magnitude.

The dependence on depth and fault type can be expressed by a relationship of the form:

$$
\frac{R v}{M_{0}{ }^{\frac{1}{3}}}=c_{3}+c_{4} z
$$

When McGarr's (1984) data set is separated into normal and thrust events, the data are fit by this equation with constants:

$$
\begin{array}{ll}
c_{3}=3.00 & c_{4}=0.69 \\
c_{3}=4.63 & c_{4}=1.82
\end{array}
$$

Constants for strike-slip events are thought by McGarr(1984) to lie between constants for normal and thrust events.

The mean values for $R v$ for the southern NTS earthquakes were plotted in figure 9 as a function of seismic moment. Although $R \mathrm{v}$ increases with seismic moment, figure 9 demonstrates that the southern NTS earthquakes do not fit McGarr's (1984) log $R v$ versus $\log M_{0}$ relationship. Three simple hypotheses are suggested by this result: (1) McGarr's relationship is not universal; (2) the moment determinations are too large by three orders of magnitude; or (3) the peak velocity measurements are too small by over one order of magnitude. The second and third hypotheses, if true, would imply that moment magnitude would be too large by about 2.5 magnitude units and $M_{W A}$ would be too small by over one magnitude unit, respectively. Such extreme hypotheses seem to be ruled out by the agreement of both moment magnitude and $M_{W A}$ with the independently determined coda duration magnitude $M_{d}$ discussed in previous sections.

If the first hypothesis is true, then it is necessary to explain why the relationship does not work for southern NTS earthquakes. It is possible that the linear relationship is accurate at large magnitudes for some tectonic environments but that local conditions increasingly influence (in this case reduce) the peak ground motion parameters as the moment decreases and as the corner frequency increases (fig. 3). Perhaps the peak ground motion is reduced for small moment earthquakes because of strong attenuation of high frequencies in the near-surface crustal structure under the recording site. Because anelastic attenuation becomes important at high frequencies, the low-frequency level $\Omega_{0}$ (and therefore the moment) is not affected by attenuation as strongly as the peak motion is in its higher frequency band. 


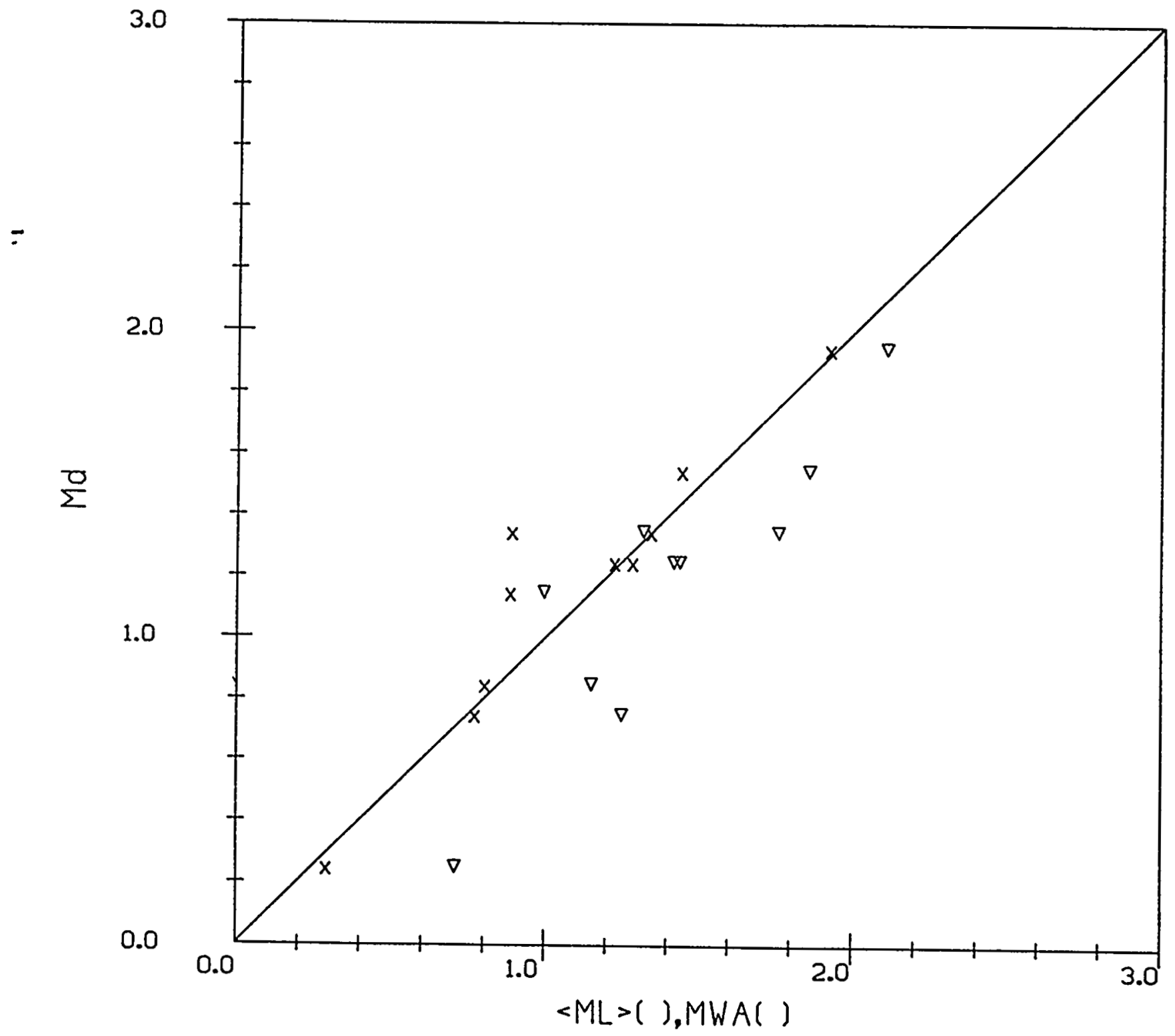

Figure 7. Graph showing comparison of moment magnitude $\left\langle\overline{M_{L}}\right\rangle$ (crosses) and equivalent Wood-Anderson local magnitude $\overline{M_{W A}}$ (triangles) with coda duration magnitude $M_{d \cdot}$. 


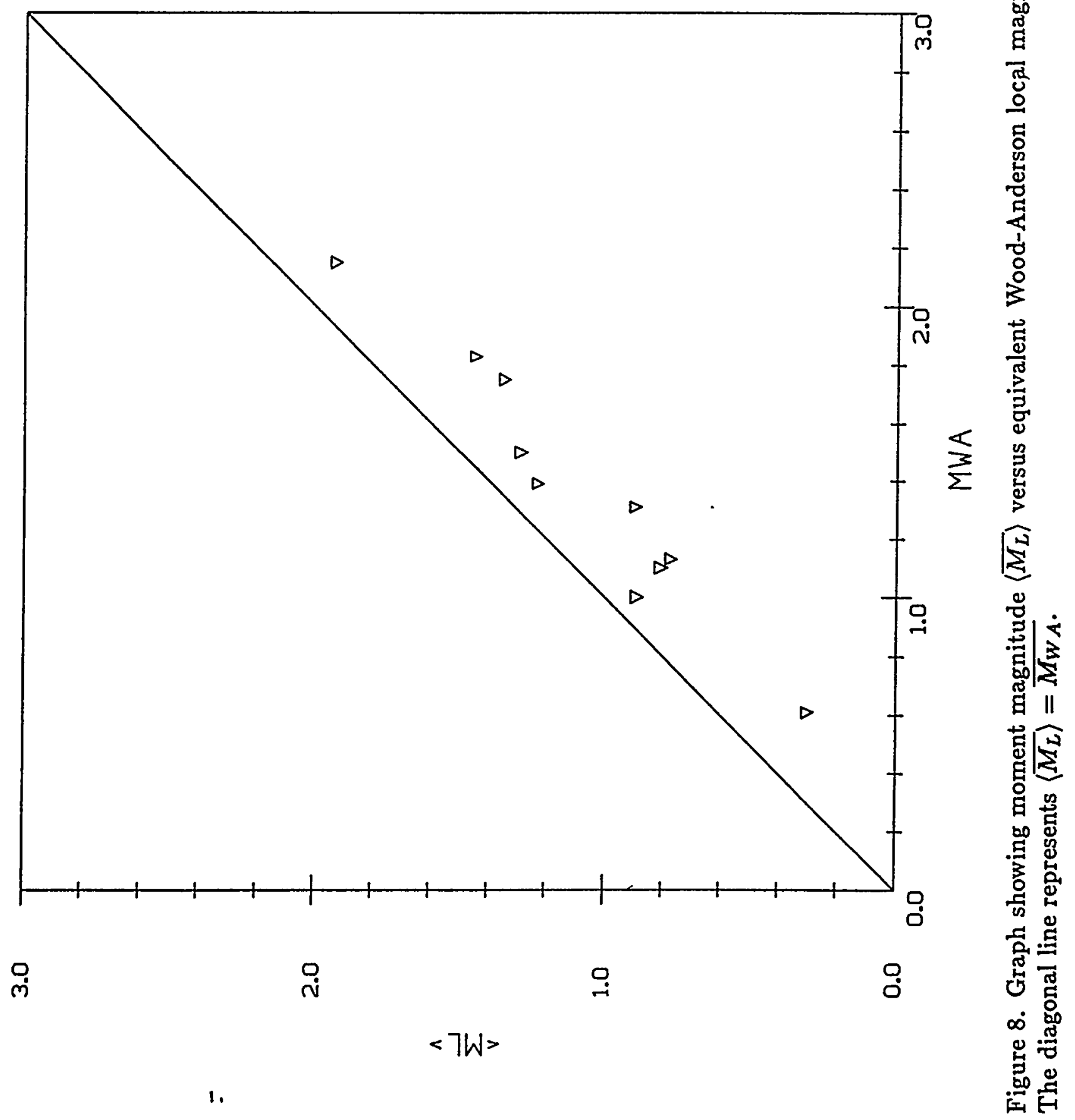




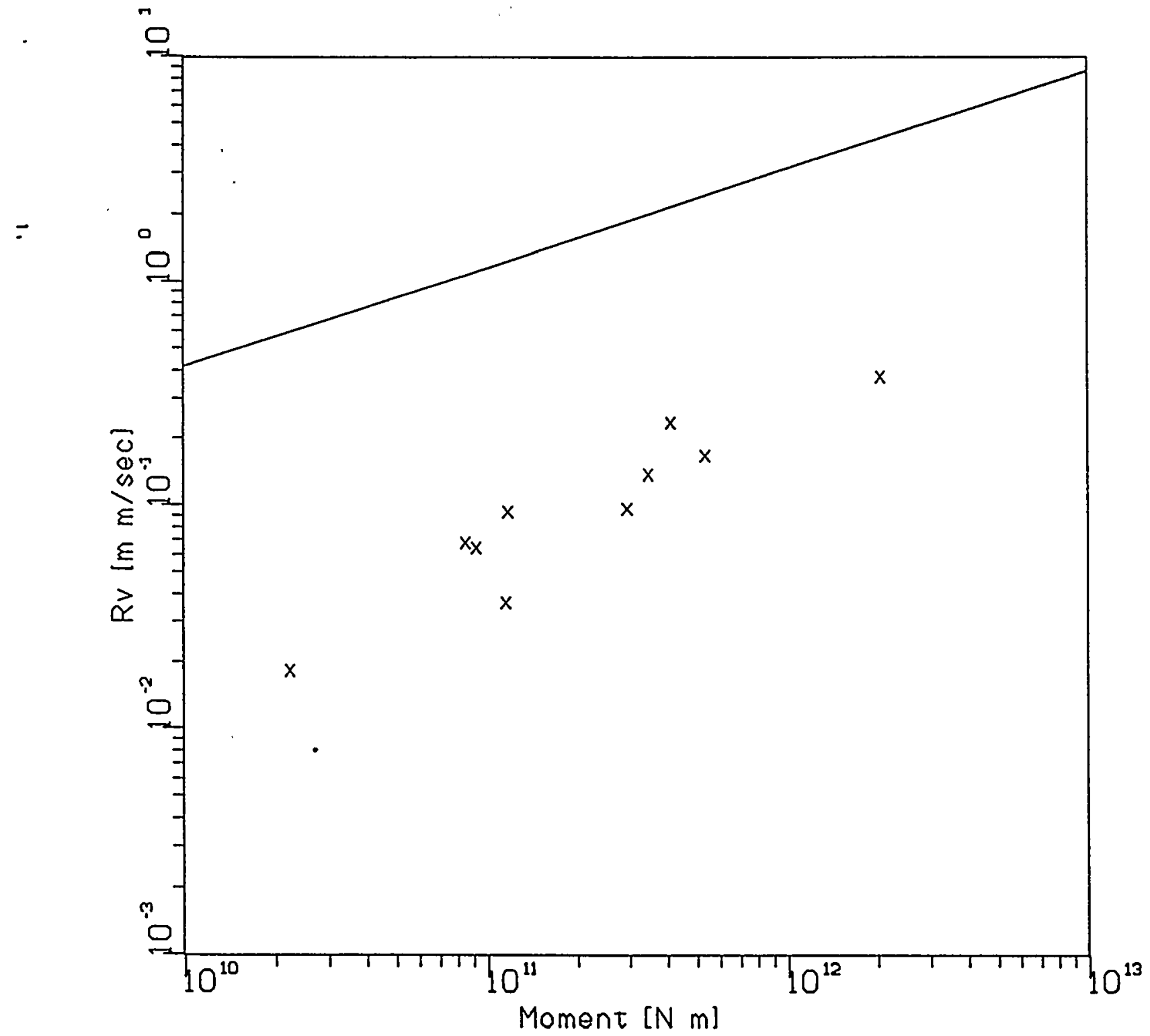

Figure 9. Graph showing peak ground motion parameter $R v$ versus seismic moment $M_{0}$. The diagonal line represents the relationship $\log R v=-4.78+0.44 \log M_{0}$. 


\subsection{DISCUSSION}

Determination of source parameters of earthquakes in and near the NTS was accomplished effectively by means of spectral analysis techniques and digital seismic data recorded in 1981. Not only were hypocenters and focal mechanisms more completely determined as a result of the digital data, but the general quality of routinely-computed SGBSN locations and magnitudes were validated by the analyses. In particular, a new $M_{d}$ magnitude scale based on measurements of coda duration was shown to be consistent with $\left\langle M_{L}\right\rangle$ determined from spectral measurements. Further, this study has demonstrated that moment magnitude is an accurate estimator of $M_{W A}$, despite the need for a systematic adjustment of about 0.4 magnitude units.

This study suggests that southern NTS earthquakes in the $M_{L}=0$ to 2 range are characterized by low stress drops and very low apparent stresses relative to values determined in other areas, even at depths of $16 \mathrm{~km}$ where higher stress drops and apparent stresses are expected. In addition, estimates of the peak ground motion parameter $R \mathrm{v}$ are an order of magnitude or more smaller than McGarr's (1984) empirical formula. The data could be interpreted to imply that the region in the southern NTS is under relatively lower stresses than regions elsewhere that have higher stress drop earthquakes although the small sample of events does not permit estimates of maximum stress drop gradient to be made at this time. In addition, the data may also indicate the presence of strong anelastic attenuation, possibly in the near-surface geology of the recording site, which significantly reduces peak velocities and apparent corner frequencies.

Studies similar to the present one should be conducted on earthquakes in the regions surrounding the southern NTS. Comparison of source parameters of southern NTS earthquakes with source parameters of northern NTS shocks and regional earthquakes such

as occur along the California-Nevada border could provide valuable insight into regional variation of apparent stress and local variations in attenuation. 


\section{REFERENCES CITED}

Aki, K., 1966, Generation and propagation of $G$ waves from the Niigata earthquake of June 16, 1964, 2, Estimation of earthquake moment, released energy, and stress-strain drop from $G$ wave spectrum: Bulletin Earthquake Research Institute Tokyo University, v. $44,73-88$.

Aki, K. and Richards, P., 1980, Quantitative seismology Theory and methods: San Francisco, Freeman and Sons, $932 \mathrm{p}$.

Bakun, W. H., 1984, Seismic moments, local magnitudes, and coda duration magnitudes for earthquakes in central California: Bulletin Seismological Society America, v. 74, 439-458.

Bakun, W. H. and Lindh, A. G., 1977, Local magnitudes, seismic moments, and coda durations for earthquakes near Oroville, California: Bulletin Seismological Society America, v. 67, 615-630.

Bakun, W. H. and McEvilly, T. V., 1981, $P$-wave spectra for $M_{L} 5$ foreshocks, aftershocks, and isolated earthquakes near Parkfield, California: Bulletin Seismological Society America, v. 71, 423-436.

Boatwright, J., 1985, Characteristics of the aftershock sequence of the Borah Peak, Idaho, earthquake determined from digital recordings of the events: Bulletin Seismological Society America, v. 75, 1265-1284.

Boore, D. M. and Boatwright, J., 1984, Average body-wave radiation coefficients: Bulletin Seismological Society America, v. 74, 1615-1621.

Brune, J. N., 1968, Seismic moment, seismicity, and rate of slip along major fault zones, Journal of Geophysical Research, v. 73, 777-784.

Brune, J. N., 1970, Tectonic stress and the spectra of seismic shear waves from earthquakes: Journal Geophysical Research, v. 75, 4997-5009.

Brune, J. N., 1971, Corrections: Journal Geophysical Research, v. 76, 5002.

Brune, J. N., Archuleta, R. J., and Hartzell, S., 1979, Far-field S-wave spectra, corner frequencies, and pulse shapes: Journal Geophysical Research, v. 84, 2262-2272.

Fletcher, J. B., 1980, Spectra from high-dynamic range digital recordings of Oroville, California aftershocks and their source parameters: Bulletin Seismological Society America, v. 70, 735-755.

Fletcher, J., Boatwright, J., Harr, L., Hanks, T., and McGarr, A., 1984, Source parameters for aftershocks of the Oroville, California, earthquake: Bulletin Seismological Society America, v. 74, 1101-1124.

Hanks, T.C. and Boore, D.M., 1984, Moment-magnitude relations in theory and practice: Journal Geophysical Research, v. 89, 6229-6235. 
Hanks, T. C. and Thatcher, W., 1972, A graphical representation of seismic source parameters: Journal Geophysical Research, v. 77, 4393-4405.

McGarr, A., 1984, Scaling of ground motion parameters, state of stress, and focal depth: Journal Geophysical Research, v. 89, 6969-6979.

Molnar, P., Tucker, B. E., and Brune, J. N., 1973, Corner frequencies of $P$ and $S$ waves and models of earthquake sources: Bulletin Seismological Society America, v. 63, 2091-2104.

Rogers, A.M., Harmsen, S. C., Hermann, R.B., and Meremonte, M.E., 1986, A study of ground motion attenuation in the southern Great Basin, Nevada-California, using several techniques for estimation of $Q_{S}, \log A_{0}$, and coda $Q$, submitted to Journal Geophysical Research.

Rogers, A. M., Harmsen, S. C., Carr, W. J., and Spence, W., 1983, Southern Great Basin seismological data report for 1981 and preliminary data analysis: U.S. Geological Survey Open-File Report 83-669, 240 p.

Scherbaum, F. and Kisslinger, C., 1984, Variations of apparent stresses and stress drops prior to the earthquake of 6 May $1984\left(m_{b}=5.8\right)$ in the Adak seismic zone: Bulletin Seismological Society of America, v. 74, 2577-2592.

Thatcher, W. and Hanks, T., 1973, Source parameters of Southern California earthquakes: Journal Geophysical Research, v. 78, 8547-8575. 


\section{Appendix A}

Displays of time series by event

[Each page consists of six graphs, the left-most three corresponding to components of velocity time series and the right-most three corresponding to displacement time series. The component of motion is shown by a numeral in the lower left corner of each graph; 1 designates the vertical component, and 2 and 3 designate the $\mathrm{N}-\mathrm{S}$ and $\mathrm{E}-\mathrm{W}$ horizontal components, respectively. The large numerals above each graph identify the starting time of the earliest digital time series displayed; the vertical coordinate of each graph is time (in sec.) measured from that starting time. The time is coded as YY*DDD+HH:MM:SS.SSS where YY represents the last digits of the year, DDD is the day (January $1=001$ ), and HH:MM:SS.SSS is the starting time (UTC) in hours, minutes, and seconds. Letters above the trace are in the form XXX.M where XXX is the station code and $M$ identifies the units of motion as velocity $(M=V)$ and displacement $(M=D)$ units. Each displayed trace has been scaled such that the maximum amplitude equals the normalizing bar plotted to the left of the starting time; the length of the bar, in counts, is enumerated below each trace.] 

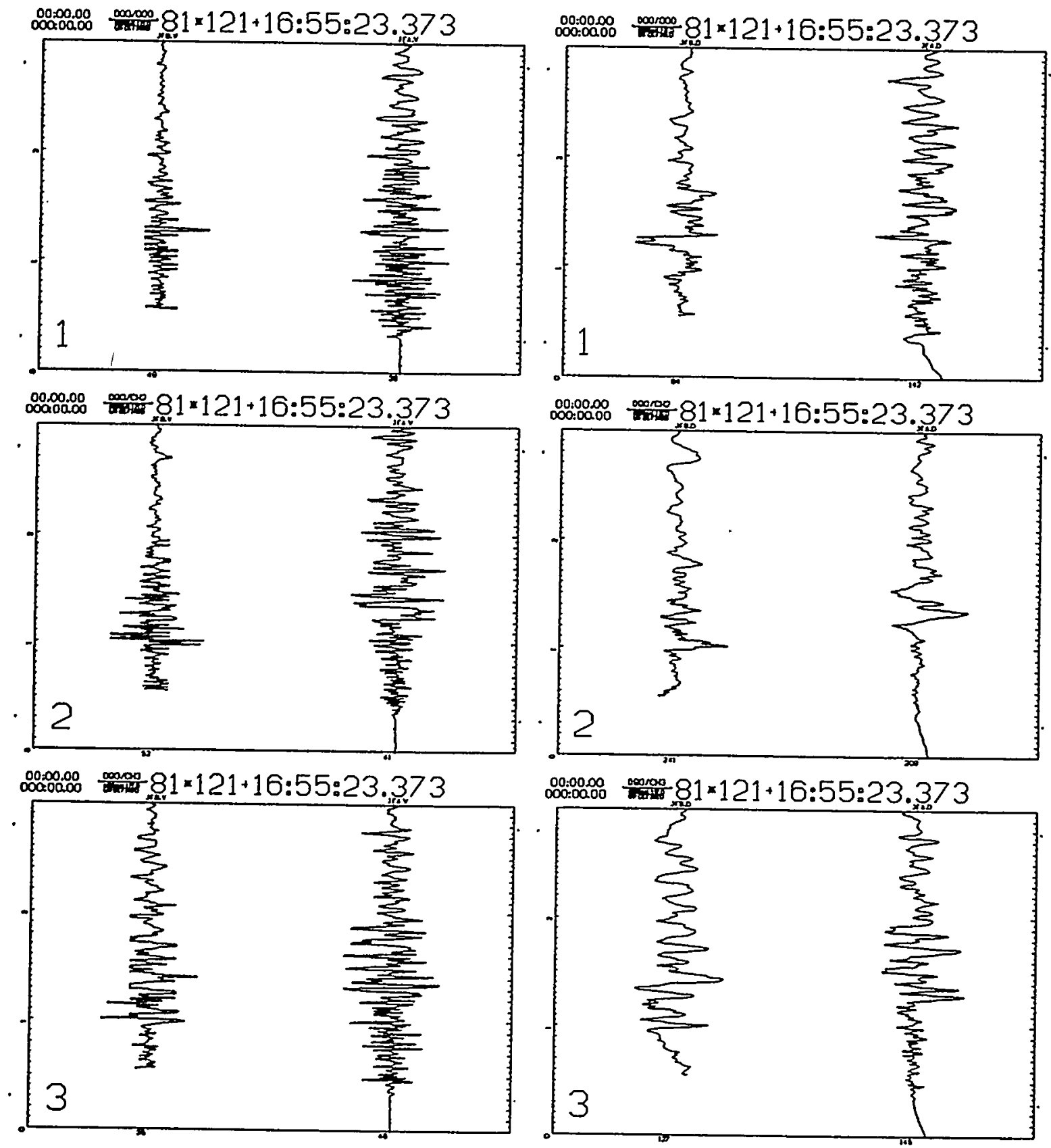

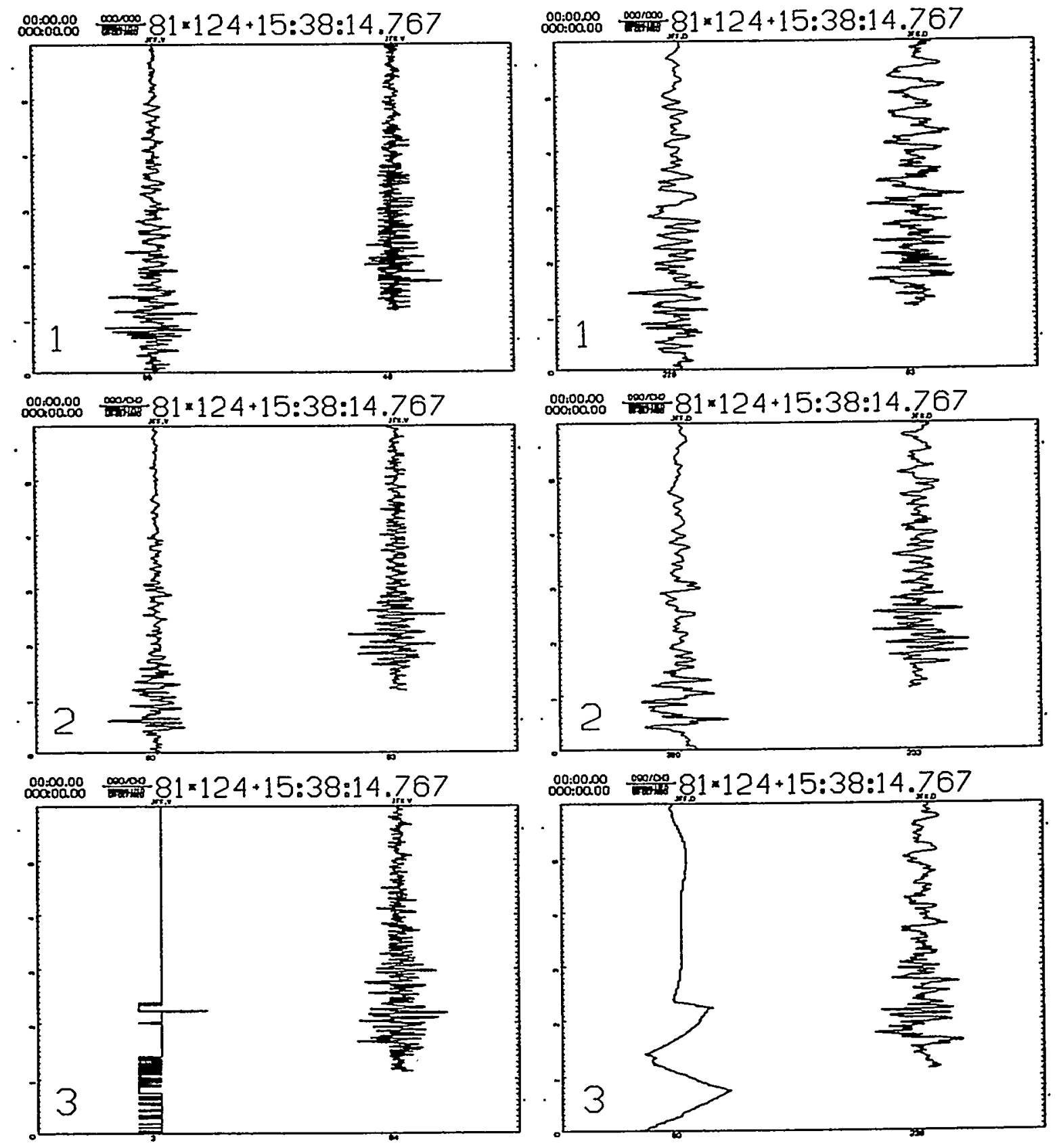

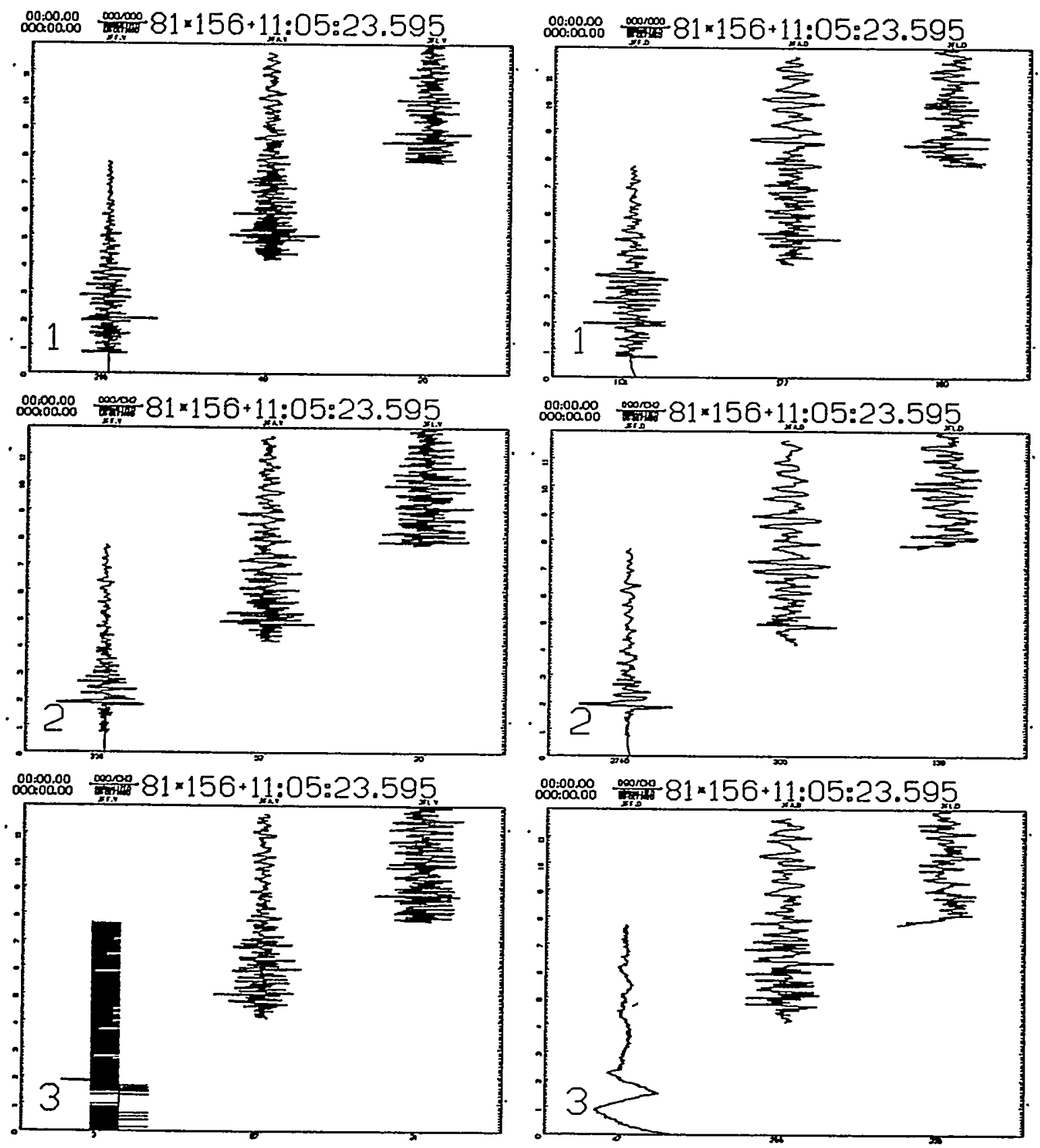


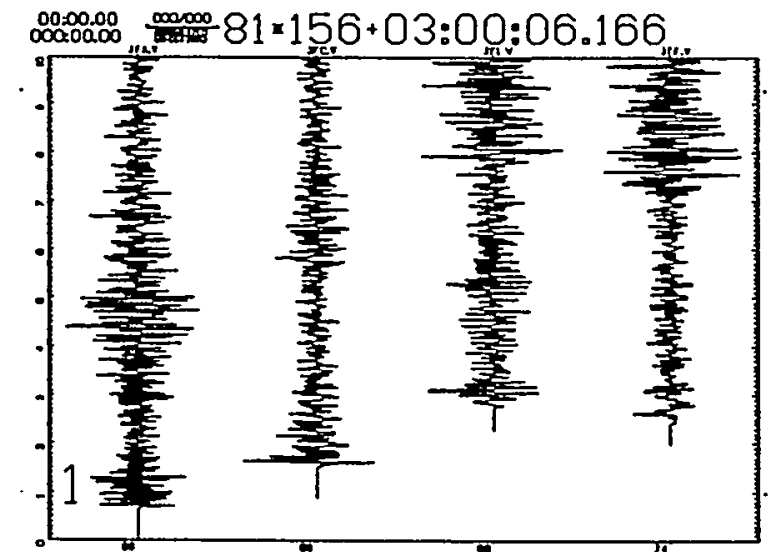

然:00000

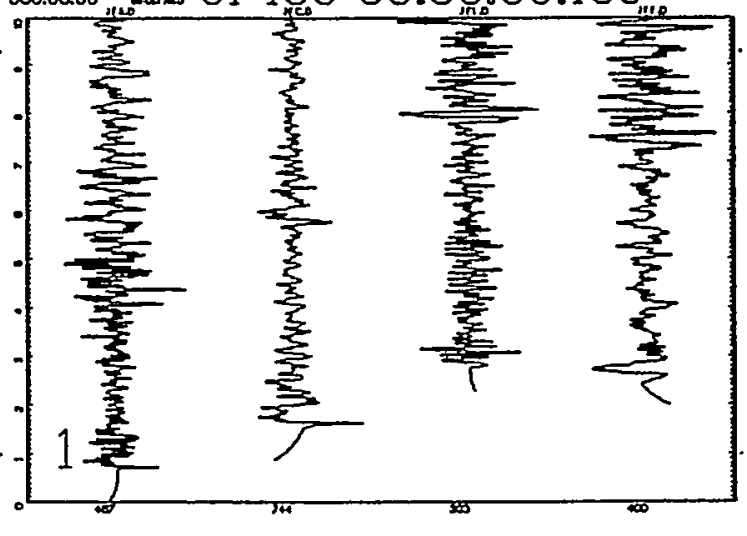

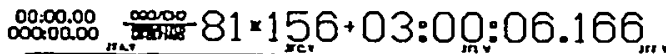

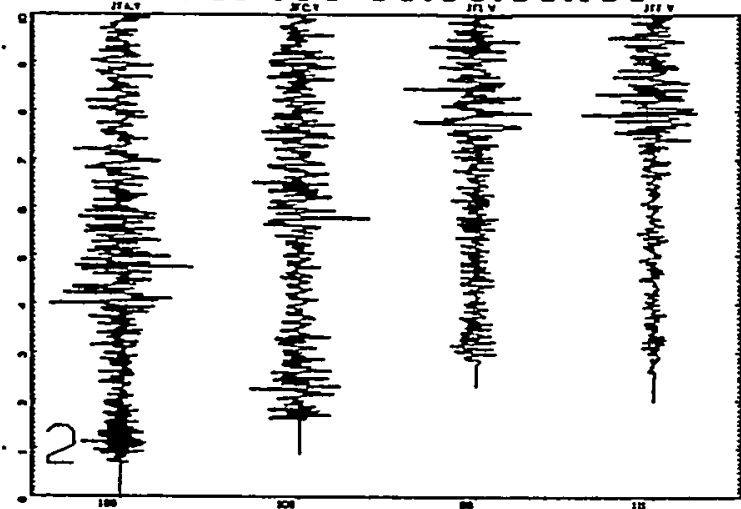

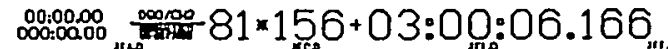

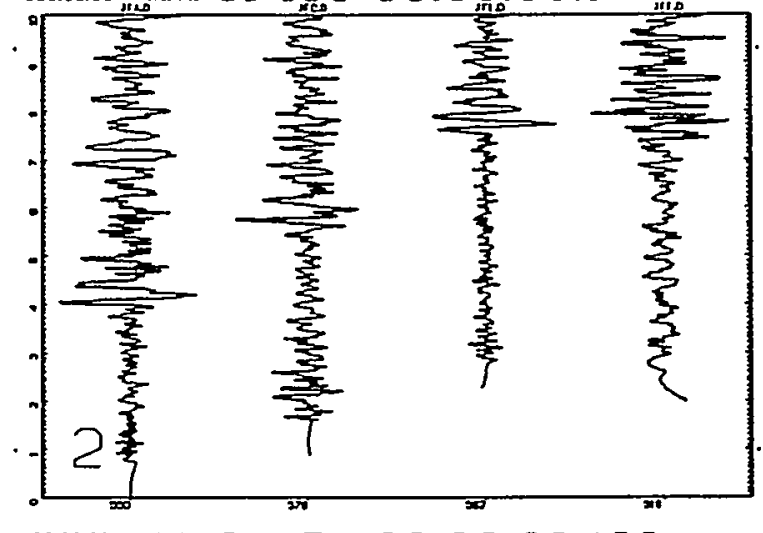

o.:00.00

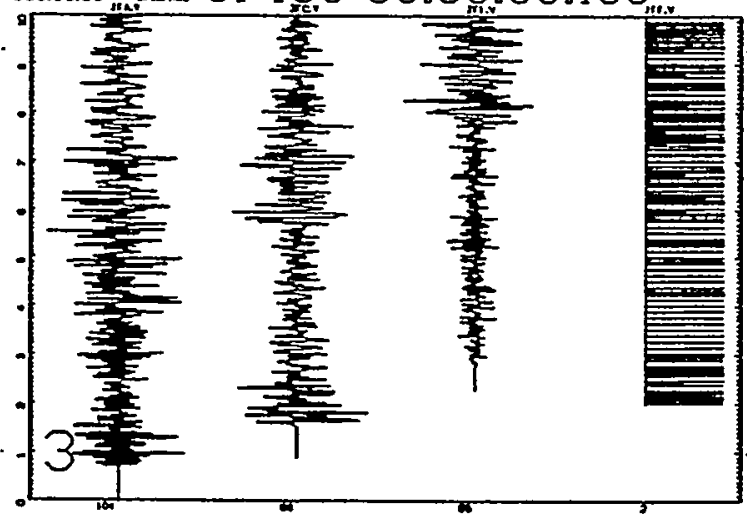

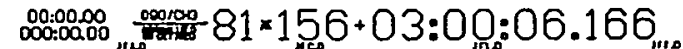

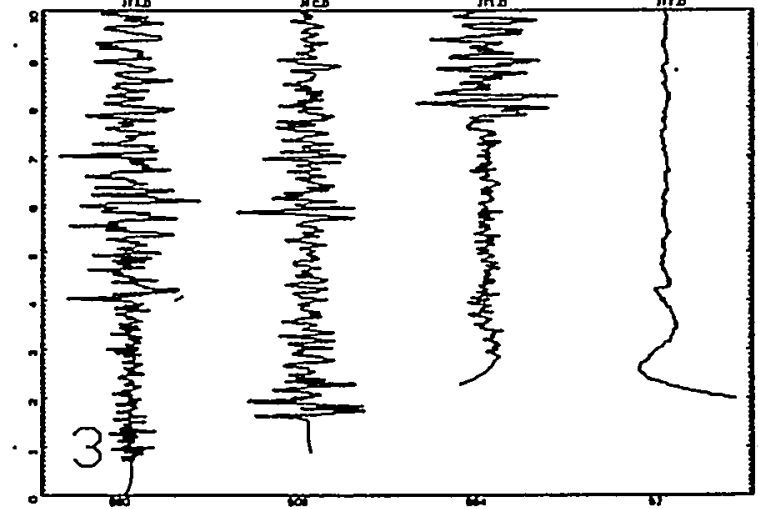



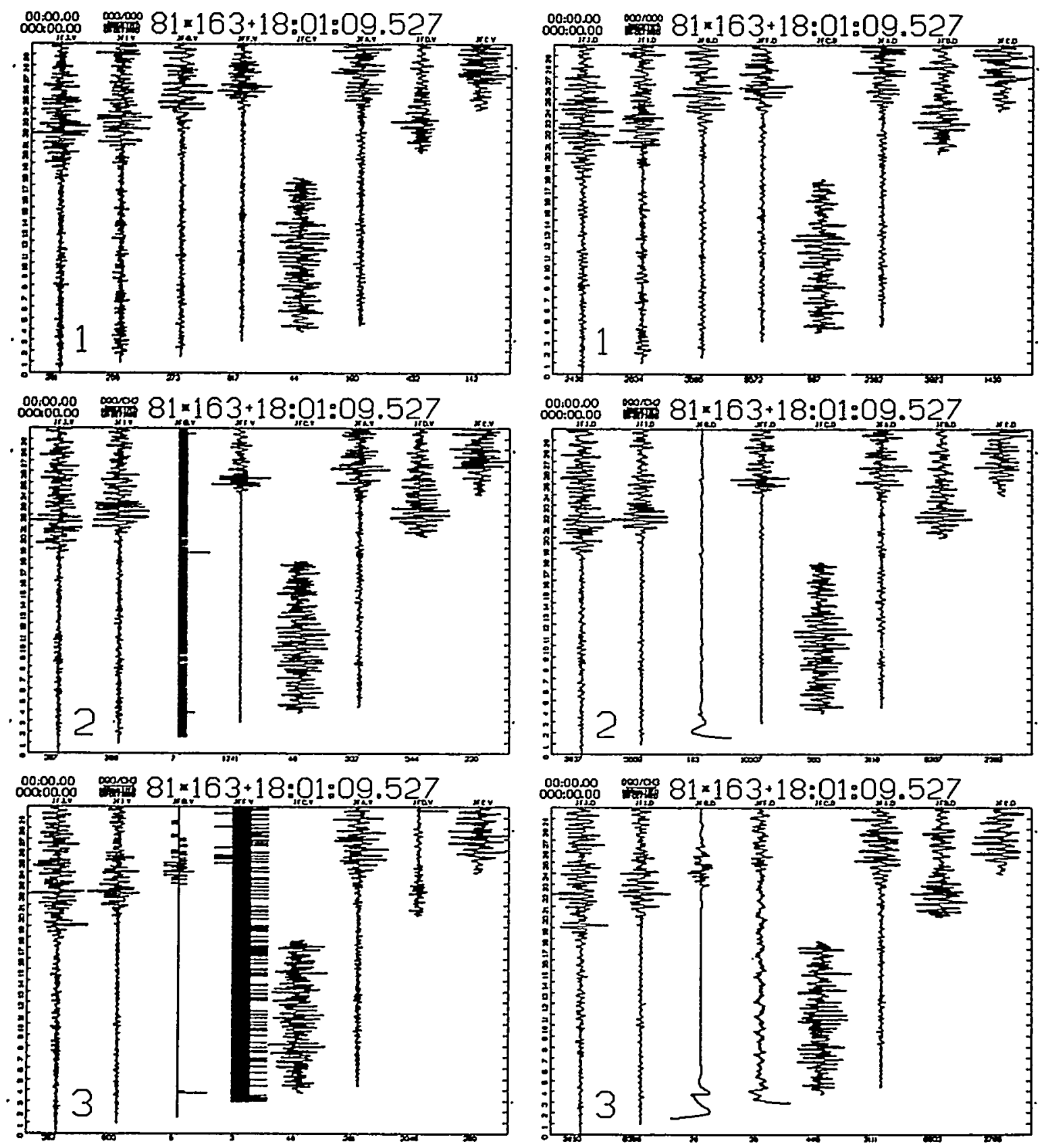

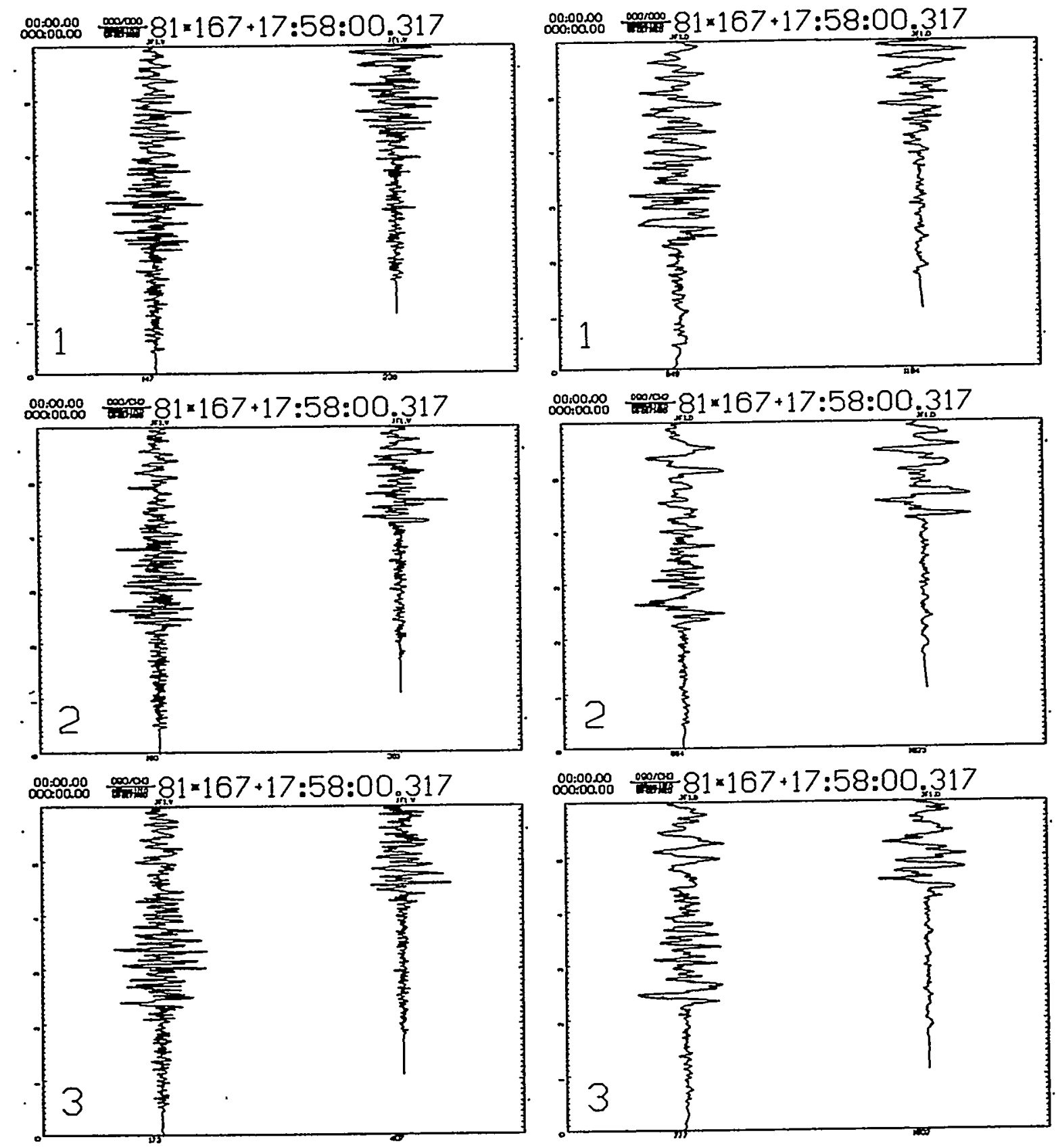

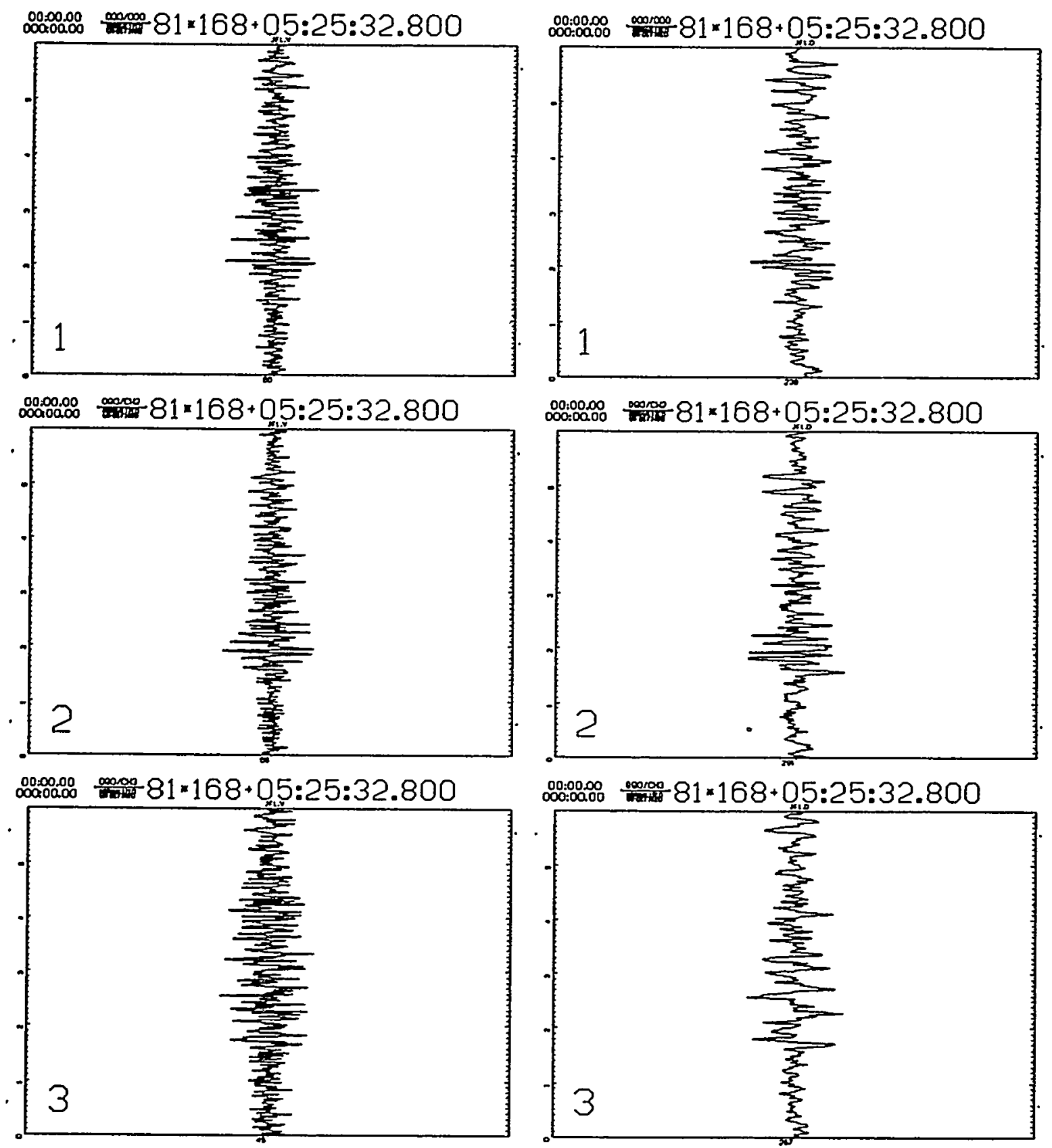

o0:00:00

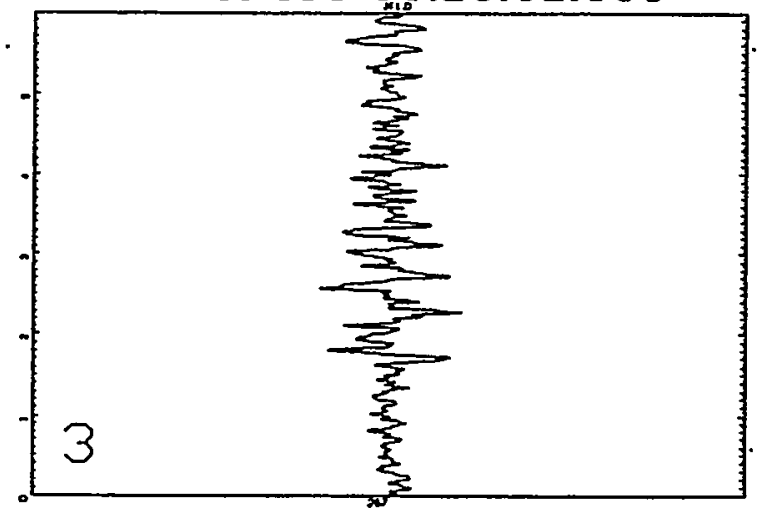



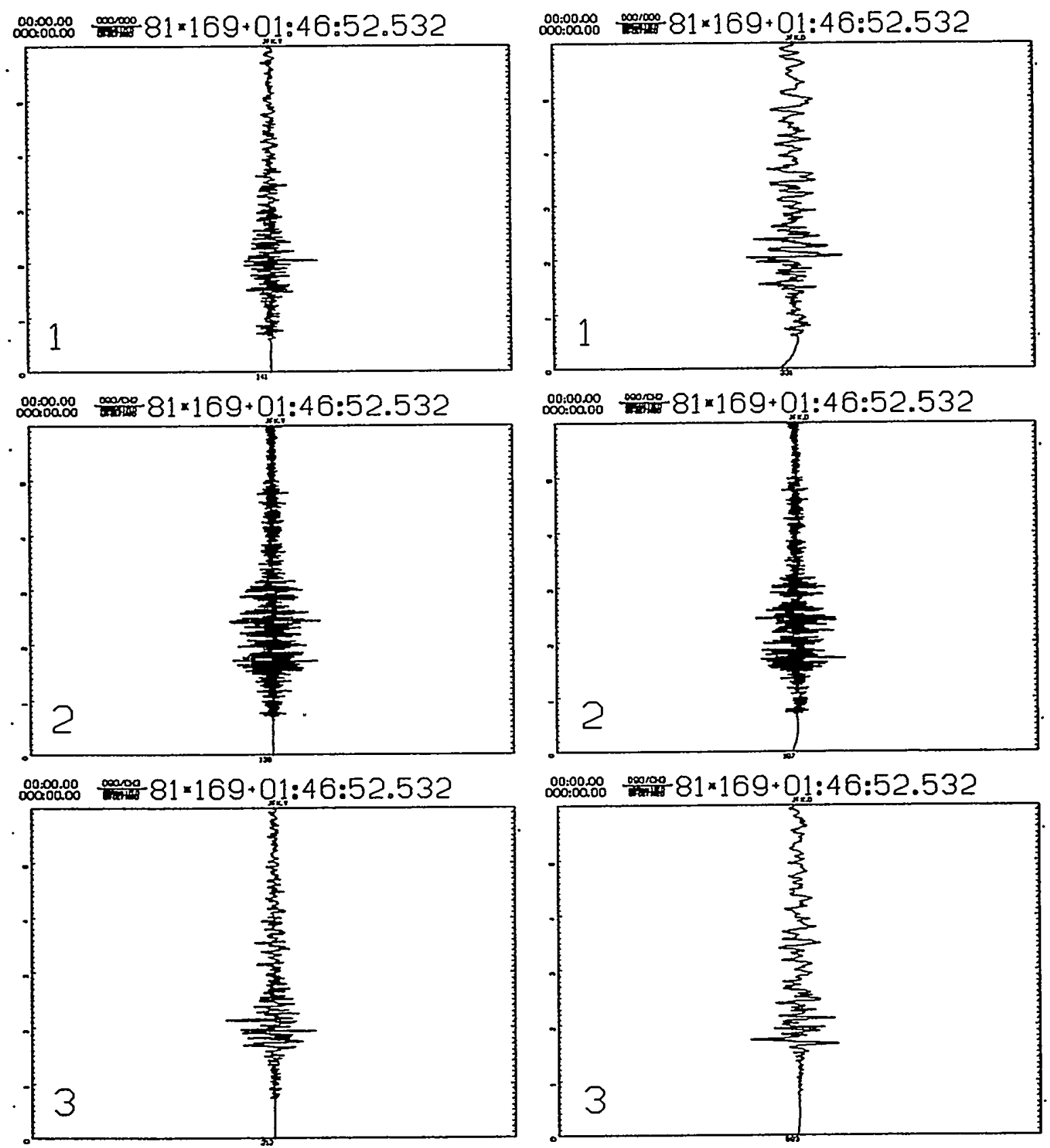

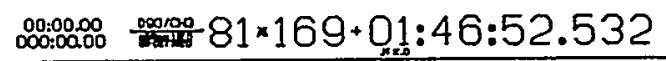

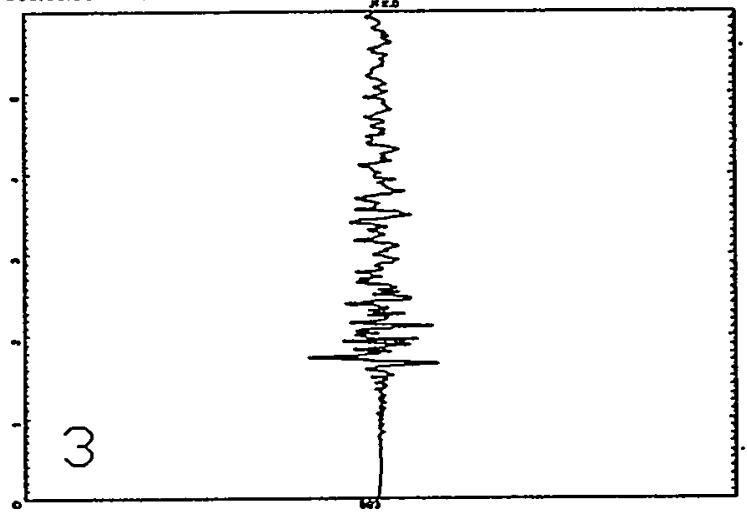




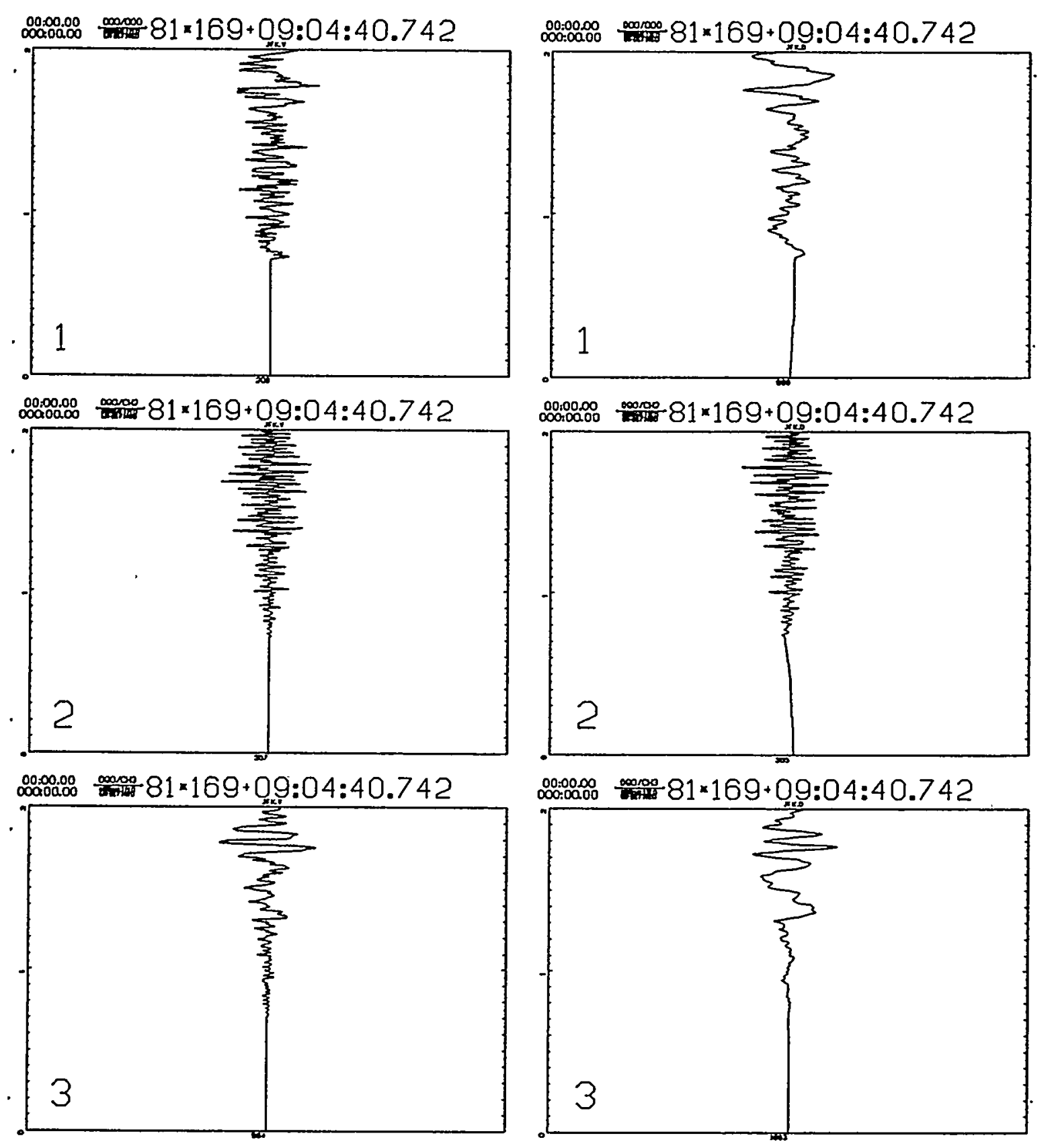



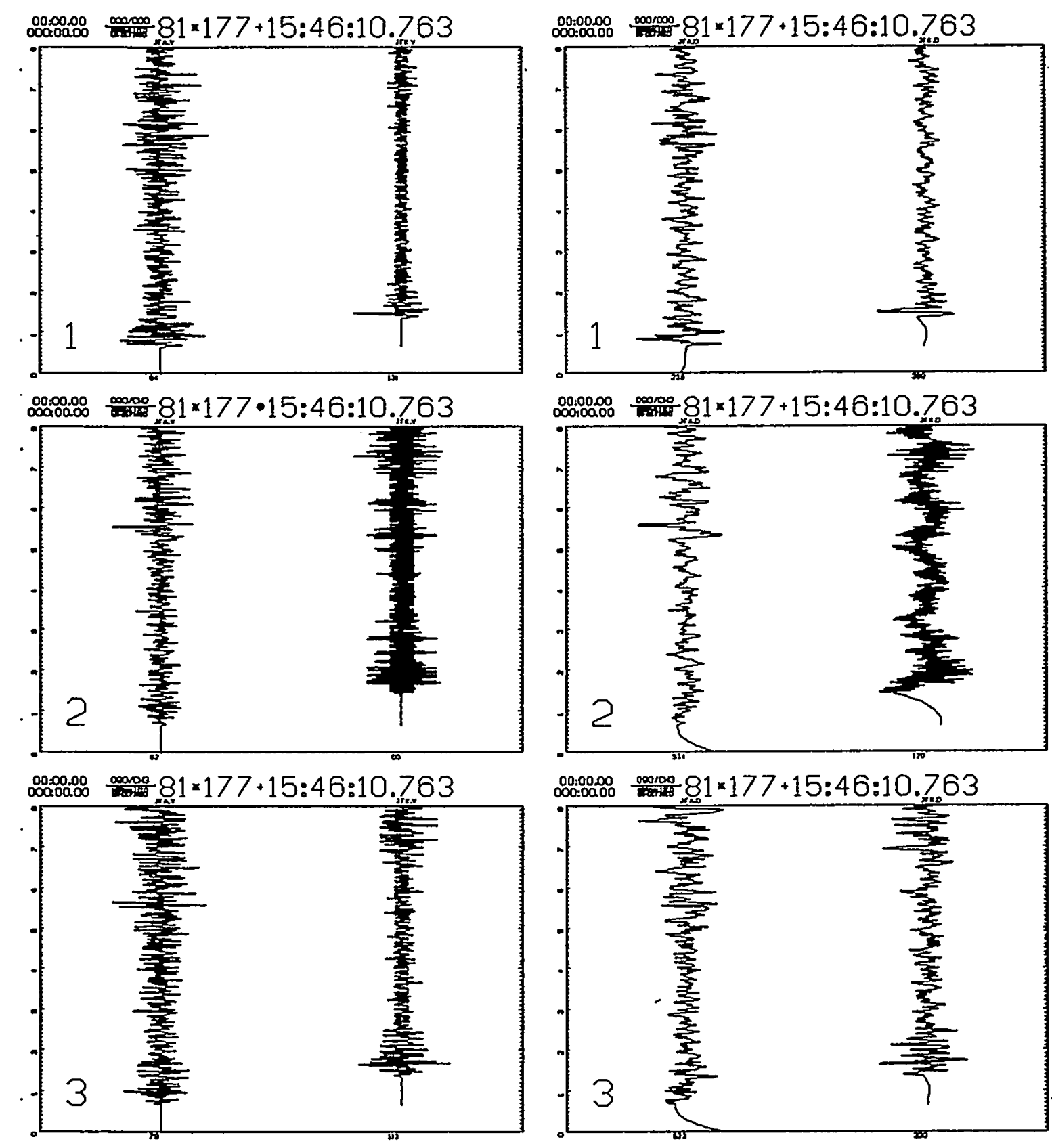

oc.0000

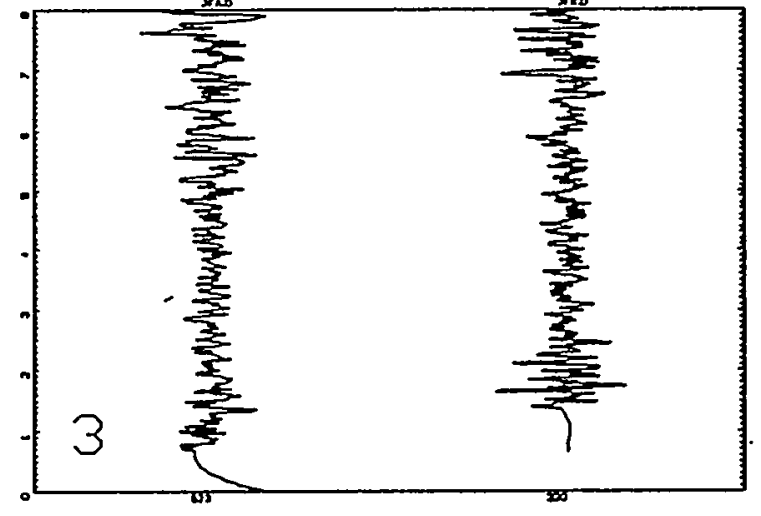



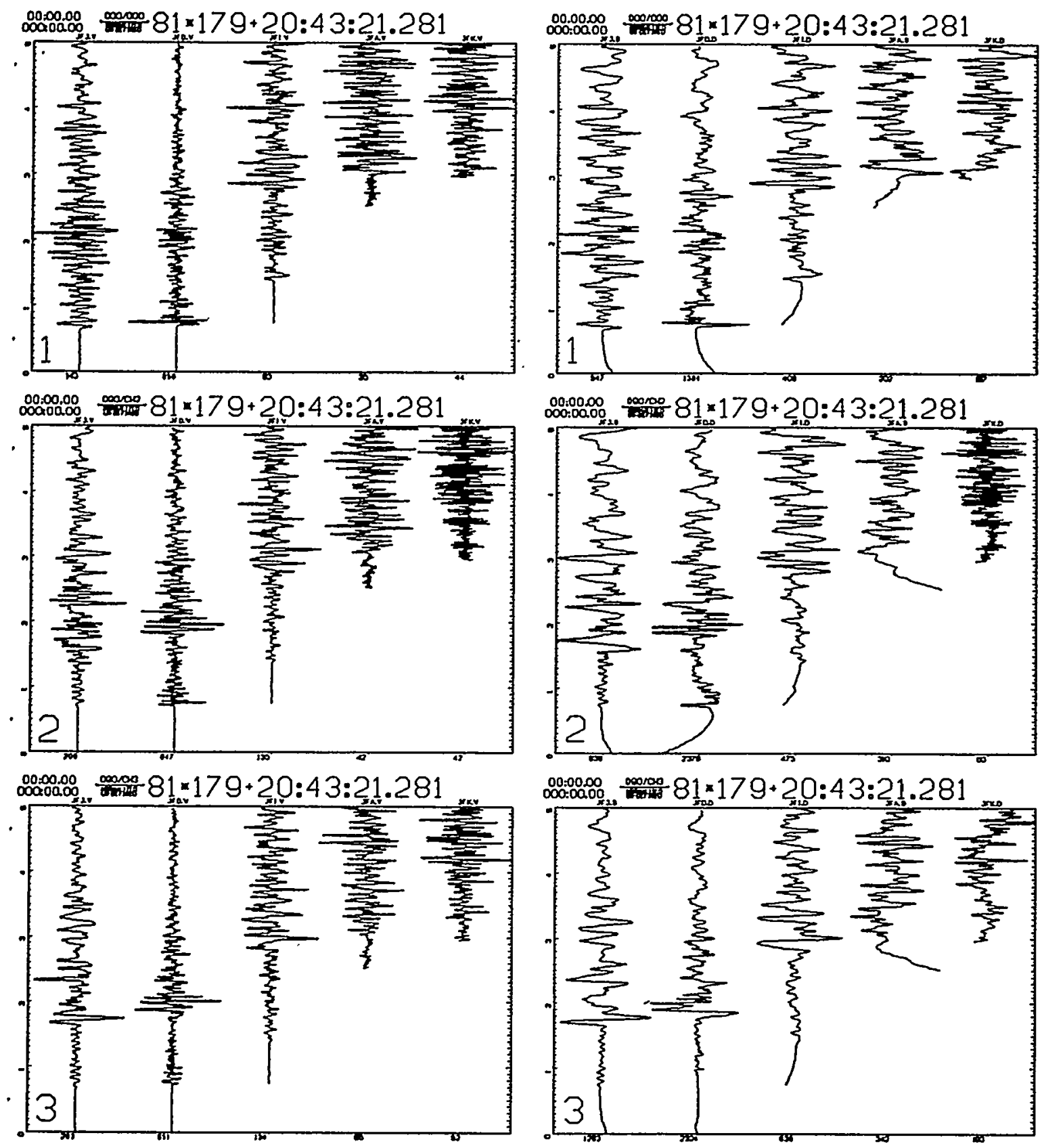

oa:0000

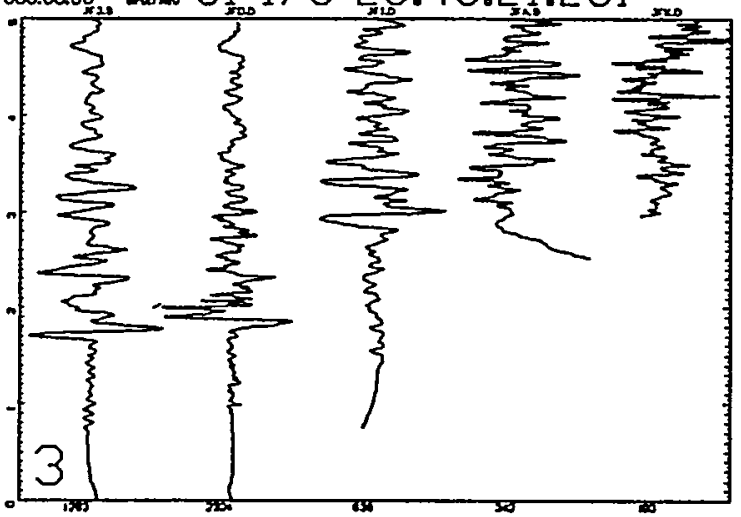




\section{Appendix B}

Displays of time series and spectra by station

[Each page consists of one graph of the three-component digital time series of an event recorded by one station, and as many as three $S$-wave displacement amplitude spectra computed for each of the three components. Cosine-bell windows are plotted over the $S$ wave components on the time series graph. The numeral above each window corresponds to the numeral plotted in the lower left corner of each spectrum (when viewed side measure); 1 designates the vertical component, and 2 and 3 designate the N-S and E-W components, respectively. The units are $\mathrm{cm} / \mathrm{sec}$ on the ordinate and sec on the abscissa of the time series graph; on the graphs of spectra, the units are cm-sec on the ordinates and $\mathrm{Hz}$ on the abscissas. The ruled lines on the spectra indicate octave divisions (powers of 2) while the tick marks indicate logarithmic (base 10) divisions. Dashed lines on the spectra show estimated levels of asymptotic spectral displacement amplitude $\Omega_{0}$ and $\omega^{-2}$ falloff above the corner frequency $f_{c}$.] 

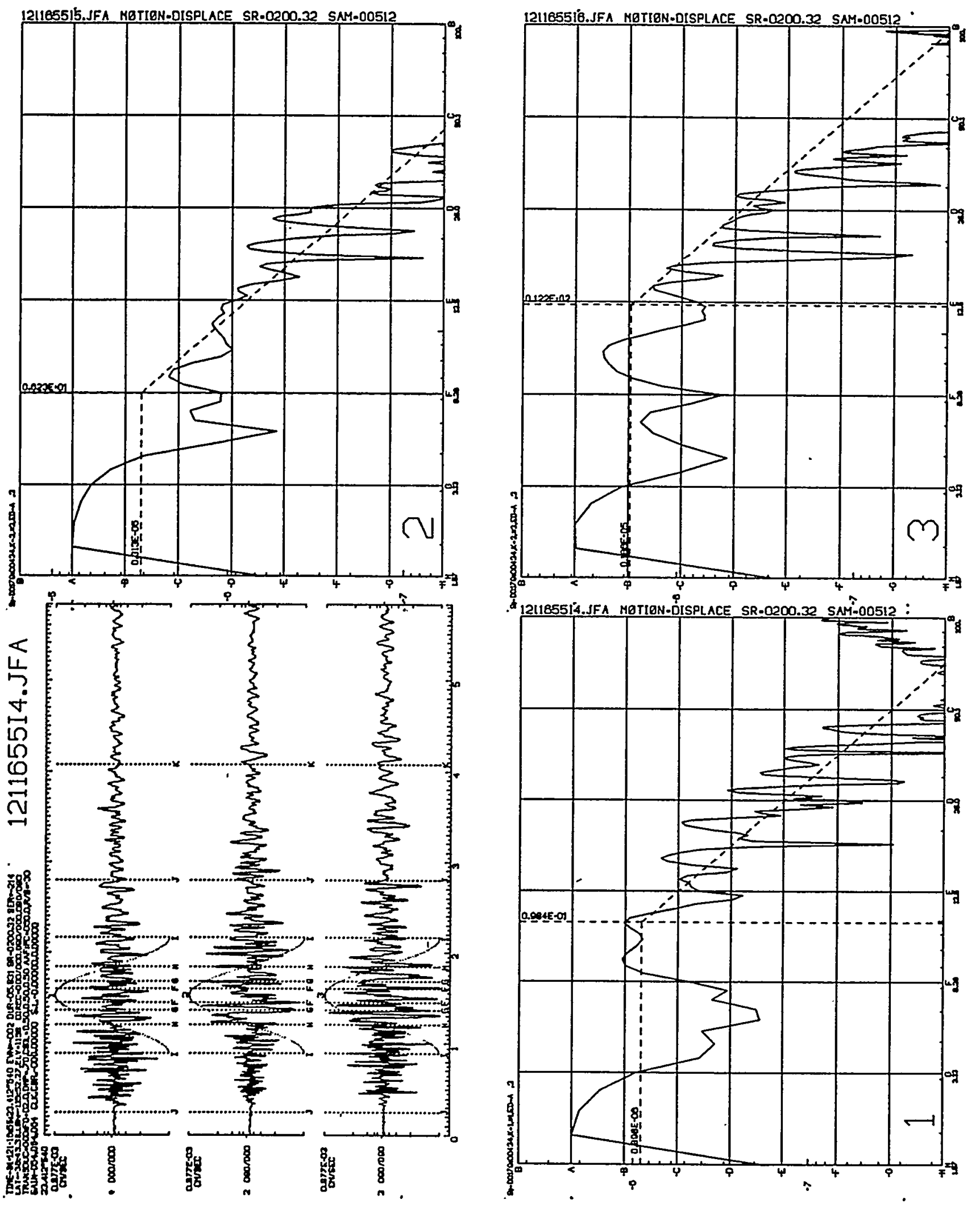

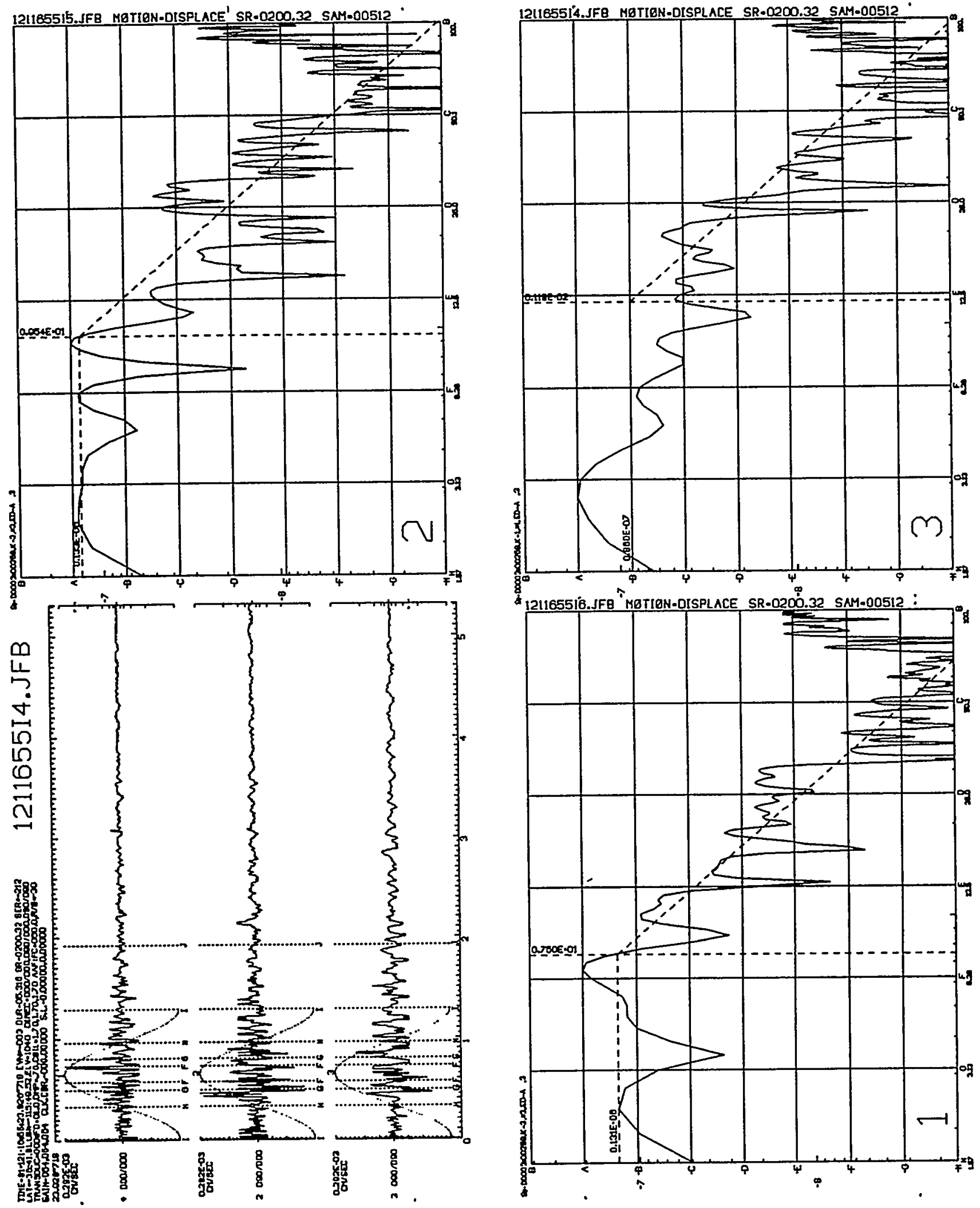


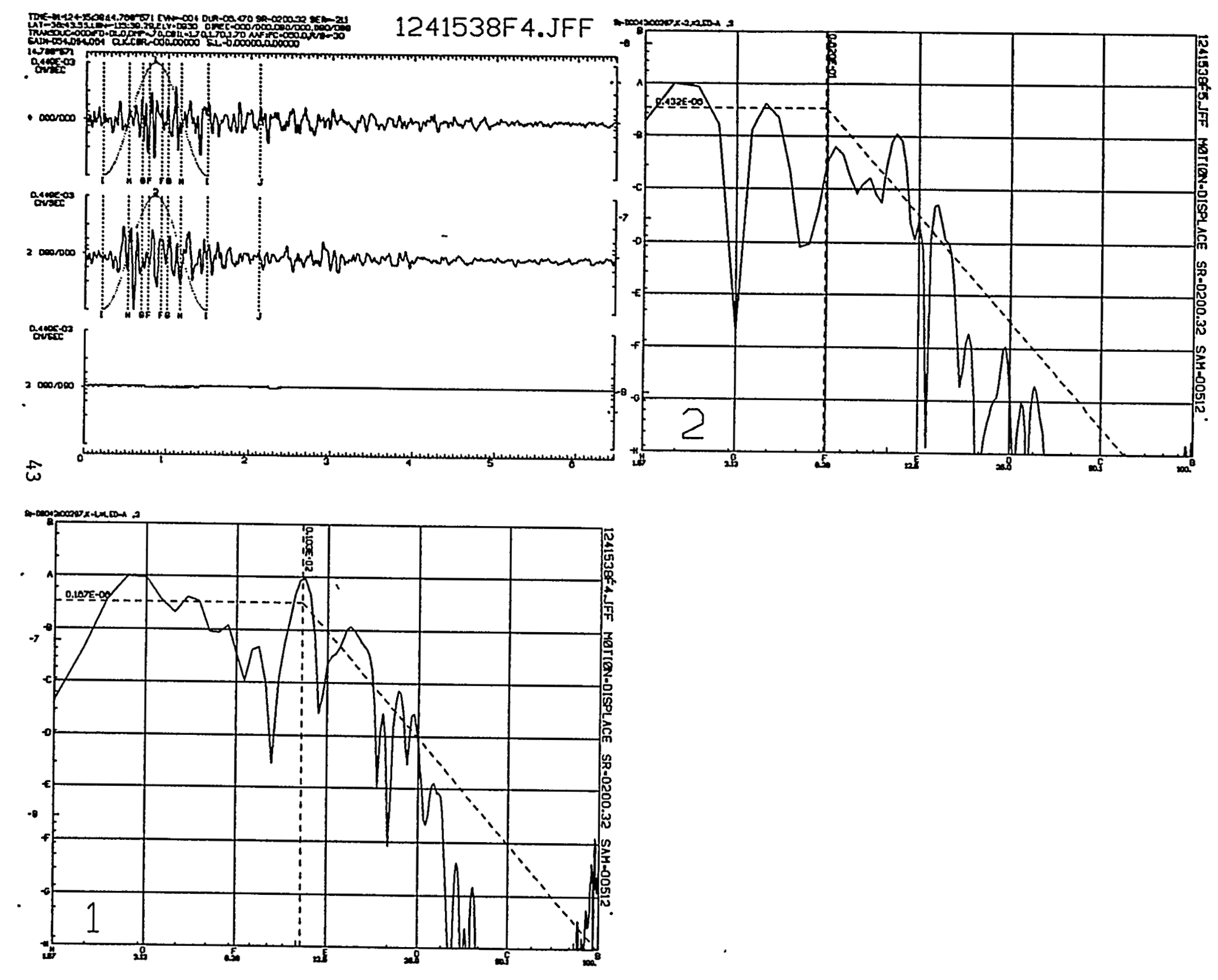


1241538F5.JFK MOTLEN-DISPLACE SR-0200.32 SAM-00512

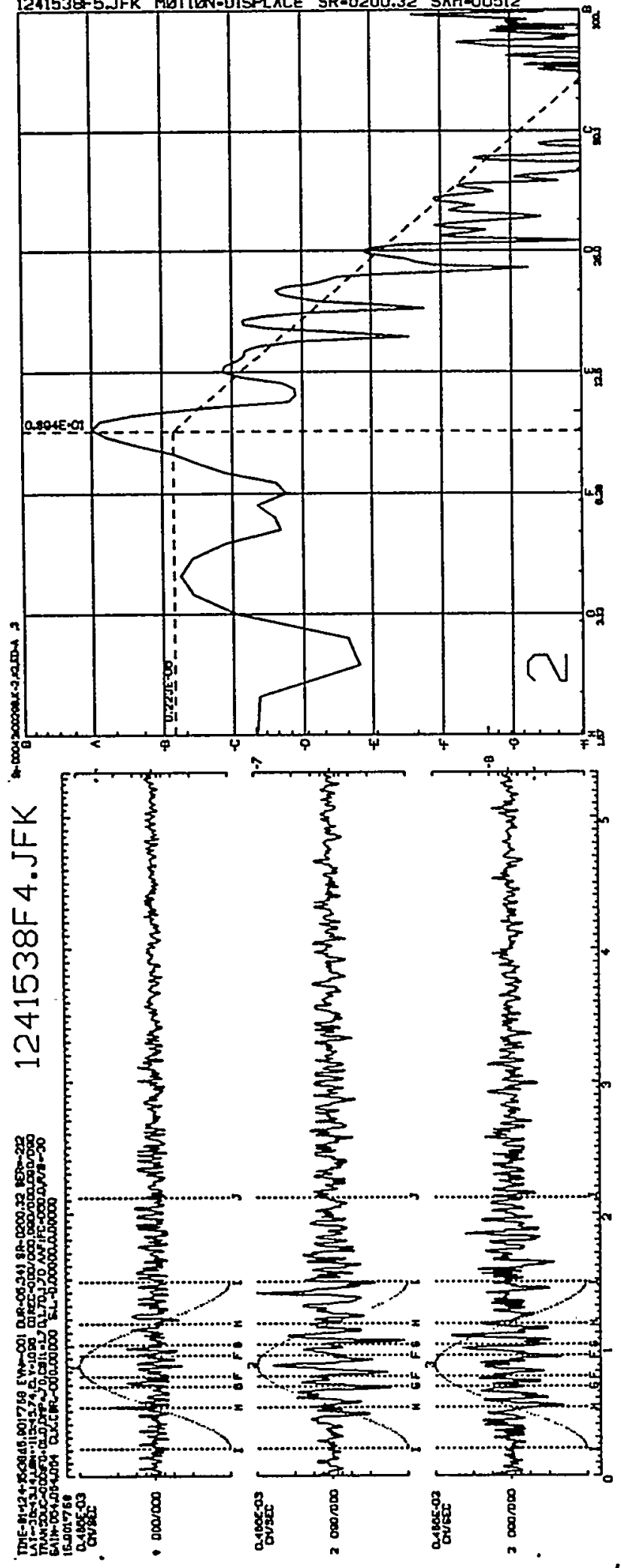

1241538*6.JFK MaIIQN-DISPLACE SR-0200.32 SAM-00512.

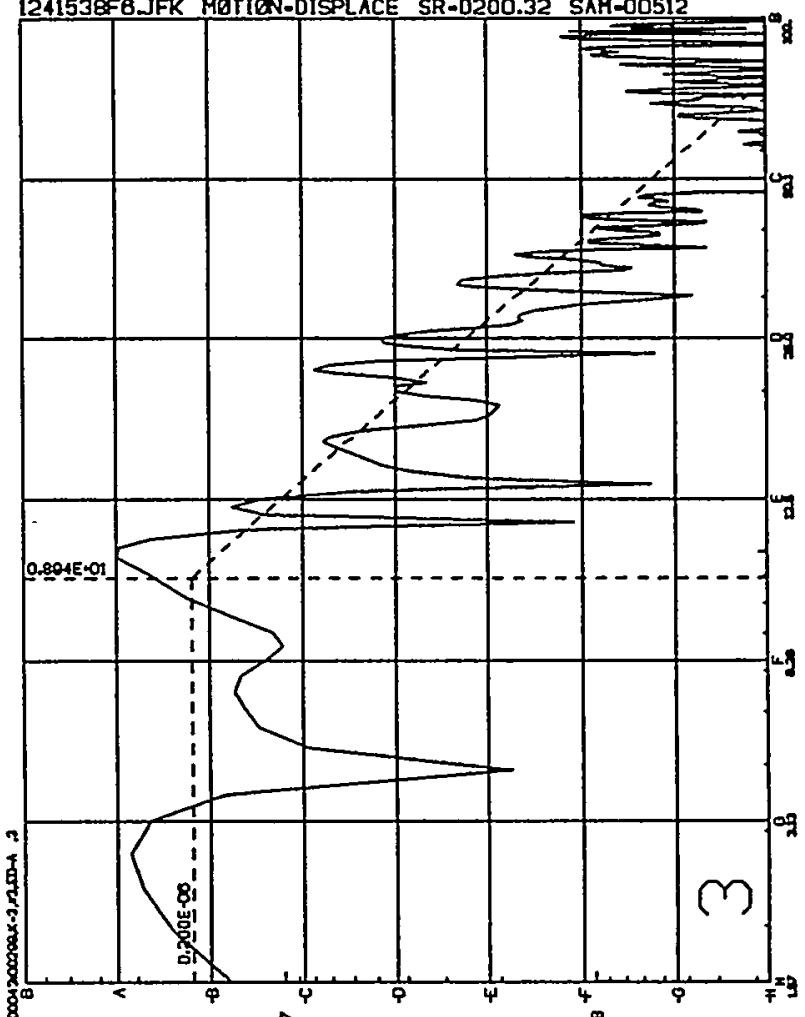

¿1241538\%4.JFK MOTIQNi-0ISPLACE SR-0200.32 SAM-00512:

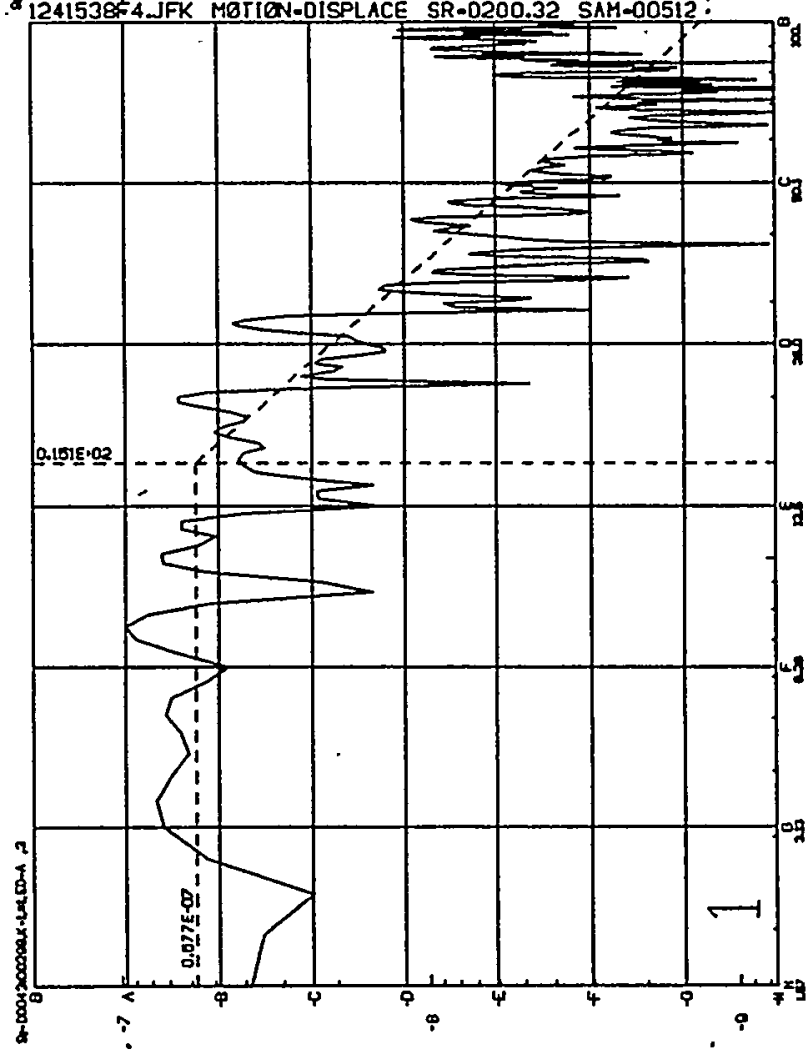


1580300'5.JFA METION-OISPLACE SR-0200.32 SAM-01024.

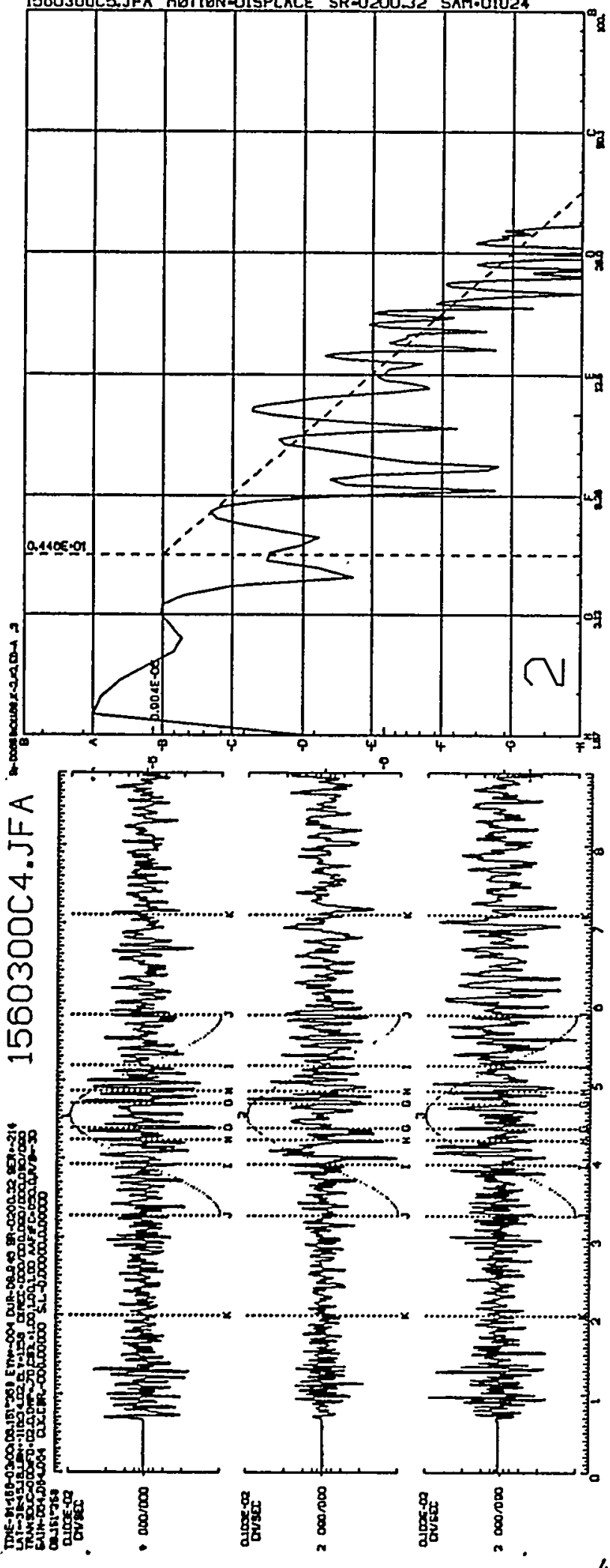

15BO30OCE.JFA METION-DISPLACE SR-020032 SAM-01024.
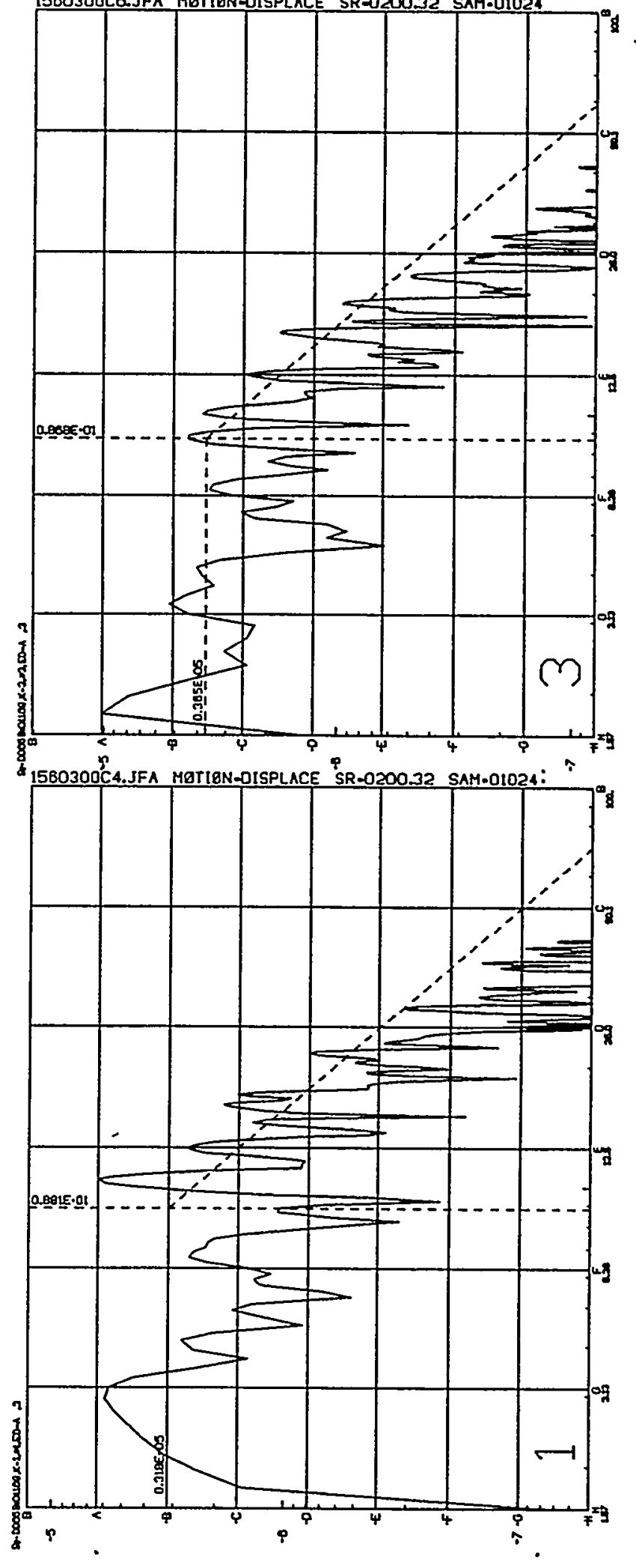

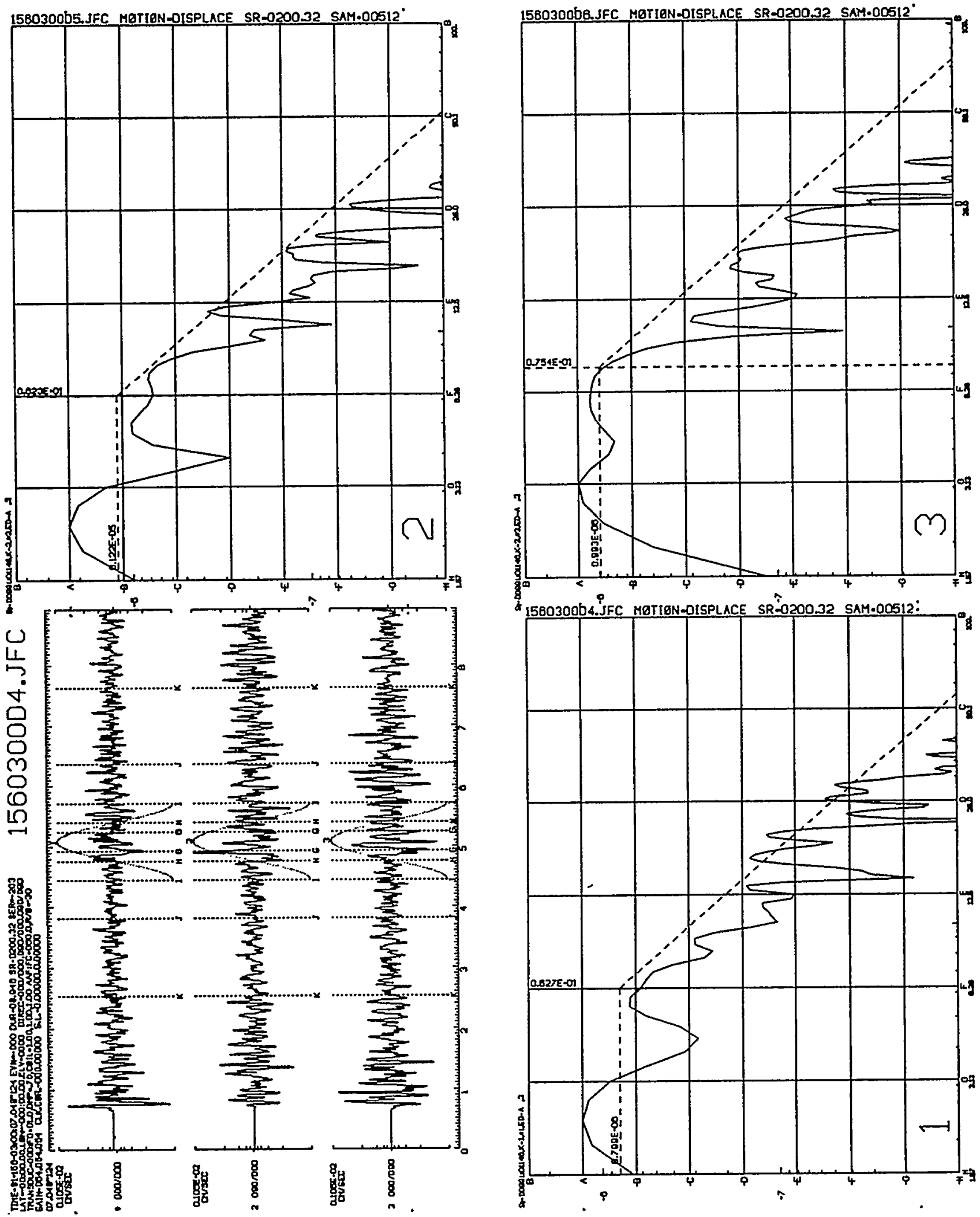

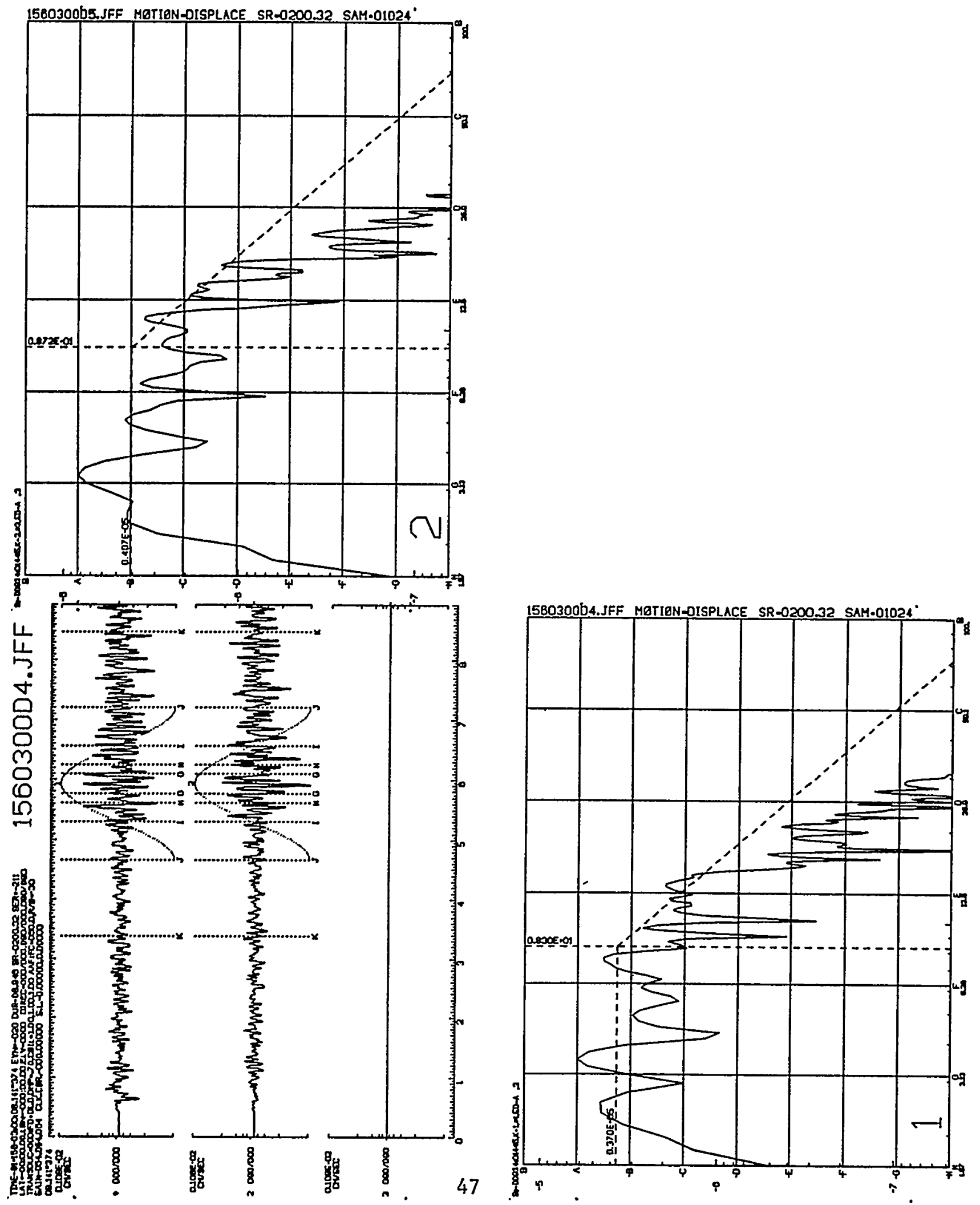

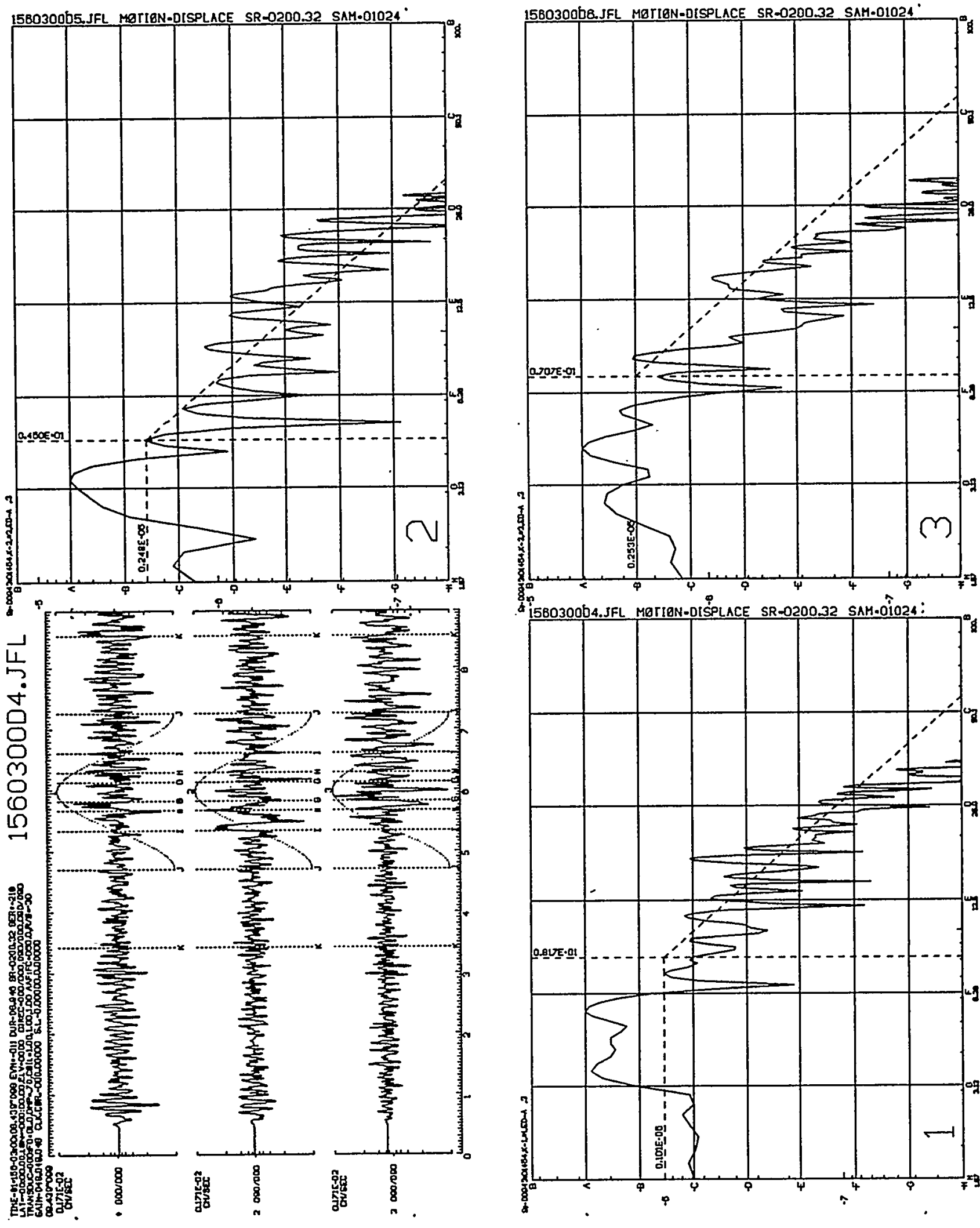

\&56030004.JFL MOTION-0IŚPLACE SR-0200.32 SAM-0iOO24:
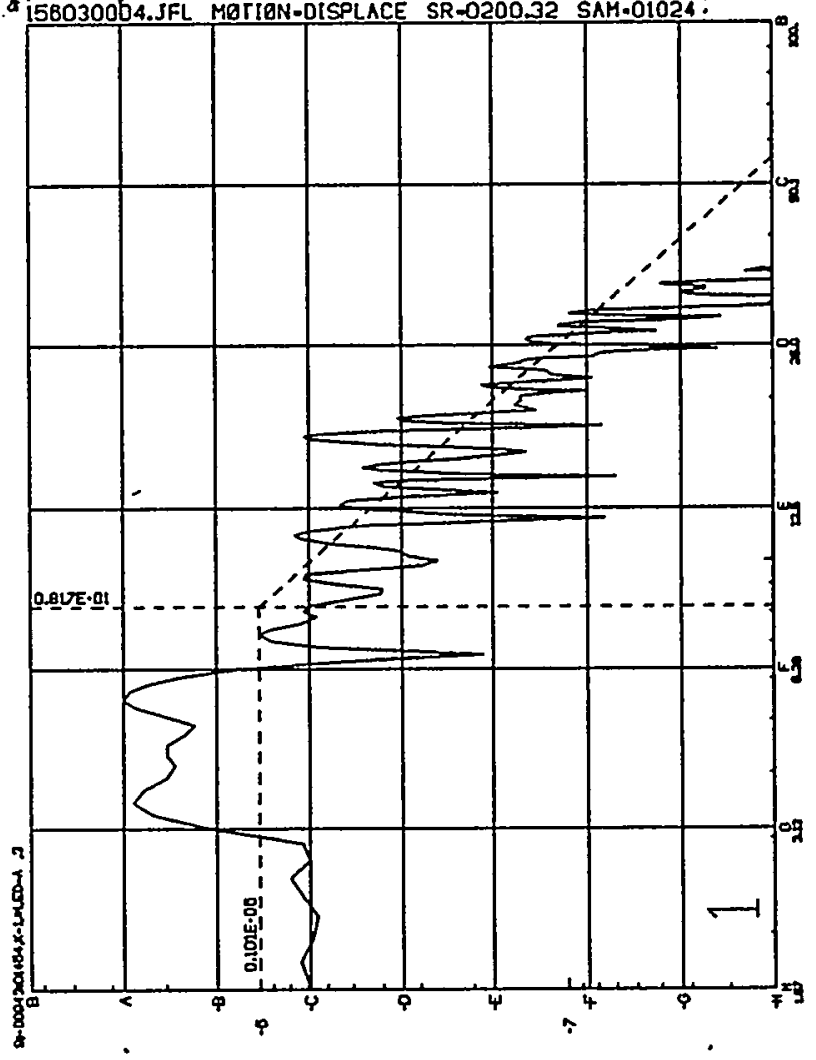

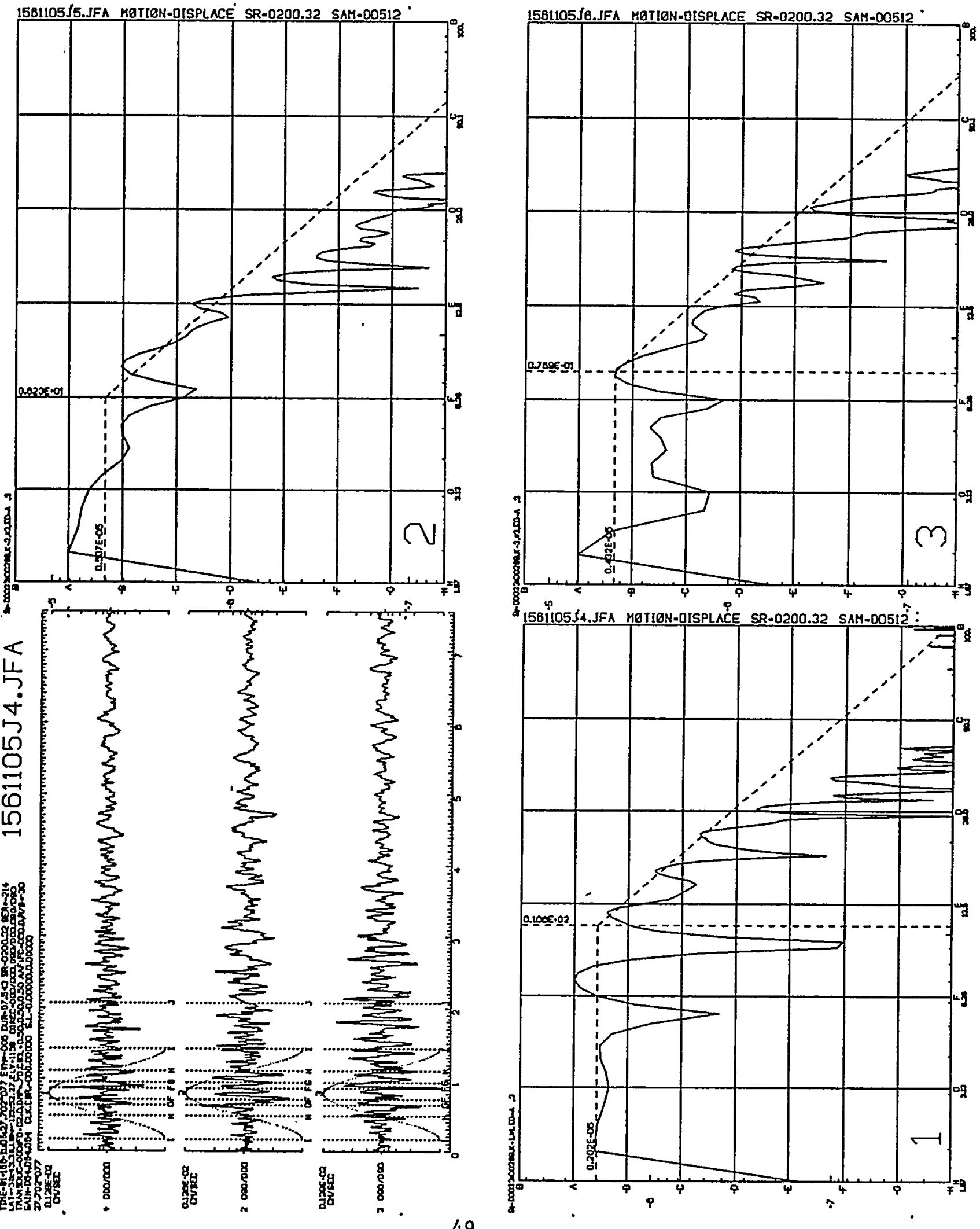

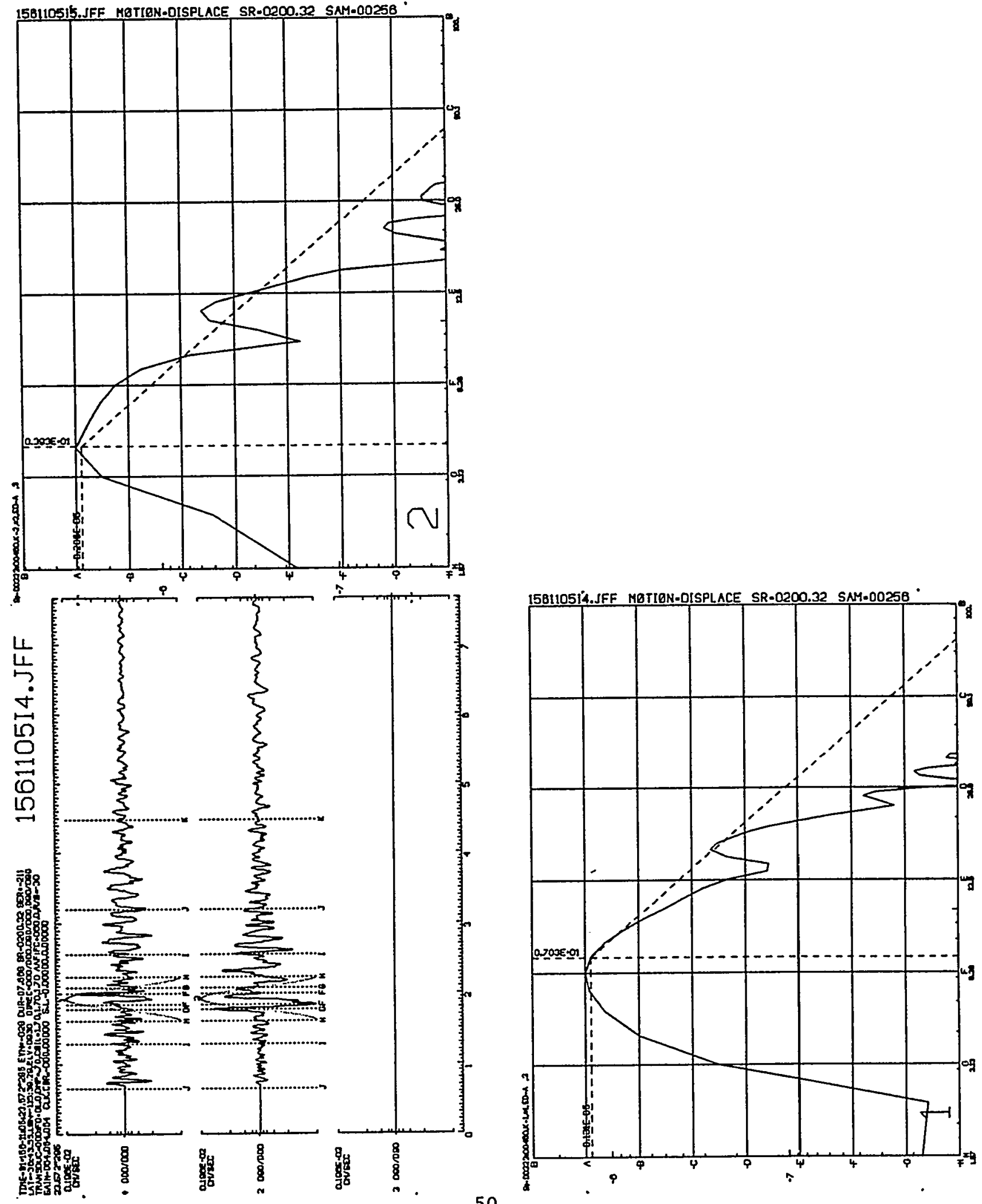

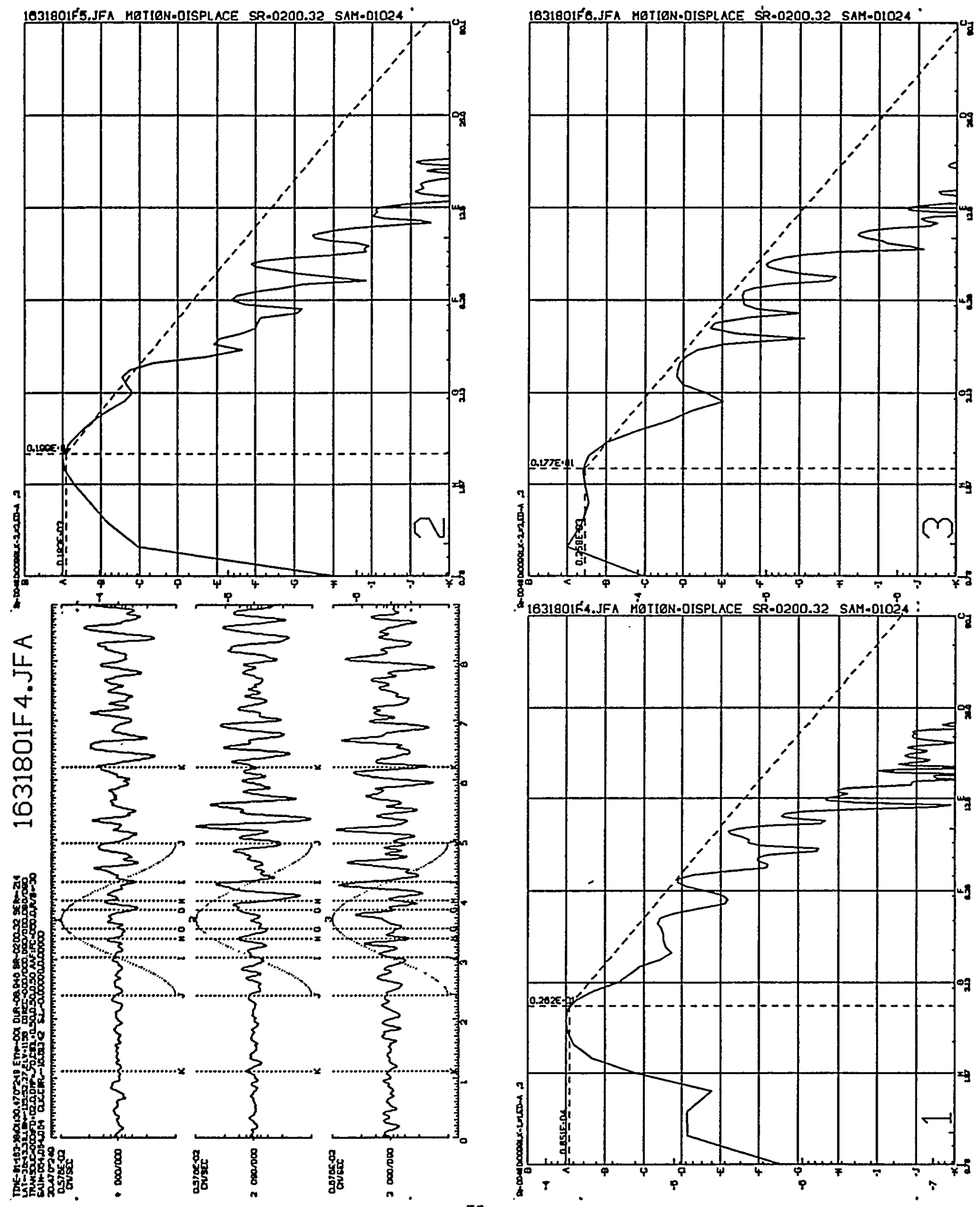


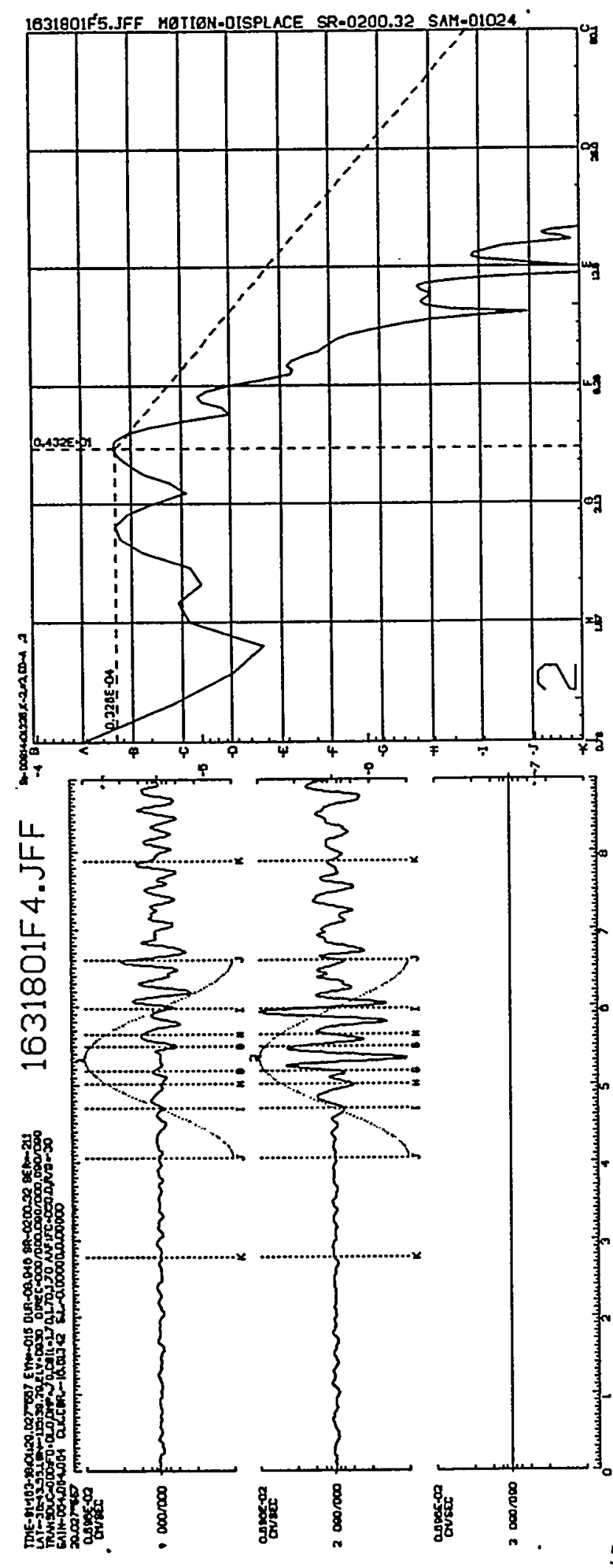

1831801F4.JFF MOTIQN-DISPLACE SR-0200.32 SAM-01024

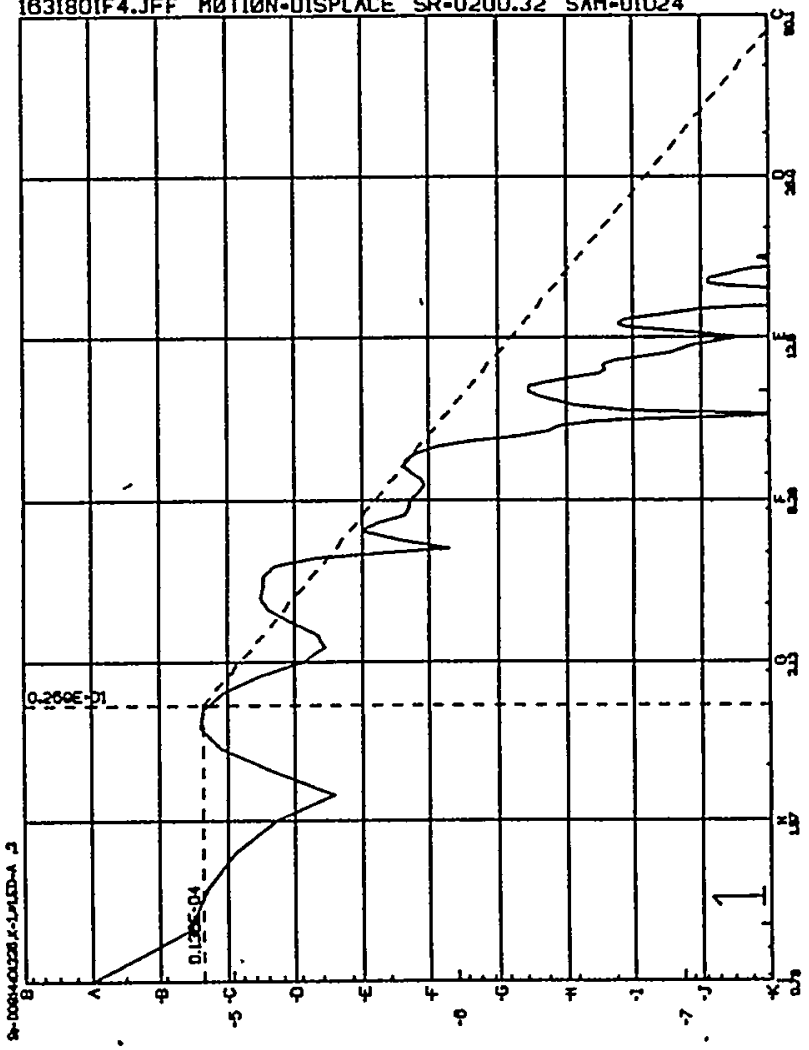



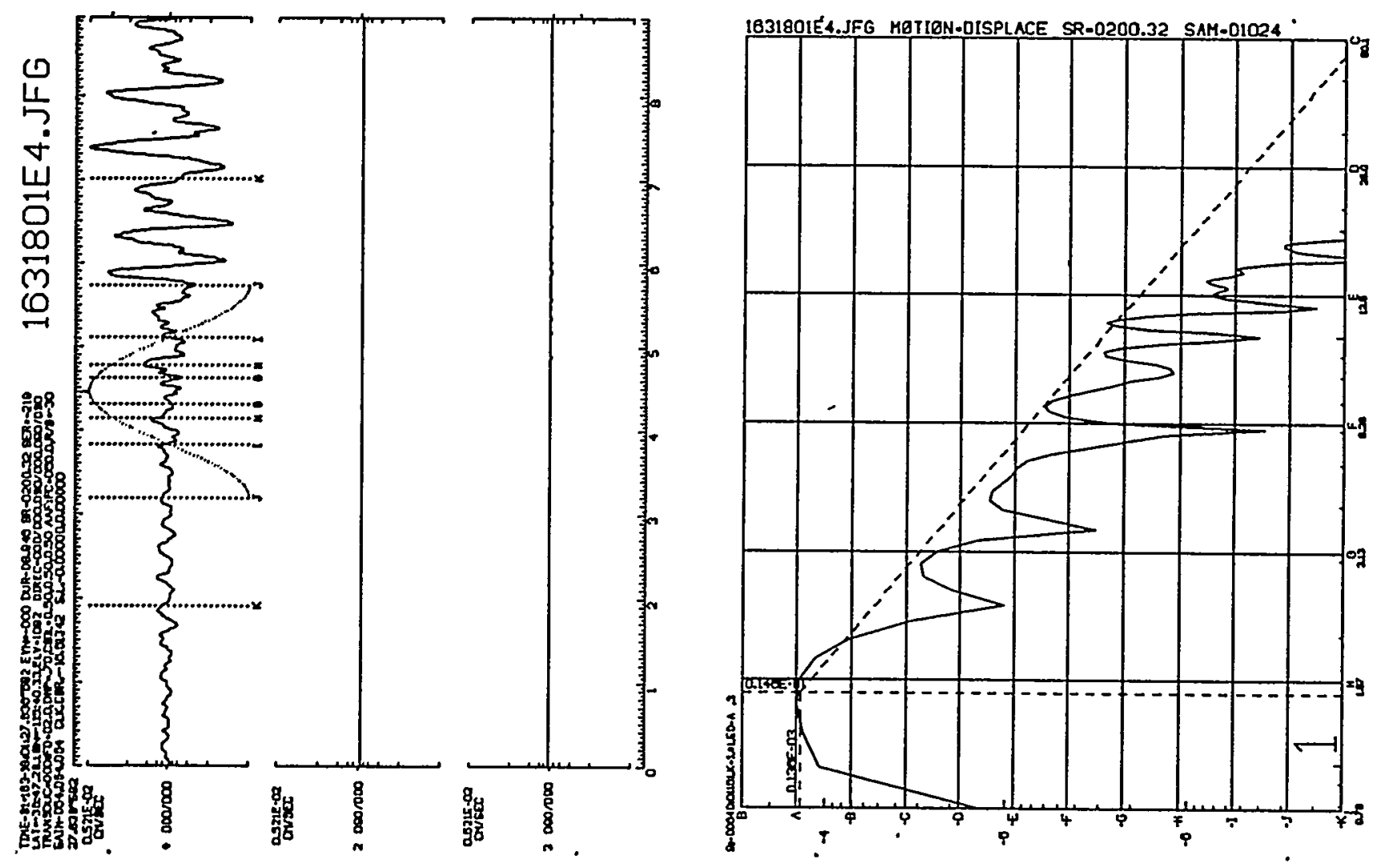

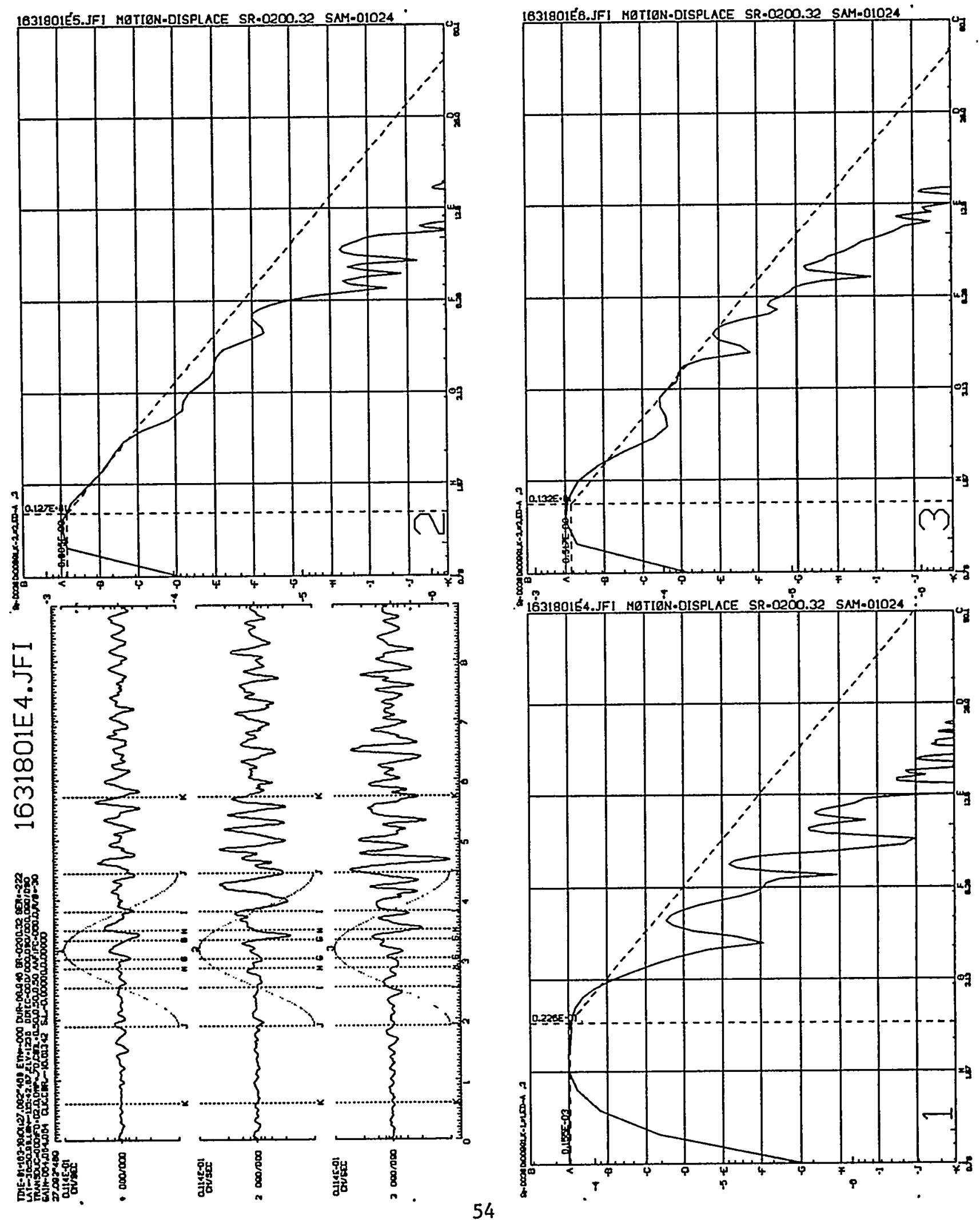


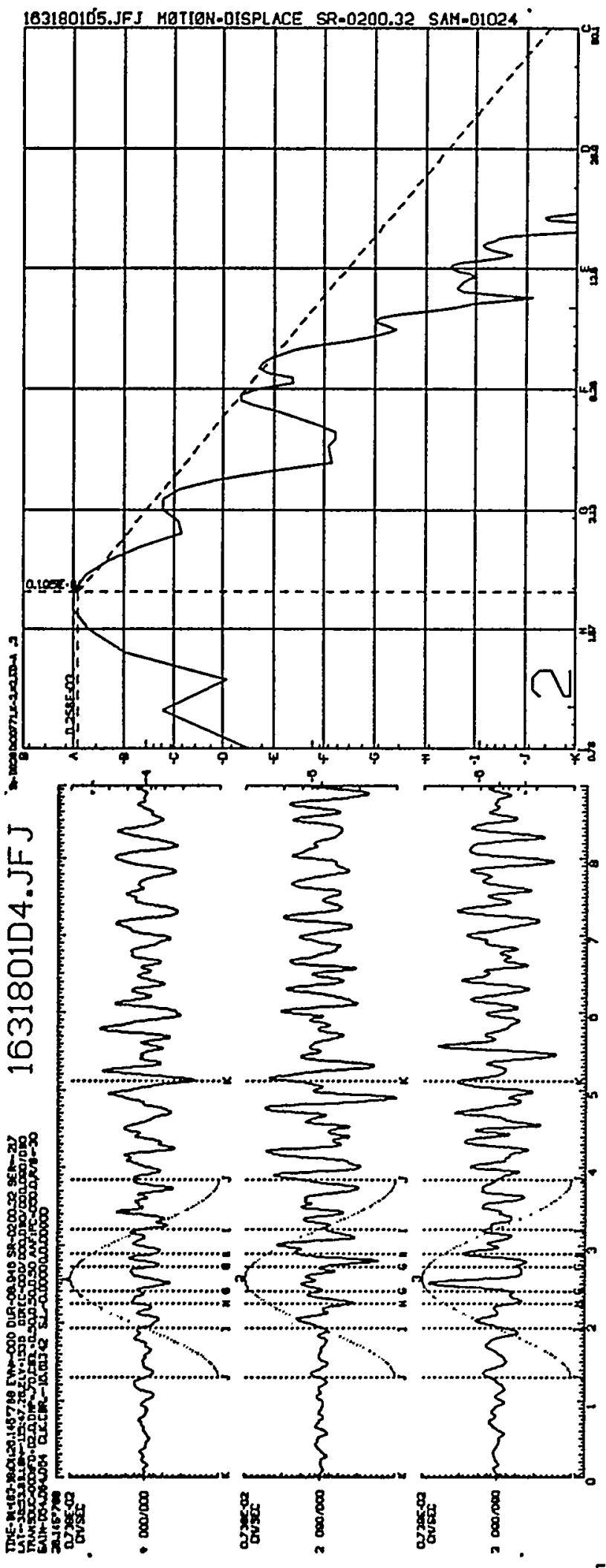

18318010́B.JFJ MGTION-DISPLACE SR-0200.32 SAM-DIO24.
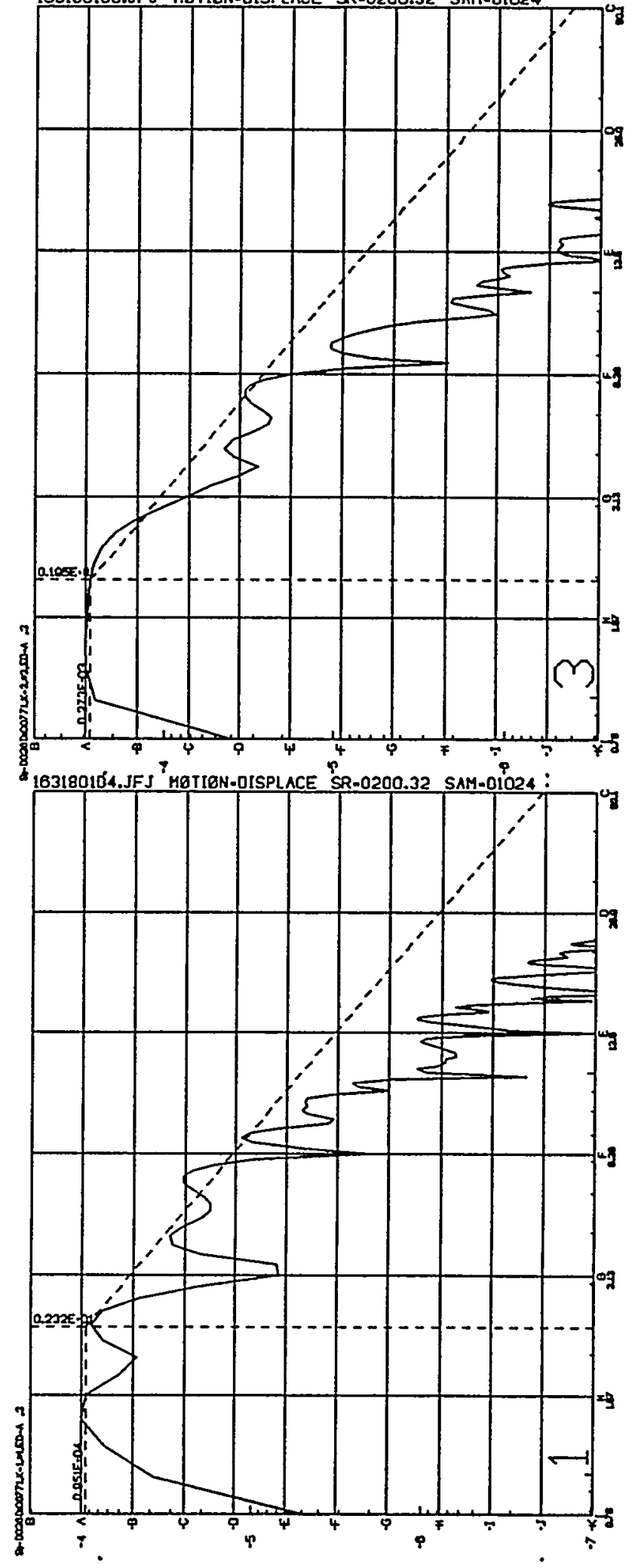

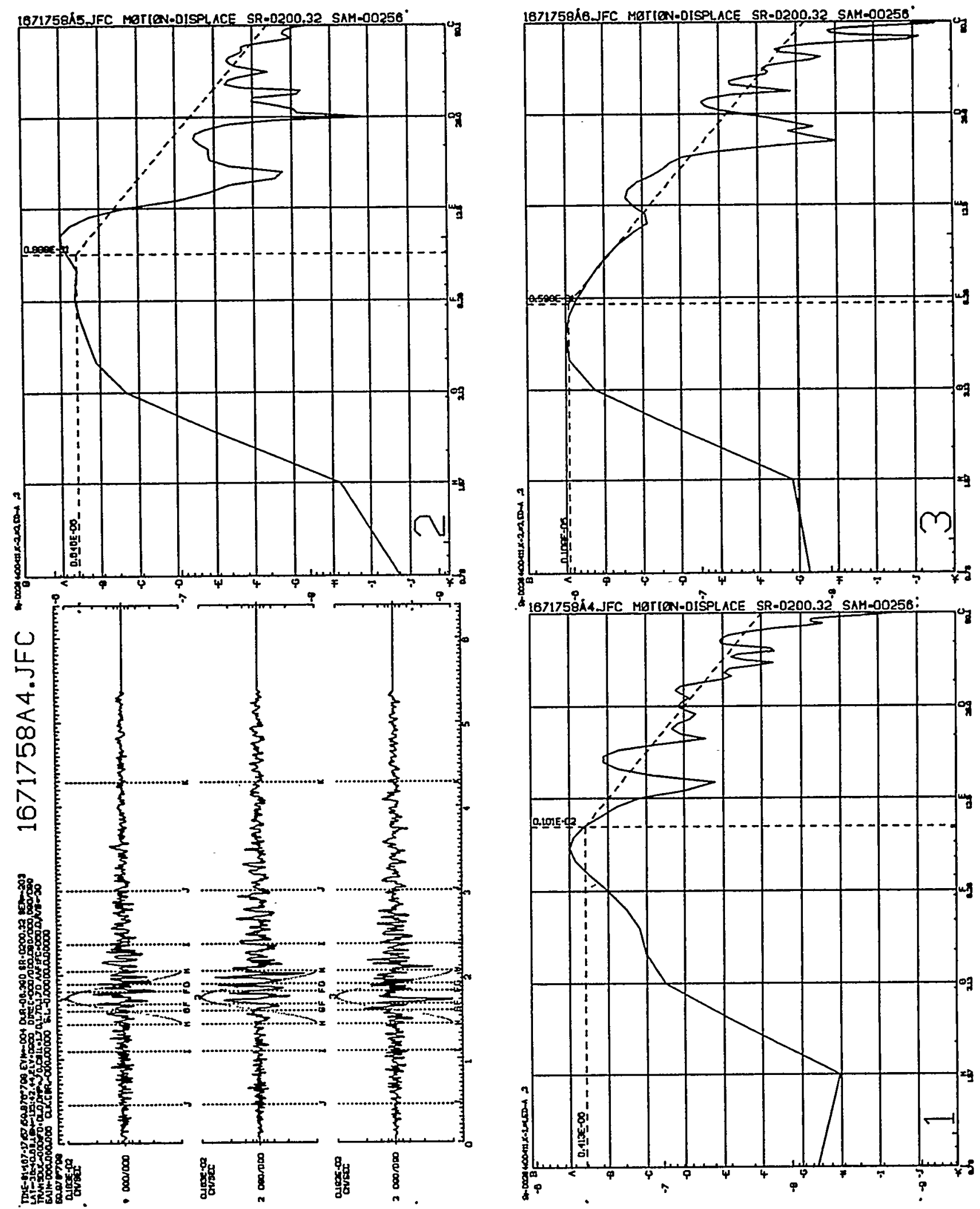

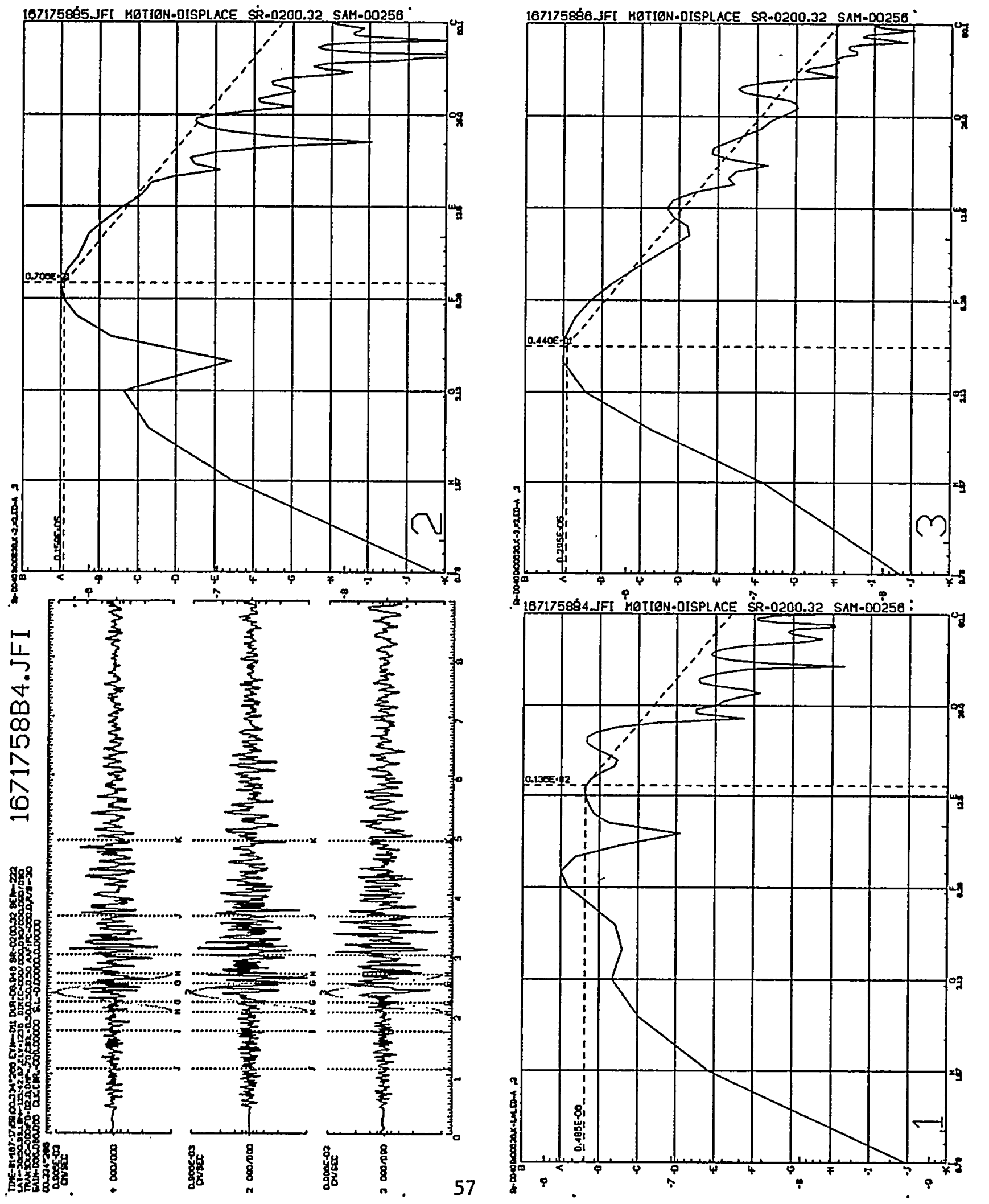

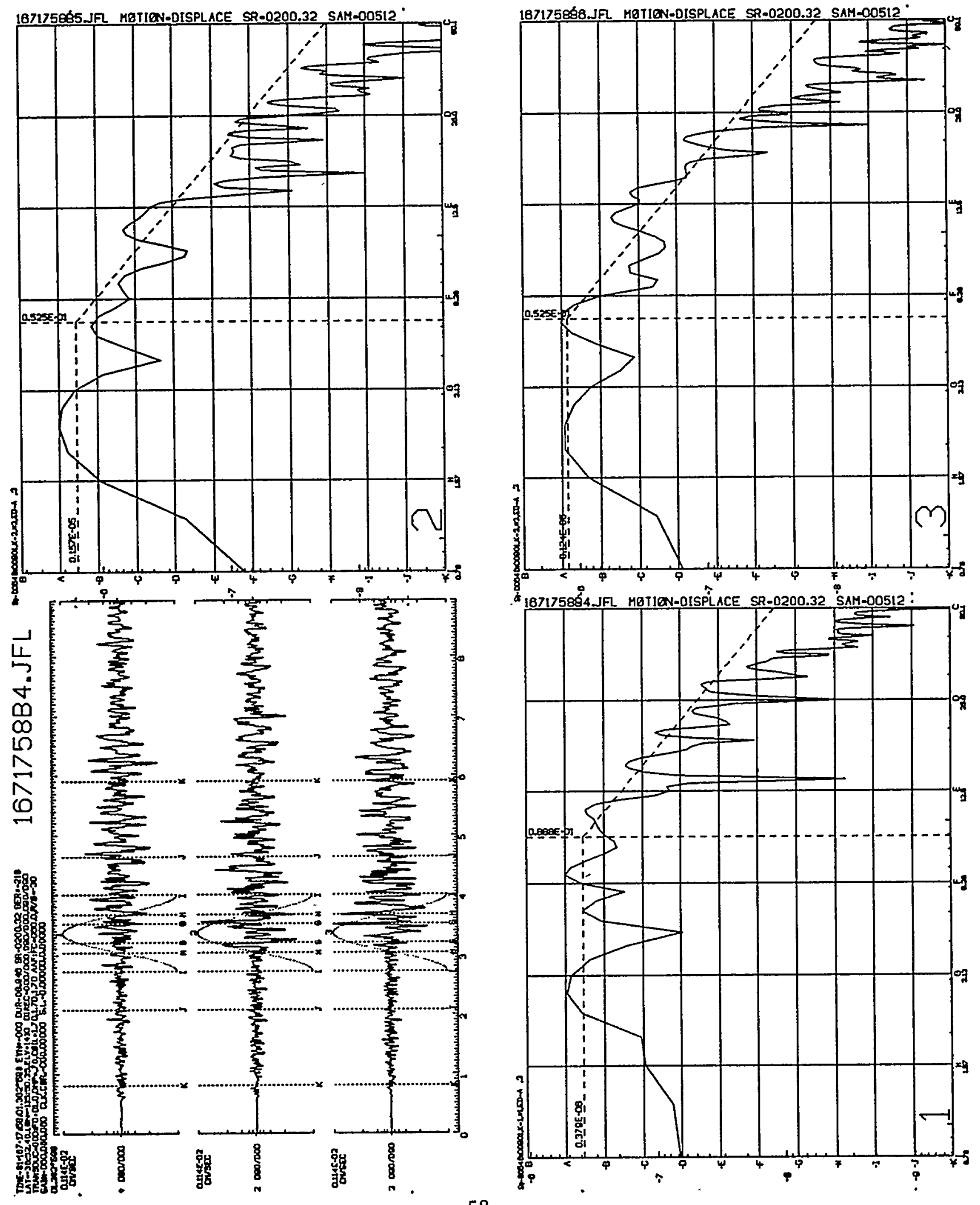

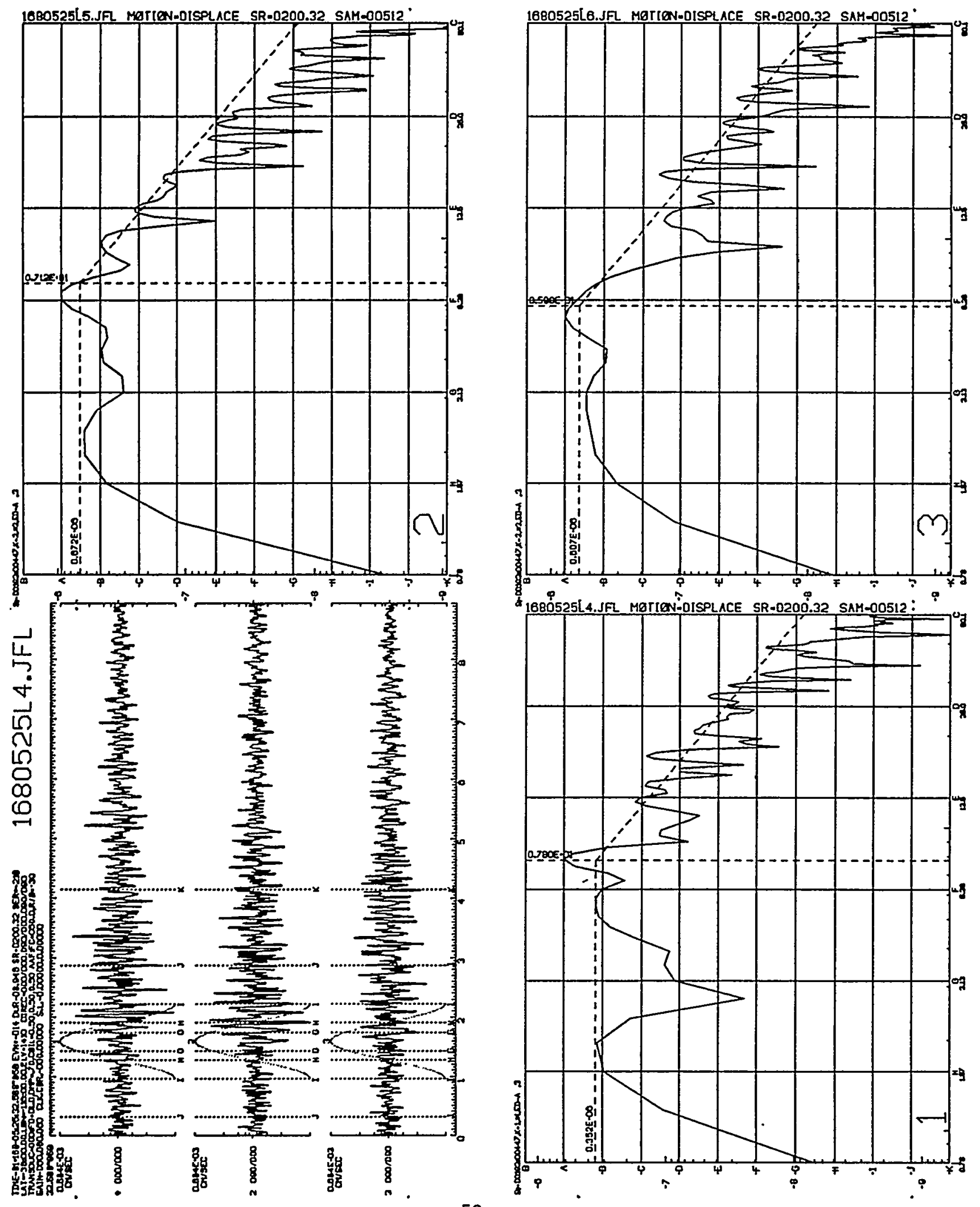

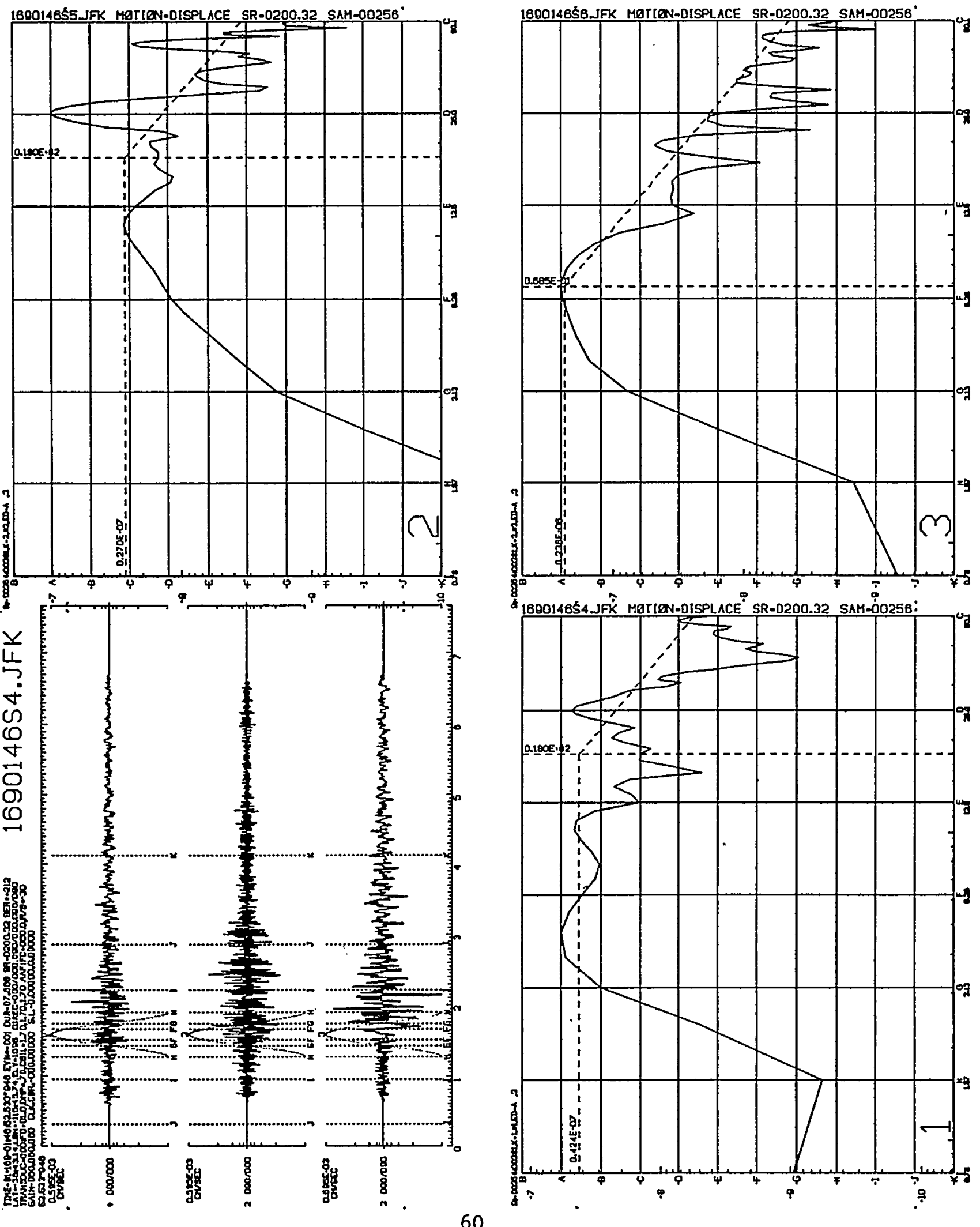

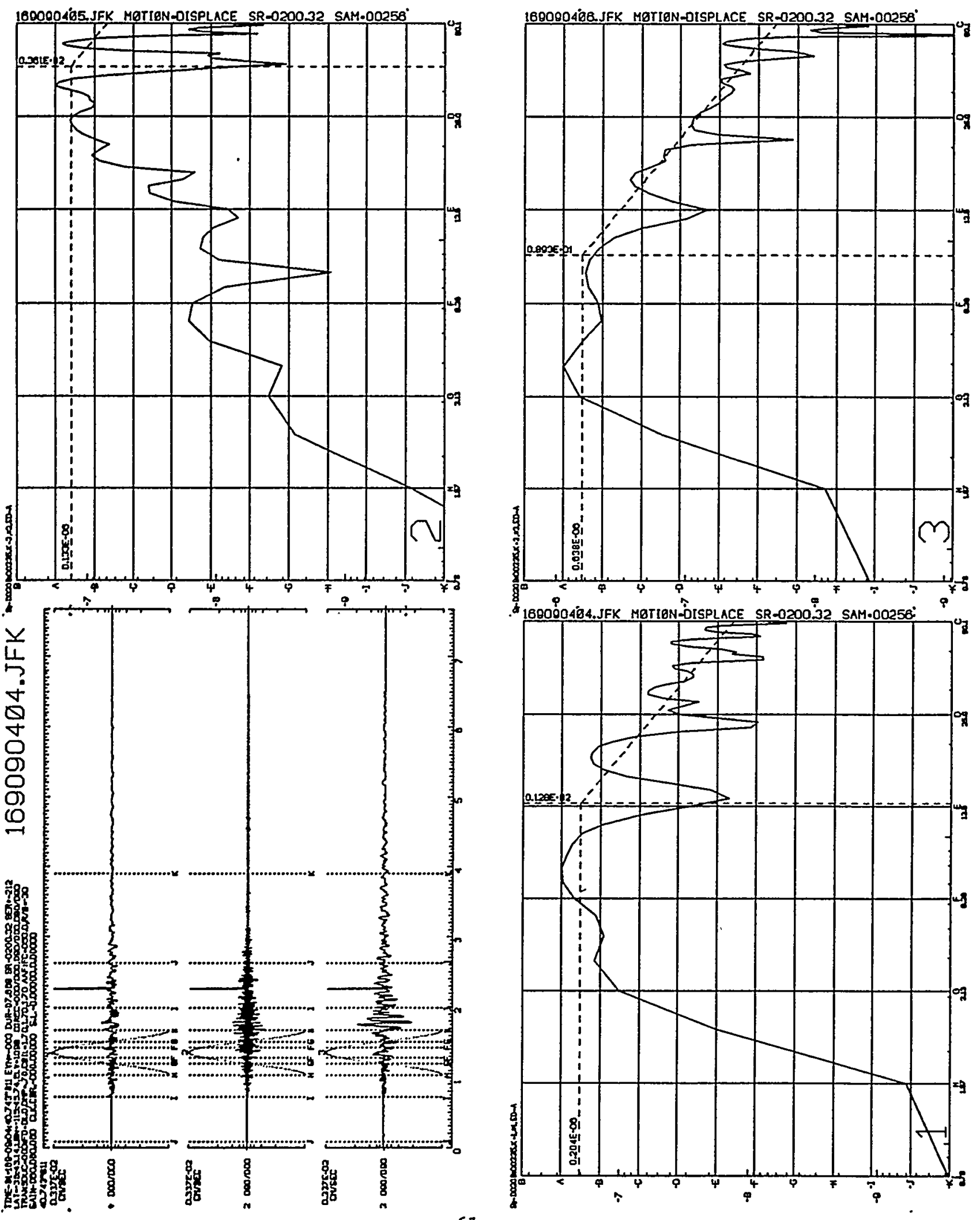

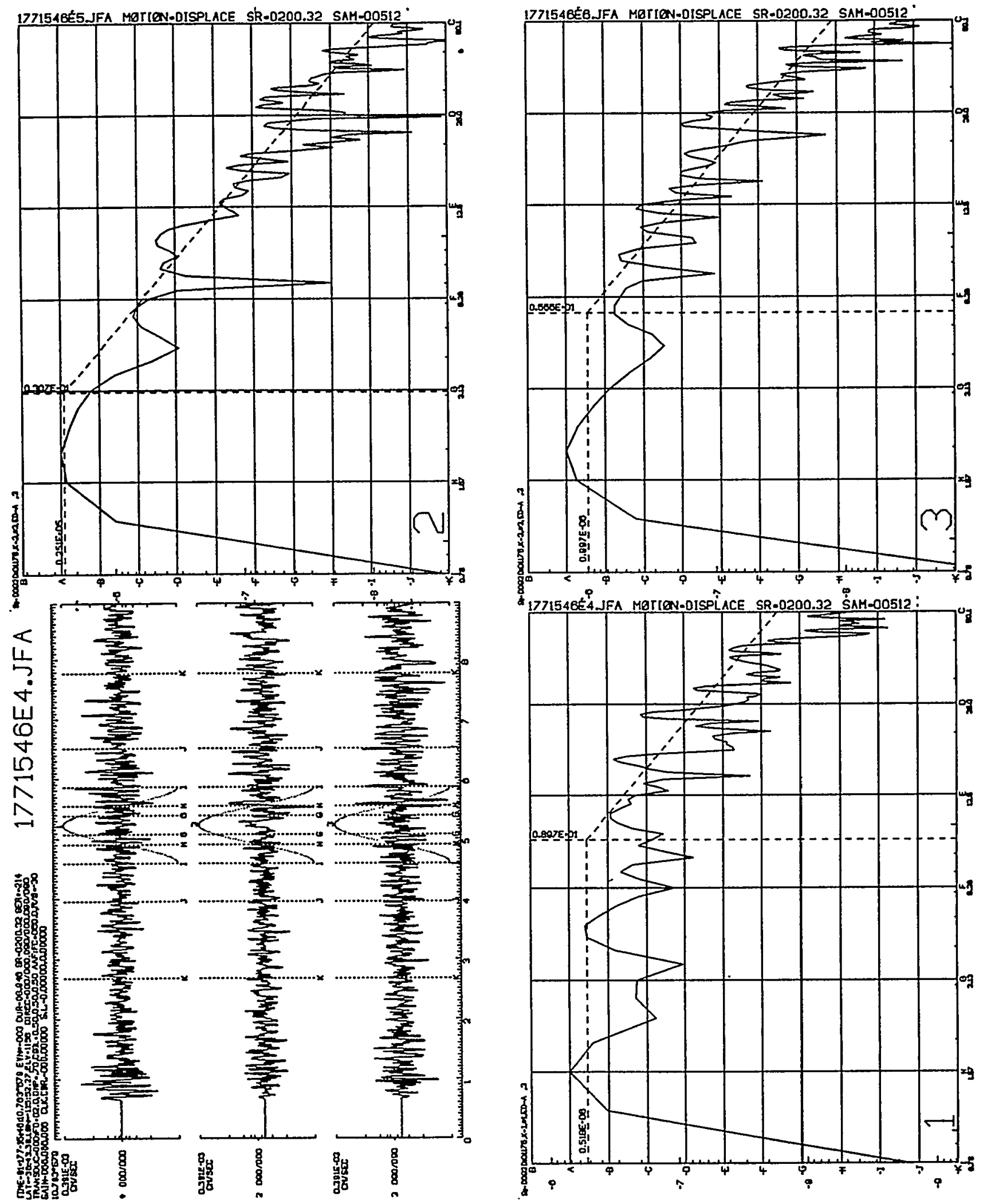

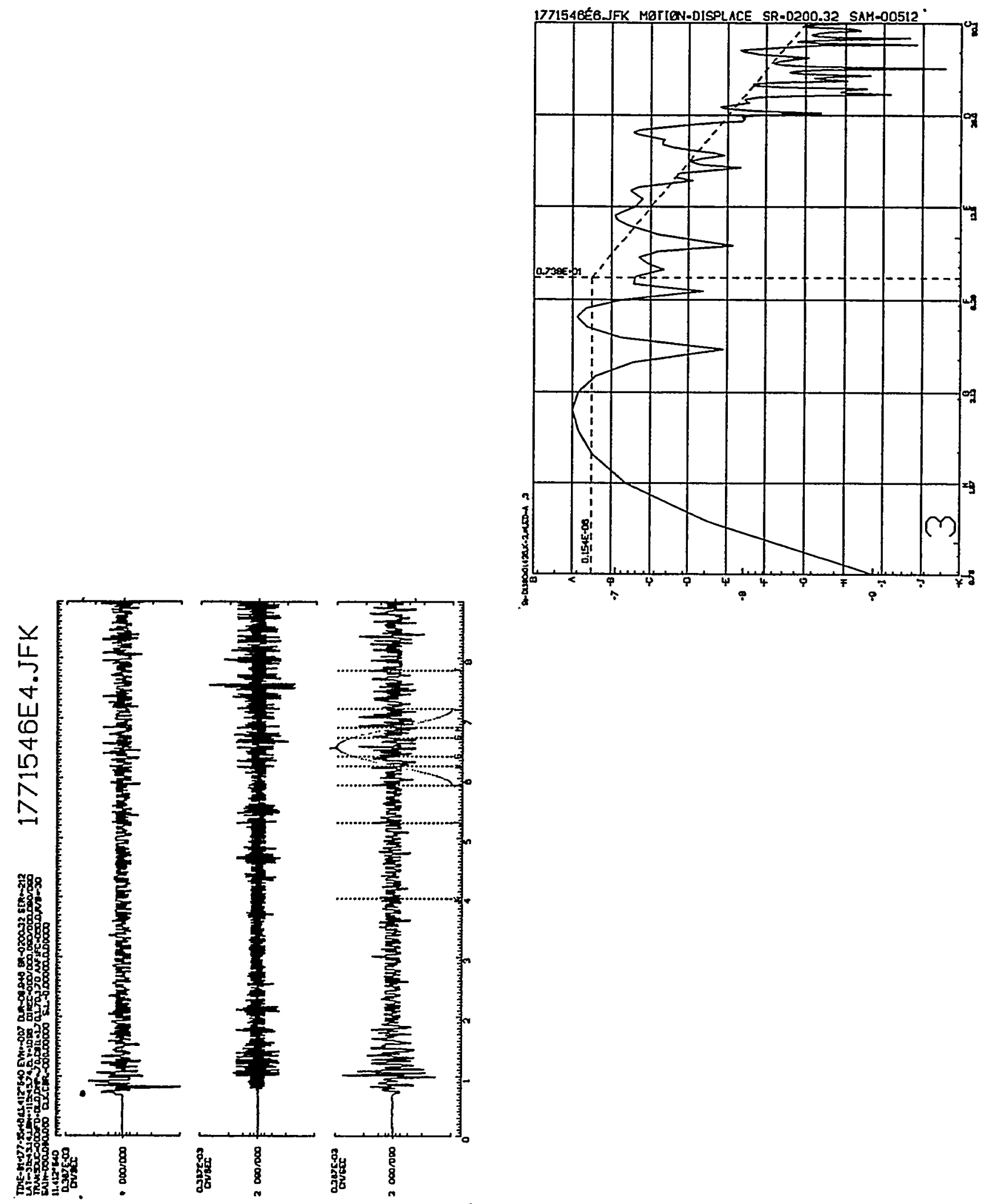

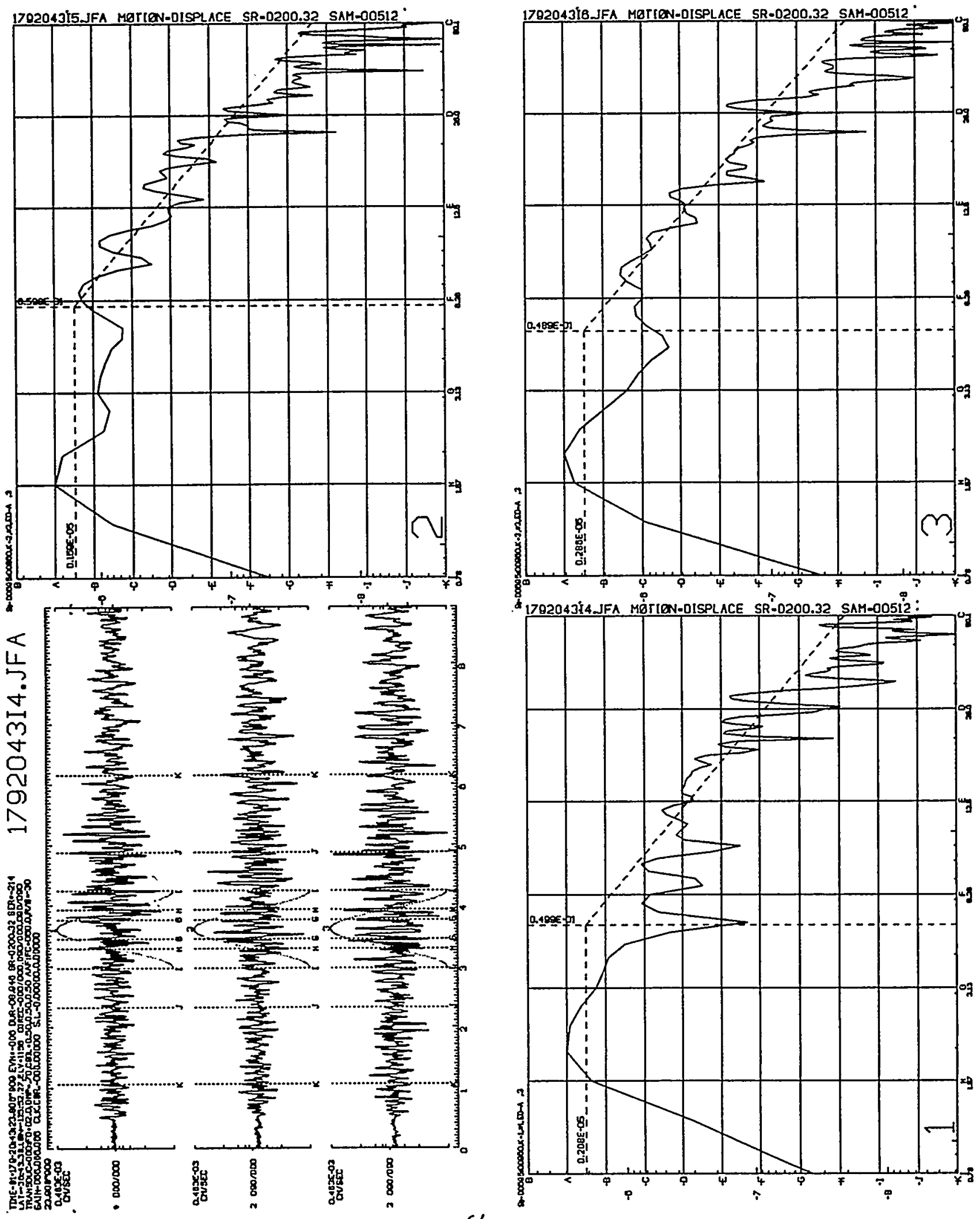

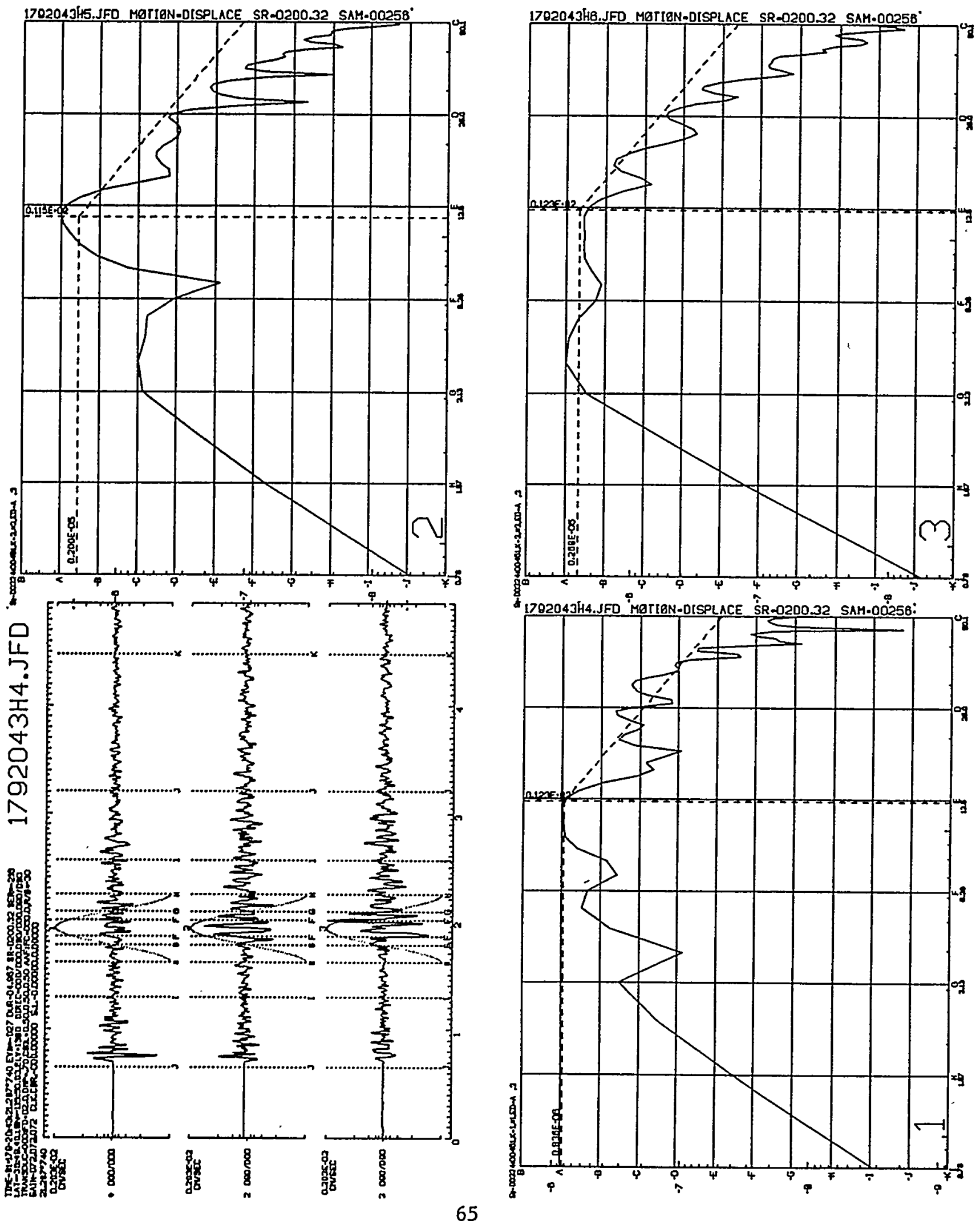

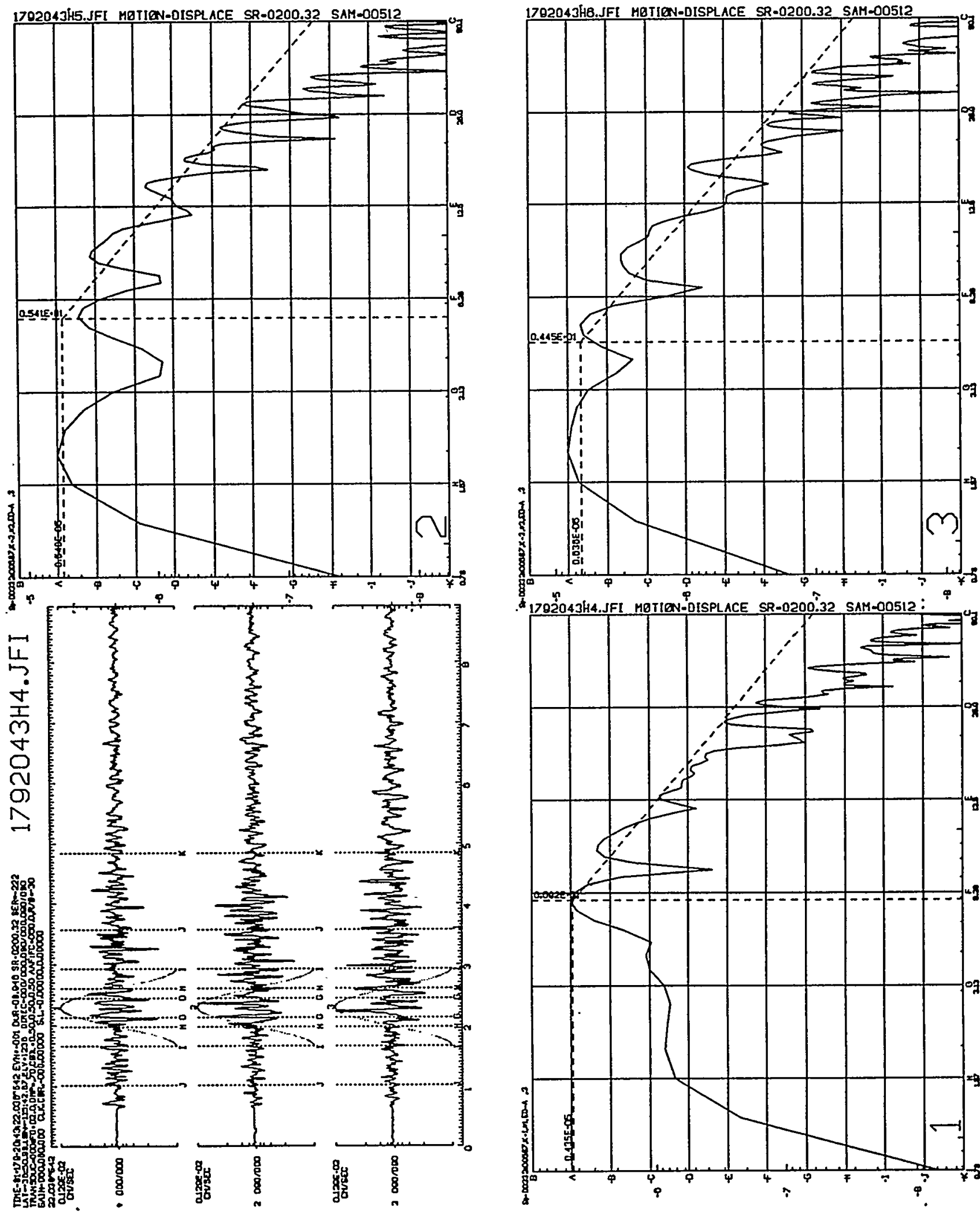

d17820043H4.SFI MOTIEN-0ISPLACE SR-0200\%32 SAM-00512:

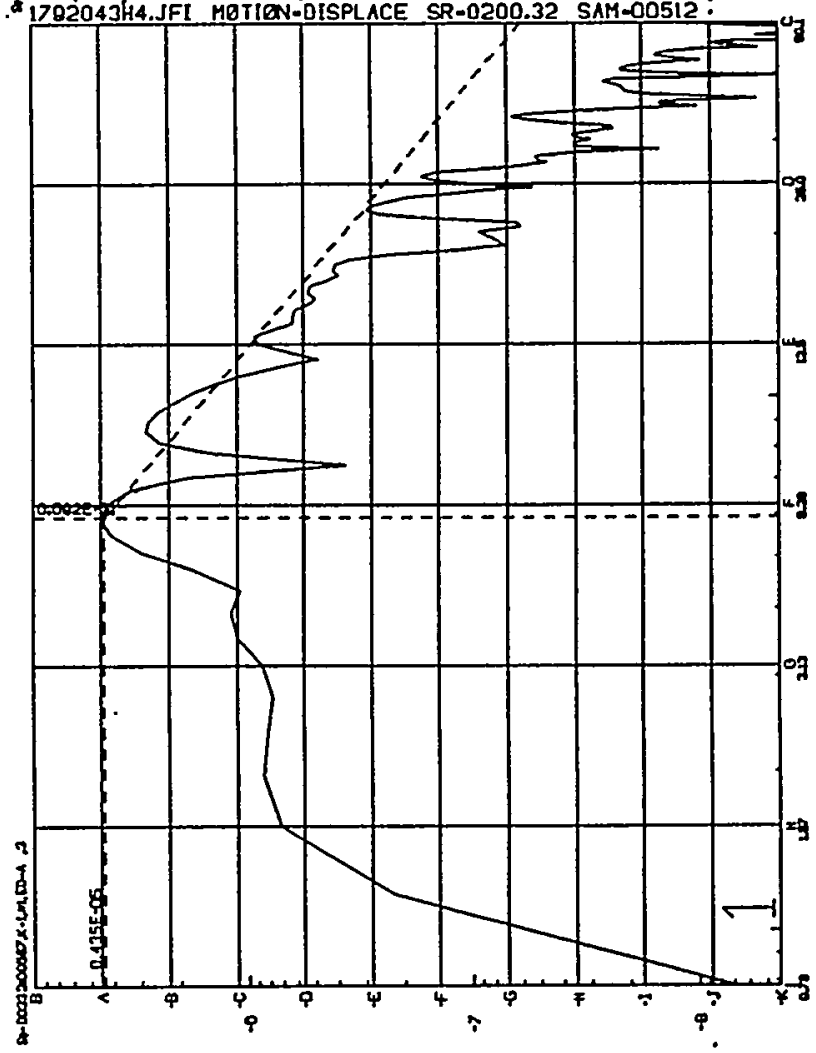



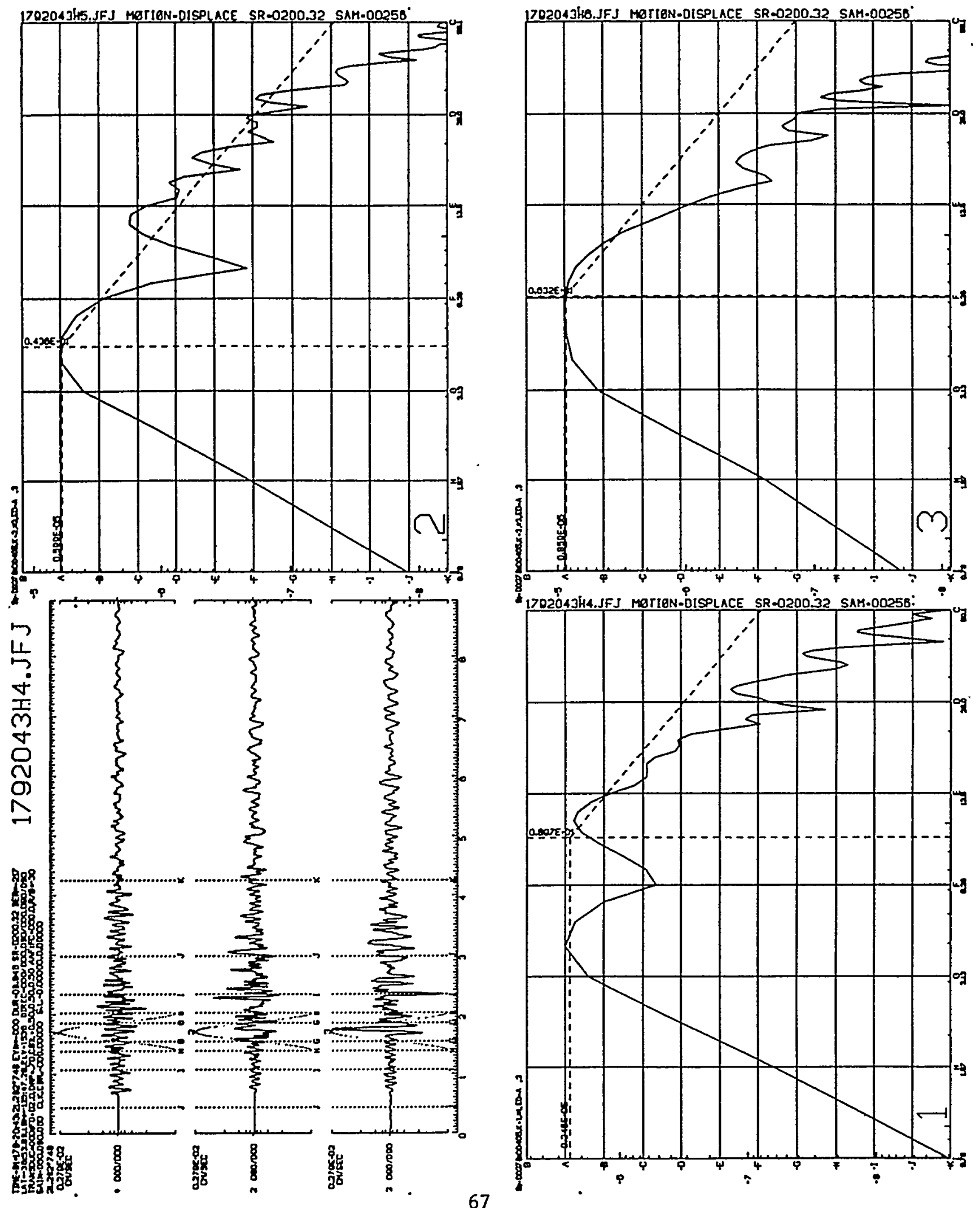

LU,S. GOVERNMENT PAINTING OFFICE:1986 -672-979/45312 